UNIVERSIDADE DE SÃO PAULO

ESCOLA DE ENFERMAGEM DE RIBEIRÃO PRETO

\title{
SANDRA DE SOUZA PEREIRA
}

Incidência da Síndrome de Burnout em técnicos e auxiliares de enfermagem e sua associação com o estresse precoce e estratégias de enfrentamento

\section{RIBEIRÃO PRETO}




\section{SANDRA DE SOUZA PEREIRA}

Incidência da Síndrome de Burnout em técnicos e auxiliares de enfermagem e sua associação com o estresse precoce e estratégias de enfrentamento

Dissertação apresentada à Escola de Enfermagem de Ribeirão Preto da Universidade de São Paulo para obtenção do título de Mestre em Ciências, Programa de Enfermagem Psiquiátrica.

Linha de Pesquisa: Promoção à Saúde

Orientadora: Profa. Dra. Lucilene Cardoso

Ribeirão Preto 
Autorizo a reprodução e divulgação total ou parcial deste trabalho, por qualquer meio convencional ou eletrônico, para fins de estudo e pesquisa, desde que citada a fonte.

Pereira, Sandra de Souza

Incidência da Síndrome de Burnout em técnicos e auxiliares de enfermagem e sua associação com o estresse precoce e estratégias de enfrentamento. Ribeirão Preto, 2013.

128 p. : il. ; $30 \mathrm{~cm}$

Dissertação de Mestrado, apresentada à Escola de Enfermagem de Ribeirão Preto/USP. Área de concentração: Enfermagem Psiquiátrica.

Orientador: Cardoso, Lucilene.

1. Síndrome de Burnout. 2. Estratégias de Enfrentamento. 3. Estresse precoce. 4. Enfermagem. 5. MBI. 6. EMEP. 7. CTQ 
PEREIRA, Sandra de Souza

Incidência da Síndrome de Burnout em técnicos e auxiliares de enfermagem e sua associação com o estresse precoce e estratégias de enfrentamento

Dissertação apresentada à Escola de Enfermagem de Ribeirão Preto da Universidade de São Paulo, para a obtenção do título de Mestre em Ciências, Programa Enfermagem Psiquiátrica.

Área de Conhecimento: Enfermagem Psiquiátrica

Linha de Pesquisa: Promoção em Saúde.

Aprovado em: / /

Comissão Julgadora

Prof. Dr.

Instituição:

Prof. Dr.

Instituição:

Prof. Dr.

Instituição: 
Aos meus queridos pais, Geraldo e Jonairques (in memorian), exemplos de vida a serem seguidos $e$ imensurável amor... sempre presentes em minha vida, em meus pensamentos e em meu coração. 
AGRADECIMENTO ESPECIAL

À Profa. Dra. Lucilene Cardoso, por acreditar no meu potencial e no meu sonho, pela confiança $e$ oportunidade oferecida, pelos ensinamentos $e$ amizade. 


\section{AGRADECIMENTOS}

A Deus, fonte de esperança e fé, força sempre presente em minha vida, por permitir que ao meu lado estivessem pessoas maravilhosas e abençoadas.

Ao meu querido pai Geraldo, meu grande exemplo de vida, por respeitar minhas escolhas.

Ao meu irmão Eder, pela amizade e companheirismo.

À minha irmãzinha Talita, fonte de amor e alegrias.

À Luciane, por cuidar do meu bem mais precioso, minha família.

À Regina, minha mãe de coração, pelo incentivo e apoio.

Ao Prof. Dr. Mário Juruena, por suas contribuições para o enriquecimento deste trabalho.

Às professoras Sueli Galera, Edilaine e Toyoko, por me acolherem em seus respectivos grupos de pesquisa.

Ao amigo Antonio Borges, pelo incentivo durante o ingresso ao mestrado.

Às amigas Bruna, Juliana, Emily e Dani Baragatti pelas experiências compartilhadas, pela grande amizade, apoio e palavras amigas nas horas difíceis.

Aos amigos da casa 12 Elton e Pâmina, pela amizade e por estarem sempre presentes durante essa importante etapa da minha vida acadêmica e demais colegas Ana Paula, Micássio, Carmen, Douglas, Fernando, Christian, Rafaela e Gean por fazerem parte do meu cotidiano.

À amiga Emilene, pela paciência e grande contribuição durante todo o trabalho, principalmente nas análises estatísticas.

À amiga Fernanda, pelas experiências compartilhadas.

À amiga Carla Bastos, presente nos momentos de alegrias e dificuldades.

Aos amigos Driele e Adilson, pelas longas conversas e companheirismo.

À todos os meus amigos, antigos e recentes, por compartilharem a vida comigo e fazerem dela uma caminhada mais alegre e admirável.

À funcionária Cida, do setor de Recursos Humanos do Hospital das Clínicas, pela agilidade em fornecer as informações necessárias à pesquisa. 
À Mieyko, pela contribuição na aleatorização da amostra e validação do banco de dados.

Ao Prof. Dr. Jair, pela disponibilidade e ajuda no cálculo amostral.

Aos auxiliares e técnicos de enfermagem do Hospital das Clínicas da Faculdade de Medicina de Ribeirão Preto, não só pela generosidade e colaboração na participação desse estudo, mas principalmente pela contribuição para a Enfermagem.

Aos alunos de Iniciação Cientifica Maria Tereza, Kaique, Isabela, Jaqueline e Erick, pela contribuição na coleta e segunda digitação do bando de dados.

À amiga Gisele, pela revisão de português.

À amiga Mara, pela correção do abstract.

Ao colega Rodrigo da casa 13 e ao amigo Gerardo, por colaborarem na elaboração do resumen.

Ao bibliotecário Robson pela disponibilidade e revisão das referências bibliográficas.

Ao CNPq, pela concessão da bolsa de Mestrado.

Aos amigos que conquistei dentro da EERP.

À Ángela Márcia, Ivanhoé e demais profissionais do Núcleo de Saúde Mental, pelo acolhimento e experiências compartilhadas.

Agradeço a todos que fizeram parte deste sonho, e embora eu não tenha recordado de citar o nome, tenha absoluta certeza de sua importância e meus sinceros agradecimentos. 
"O ser humano é capaz de adaptar-se ao meio ambiente desfavorável, mas esta adaptação não ocorre impunemente".

(Levi, 1971) 


\section{RESUMO}

PEREIRA, S. S. de. Incidência da Síndrome de Burnout em técnicos e auxiliares de enfermagem e sua associação com o estresse precoce e estratégias de enfrentamento. 2013. 128 f. Dissertação (Mestrado) - Escola de Enfermagem de Ribeirão Preto, Universidade de São Paulo, Ribeirão Preto, 2013.

O estresse não incide apenas na vida adulta, ele pode ocorrer precocemente e repercutir na maneira como o indivíduo enfrenta as situações estressantes, seja na vida pessoal como no ambiente profissional. Neste contexto, como consequência do estresse crônico e uso de estratégias de enfrentamento inadequadas o profissional poderá ter risco aumentado para desenvolver a Síndrome de Burnout. Com o objetivo de analisar a prevalência e associação entre Síndrome de Burnout, estresse precoce e estratégias de enfrentamento em técnicos e auxiliares de enfermagem de um hospital geral do interior de São Paulo, desenvolveu-se um estudo transversal, de abordagem quantitativa, utilizando os instrumentos: questionário sociodemográfico, de condições de trabalho e saúde, Maslach Burnout Inventory (MBI), Escala de Modos de Enfrentamento dos Problemas (EMEP) e Childhood Traume Questionnaire (CTQ). Utilizou-se estatística descritiva e analítica, realizando-se testes Quiquadrado, com coeficiente de correlação de Pearson e regressão logística considerando nível de significância de 0,05. Obteve-se aprovação do Comitê de Ética em Pesquisa e a amostra foi aleatorizada com 338 técnicos e auxiliares de enfermagem, houve 8,2\% de recusas totalizando 310 participantes. Prevaleceram mulheres (76,1\%), com idade media de 47,1 anos (DP 10,94), casado ou com companheiro $(58,1 \%)$, com filhos $(74,5 \%)$, são auxiliares de enfermagem $(85,5 \%)$, trabalham em serviços de alta complexidade $(88,7 \%)$, média de tempo de serviço de 12,6 anos (DP 8,75), com único vínculo empregatício $(79,4 \%)$, passaram por consulta média no último ano $(88,4 \%)$ e tiveram afastamento do trabalho no último ano $(50 \%)$. A prevalência da Síndrome de Burnout foi de 7,4\% e as estratégias de enfrentamento mais utilizadas foram as focalizadas no problema (60\%). Quanto a prevalência de estresse precoce, esta foi de 31,3\%. A Síndrome de Burnout teve associação com as variáveis morar sozinho ( $\mathrm{p}=0,03)$, não ter filhos $(\mathrm{p}=0,04)$ e ter passado por consulta médica $(\mathrm{p}=0,05)$. A Síndrome de Burnout mostrou-se mais frequente entre os participantes que não utilizam as estratégias focalizadas no problema $(\mathrm{p}=0,01)$ e também entre os participantes que utilizam de estratégias de busca por suporte social $(\mathrm{p}=0,02)$. Ao analisar a Síndrome de Burnout por meio de suas dimensões, verificou-se que a Exaustão Emocional mostrou-se mais significativa entre as mulheres $(\mathrm{p}=0,02)$, que possuem ensino superior $(\mathrm{p}=0,04)$, que residem sozinhas $(\mathrm{p}<0,00)$, que possuem tempo de serviço variando de 6 a 10 anos $(\mathrm{p}<0,00)$, que tiveram afastamento do trabalho $(\mathrm{p}<0,00)$ e referiram ter doença crônica $(\mathrm{p}=0,01)$. Já a Despersonalização mostrou-se mais significativa entre os participantes que passaram por consulta médica no último ano $(\mathrm{p}=0,04)$ e a Realização Pessoal mostrou-se mais significativa entre os participantes que moram sozinhos $(\mathrm{p}<0,00)$ e com tempo de serviço variando de 21 a 25 anos $(\mathrm{p}=0,02)$. Os resultados deste estudo indicam considerável prevalência da Síndrome de Burnout entre estes trabalhadores e preocupante risco para o desenvolvimento desta para grande parte deles. O estresse precoce, presente em significante parcela destes trabalhadores, embora não associado à Síndrome de Burnout neste estudo, também demonstrou ser um fenômeno importante, principalmente se consideradas as possíveis consequências à saúde destas pessoas e também ao modo de enfrentamento dos problemas na vida adulta.

Palavras-chave: Síndrome de Burnout. Estratégias de Enfrentamento. Estresse Precoce. Enfermagem. MBI. EMEP. CTQ. 


\section{ABSTRACT}

PEREIRA, S. S. de. Burnout syndrome incidence in technicians and nursing assistants and their association with early life stress and coping strategies 2013. $128 \mathrm{f}$. Dissertation (Master's degree) - Nursing School of Ribeirão Preto, University of São Paulo, Ribeirão Preto, 2013.

Stress does not occur only in adult life, but also in early life and results in the way individuals face stressful situations, in both their personal and professional life. In this context, as a consequence of chronic stress and inadequate coping strategies the nursing professional may have an increased risk of developing Burnout Syndrome. This study had the objective of analyzing the prevalence and association among Burnout Syndrome, early stress and coping strategies with technicians and nursing assistants of a general hospital in the countryside of São Paulo, developing a quantitative, cross-sectional study, using such tools: socialdemographic questionnaire about health and working conditions, Maslach Burnout Inventory (MBI), Scale of Ways to copy with Problems, and Childhood Trauma Questionnaire (CTQ). The descriptive and analytical statistics was used, carrying out chi-square tests by Pearson and logistic regression considering 0, 05 significance level. Approval from the Ethics Committee was obtained and the sample was gotten randomly with 338 technicians and nursing assistants with $8.2 \%$ refusals totalizing 310 participants. Women $(76,1 \%)$ prevailed with ages of 47.1 years old (DP 10,94), married or with a partner $(58,1 \%)$, with children $(74,5 \%)$, working as nursing assistants $(85,5 \%)$, and with high complexity $(88,7 \%)$, medium service time of 12,6 years (DP 8,75) with service bonds $(79,4 \%)$, underwent medical consultation last year $(88,4 \%)$ and were laid off in the last year $(50 \%)$. Burnout syndrome prevalence was $7,4 \%$ and the most used coping strategies were those focused on the problem $(60 \%)$. The early stress prevalence was $31,3 \%$. Burnout syndrome is regarded to living alone $(\mathrm{p}=0,03)$, not having children $(p=0,04)$ and having had a doctor's consultation $(p=0,05)$. Burnout syndrome was more frequent with those who did not use the strategies focused on the problem $(p=0,01)$ and also those who used searching strategies for social support $(\mathrm{p}=0,02)$. It was possible to verify the Emotional Exhaustion when the burnout syndrome was analyzed according to its dimensions, showing more expressive among women $(\mathrm{p}=0,02)$, who have a college degree $(\mathrm{p}=0,04)$, who live alone $(\mathrm{p}<0,00)$, who have six to ten years of service $(\mathrm{p}<0,00)$, who were laid off $(p<0,00)$, and mentioned having chronic disease $(p=0,01)$. The depersonalization has shown to be more significative among the participants who had an appointment with a doctor in the last year $(\mathrm{p}=0,04)$ and the personal achievement showed to be more expressive with participants who live alone $(\mathrm{p}=0,00)$ and the service time ranging from 21 to 25 years $(\mathrm{p}=0,02)$. The results of this study indicate considerable prevalence of burnout syndrome among these workers and worrying risk for developing this for most of them. The early stress present in a significant portion of these workers, although not associated with burnout syndrome in this study, also proved to be an important phenomenon, especially when considering the possible consequences to the health of these people and also to the way of dealing with problems in adulthood.

Keywords: Burnout Syndrome. Coping Strategies. Early stress. Nursing. MBI. EMEP. CTQ. 


\section{RESUMEN}

PEREIRA, S. S. de. 2013. Incidencia del Síndrome de Burnout en técnicos y auxiliares de enfermería y su asociación con el estrés precoz y las estrategias de enfrentamiento. $128 \mathrm{f}$. Tesis (Maestría) - Facultad de Enfermaría de Ribeirão Preto, Universidad de São Paulo, Ribeirão Preto, 2013.

El estrés no incide solo en la vida adulta, puede ocurrir precozmente e repercutir en la forma como el individuo enfrenta las situaciones estresantes, ya sea en su vida personal como en el ambiente profesional. En este contexto, como consecuencia del estrés crónico y el uso de estrategias de enfrentamiento inadecuadas, el profesional puede incrementar el riesgo de desarrollar el Sindrome de Burnout. Con el objetivo de analizar la prevalencia y asociación entre el Síndrome de Burnout, estrés precoz y estrategias de enfrentamiento en los técnicos y auxiliares de enfermería del Hospital General del Interior de Sao Paulo, se realizó un estudio transversal, de abordaje cuantitativo, utilizando los siguientes instrumentos; cuestionario socio demográfico de las condiciones de trabajo y salud, Maslach Burnout Inventory (MBI), Escala de modos de enfrentamiento de Problemas (EMEP) y Childhood Traume Questionnaire (CTQ). Se utilizó estadística descriptiva y analítica considerando el nivel de significancia 0,05. Se obtuvo la aprobación del Comité de Ética en Investigación y la muestra fue aleatorizada con 338 técnicos y auxiliares de enfermería, hubo 8,2\% de recusas totalizando 310 participantes. Prevalecieron las mujeres $(76,1 \%)$, con edad media de 47,1 años (DP 10,94$)$, casados o en concubinato $(58,1 \%)$, con hijos $(74,5 \%)$, son auxiliares de enfermería $(85,5 \%)$, trabajan en servicios de alta complejidad $(88,7 \%)$ media de tiempo de servicio de 12,6 años (DP 8,75), con un único vinculo de empleo $(79,4 \%)$, pasaron por consulta médica en el último año $(88,4 \%)$, y tuvieron baja médica en el último año $(50 \%)$. La prevalencia del Síndrome de Burnout fue de $7,4 \%$ y las estrategias de enfrentamiento más utilizadas fueron las focalizadas en problemas $(60 \%)$. Respecto a la prevalencia de estrés precoz esta fue de $31.3 \%$. El síndrome de Burnout tuvo una asociación con las variables; vive solo $(\mathrm{p}=0.03)$, no tiene hijos $(0,04)$ y haber pasado por consulta médica $(p=0.05)$. El Síndrome de Burnout se mostró más frecuente entre los participantes que no utilizan estrategias focalizadas en problemas $(\mathrm{p}=0,01)$ y también entre los participantes que utilizan estrategias de búsqueda de apoyo social $(\mathrm{p}=0,02)$. Al analizar el Síndrome de Burnout a través de sus dimensiones, se verifico que el Cansancio Emocional es más significativo entre las mujeres $(p=0,02)$, que poseen educación superior $(p=0,04)$, que viven solas $(p<0,00)$, que tienen tiempo de servicio entre 6 a 10 años $(p<0,00)$, que tuvieron baja médica $(p<0,00)$ y refirieron tener enfermedades crónicas $(p=0,01)$. Ya la despersonalización fue más significativa entre los participantes que pasaron por consulta médica en el último año $(\mathrm{p}=0,04)$ y la Realización Personal fue más significativa entre los participantes que viven solos $(\mathrm{p}<0,00)$ y con el tiempo de servicio entre 21 a 25 años $(\mathrm{p}=0,02)$. Los resultados de este estudio indican una considerable prevalencia del Síndrome de Burnout entre los trabajadores, asi como un preocupante riego para el desarrollo de esta enfermedad para gran parte de ellos. El estrés precoz, aunque no presentó asociación con el Síndrome de Burnout, él se encuentra presente en una gran parte de estos trabajadores y demostró ser un fenómeno importante en las posibles consecuencias en la salud de estas personas así como el enfrentamiento a los problemas en la edad adulta.

Palabras clave: Síndrome de Burnout. Estrategias de Enfrentamento. Estrés precoz. Enfermeria. MBI. EMEP. CTQ. 


\section{LISTA DE ILUSTRAÇÕES}

Figura 1 - Classificação dos subtipos de Estresse Precoce de acordo com a gravidade 47

Figura 2 - Modelo teórico hierarquizado de associação do Burnout e suas dimensões $\mathbf{5 1}$ 


\section{LISTA DE TABELAS}

Tabela 1 - Distribuição de frequência dos técnicos e auxiliares de enfermagem segundo as variáveis demográficas. Ribeirão Preto; 2012

Tabela 2 - Distribuição de frequência dos técnicos e auxiliares de enfermagem segundo as variáveis de condições de trabalho. Ribeirão Preto; 2012

Tabela 3 - Distribuição de frequência dos técnicos e auxiliares de enfermagem segundo as variáveis de condições de saúde. Ribeirão Preto; 2012

Tabela 4 - Distribuição de frequência dos técnicos e auxiliares de enfermagem segundo o uso de medicamentos, tabaco e álcool. Ribeirão Preto; 2012

Tabela 5 - Distribuição de frequência dos técnicos e auxiliares de enfermagem segundo doenças autorreferidas, prescrição e tratamento medicamentoso. Ribeirão Preto; 2012

Tabela 6 - Descrição dos escores médios das respostas dos técnicos e auxiliares de enfermagem em cada dimensão das escalas MBI, EMEP e CTQ. Ribeirão Preto; 2012

Tabela 7 - Distribuição dos técnicos e auxiliares de enfermagem de acordo com os escores e percentis na escala MBI por dimensões. Ribeirão Preto;2012

Tabela 8 - Distribuição de técnicos e auxiliares de enfermagem segundo alteração nas dimensões que avaliam a Sindrome de Burnout. Ribeirão Preto; 2012.

Tabela 9 - Distribuição de técnicos e auxiliares de enfermagem segundo o tipo de estratégias de enfrentamento utilizada. Ribeirão Preto; 2012.

Tabela 10 - Distribuição de frequência dos técnicos e auxiliares de enfermagem com presença ou ausência de estresse precoce segundo os subtipos do mesmo. Ribeirão Preto; 2012

Tabela 11 - Associação entre Síndrome de Burnout e as características sociodemográficas entre técnicos e auxiliares de enfermagem de um hospital geral. Ribeirão Preto; 2012.

Tabela 12 - Associação entre Síndrome de Burnout e as condições de trabalho e saúde entre técnicos e auxiliares de enfermagem de um hospital geral. Ribeirão Preto; 2012.

Tabela 13 - Associação entre Síndrome de Bumout e as estratégias de enfrentamento entre técnicos e auxiliares de enfermagem de um hospital geral. Ribeirão Preto; 2012.

Tabela 14 - Associação entre Síndrome de Bumout e os subtipos de estresse precoce entre técnicos e auxiliares de enfermagem de um hospital geral. Ribeirão Preto; 2012.

Tabela 15 - Associação entre Exaustão Emocional, Despersonalização, Realização Pessoal e as características sociodemográficas entre técnicos e auxiliares de enfermagem de um hospital geral. Ribeirão Preto; 2012. 
Tabela 16 - Associação entre Exaustão Emocional, Despersonalização, Realização Pessoal e as condições de trabalho e saúde entre técnicos e auxiliares de enfermagem de um hospital geral. Ribeirão Preto; 2012. 68

Tabela 17 - Associação entre as dimensões do Bumout e as estratégias de enfrentamento entre técnicos e auxiliares de enfermagem de um hospital geral. Ribeirão Preto; 2012. 70

Tabela 18 - Associação entre as dimensões da Síndrome de Burmout e estresse precoce entre técnicos e auxiliares de enfermagem de um hospital geral. Ribeirão Preto; 2012 70

Tabela 19 - Regressão logística entre Síndrome de Burnout e as variáveis sociodemográficas, de condições de trabalho e de saúde entre técnicos e auxiliares de enfermagem de um hospital geral. Ribeirão Preto, 2012.

Tabela 20 - Regressão multivariada entre a Exaustão Emocional e as variáveis sociodemográficas, de condições de trabalho e de saúde entre técnicos e auxiliares de enfermagem de um hospital geral. Ribeirão Preto, 2012.

Tabela 21 - Regressão multivariada entre a Despersonalização e as variáveis sociodemográficas, de condições de trabalho e de saúde entre técnicos e auxiliares de enfermagem de um hospital geral. Ribeirão Preto, 2012. .75

Tabela 22 - Regressão multivariada entre a Realização Pessoal e as variáveis sociodemográficas, de condições de trabalho e de saúde entre técnicos e auxiliares de enfermagem de um hospital geral. Ribeirão Preto, 2012 


\section{LISTA DE SIGLAS}

LDB

COFEN

CEP

CONASS

EMEP

MBI

CTQ

SPSS

DP

OR

IC
Lei de Diretrizes e Bases

Conselho Federal de Enfermagem

Comitê de Ética em Pesquisa

Conselho Nacional de Secretarias de Saúde

Escala de Modos de Enfrentamento dos Problemas

Maslach Burnout Inventory

Childhood Traume Questionnaire

Statistical Package for Social Sciences

Desvio Padrão

Razão de Prevalência

Intervalo de Confiança 


\section{SUMÁRIO}

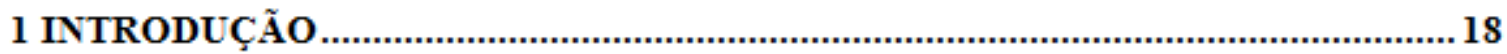

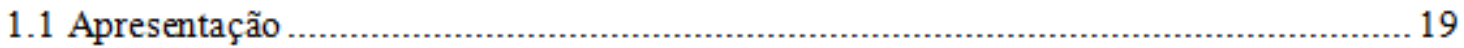

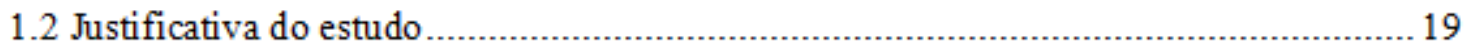

1.3 Motivação pessoal.

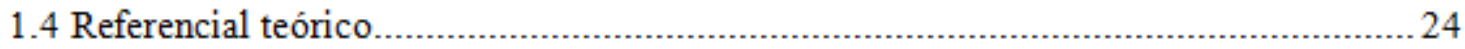

1.4.1 A relação entre o homem e o trabalho ................................................................. 24

1.4.2 Conceituando a Síndrome de Burnout ……..................................................... 26

1.4.3 $\mathrm{O}$ estresse precoce, o estresse laboral e as estratégias de enfrentamento ................ 28

1.4.4 O exercício da enfermagem e as categorias de auxiliar e técnico em enfermagem 31

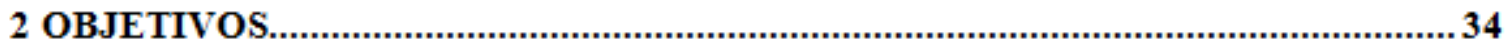

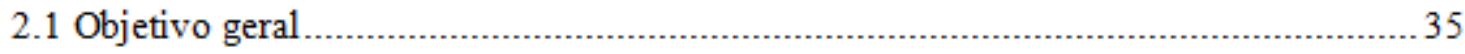

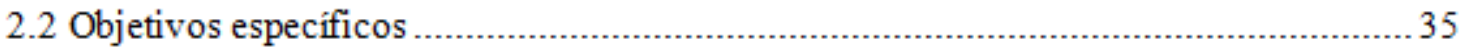

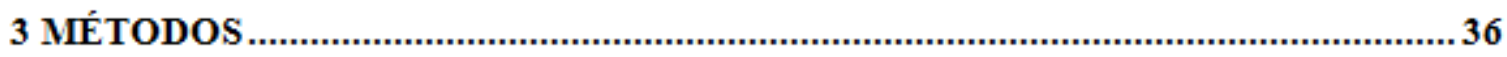

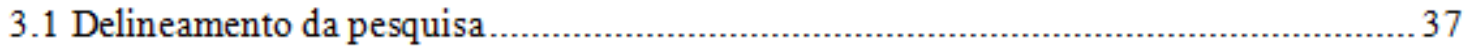

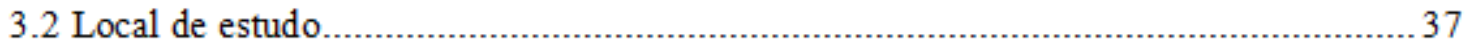

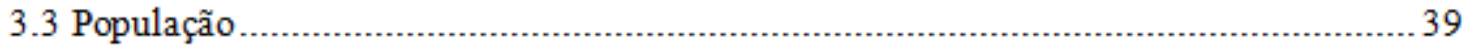

3.4 Critérios de inclusão e exclusão.......................................................................... 39

3.5 Procedimento amostral

3.6 Proteção de participação do estudo

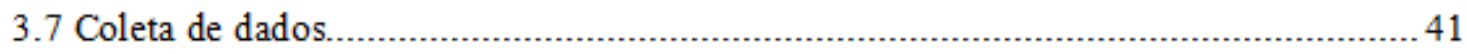

3.7.1 Questionário sociodemográfico, de condições de trabalho e saúde........................ 41

3.7.2 Escala modos de enfrentamento de problemas - EMEP ................................... 42

3.7.3 Maslach Burnout Inventory (MBI)............................................................ 44

3.7.4 Childhood Trauma Questionnaire (CTQ) ..................................................... 45

3.8 Permissão para uso dos instrumentos............................................................ 48

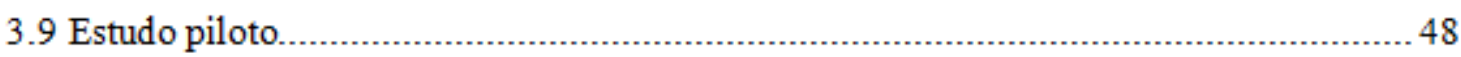

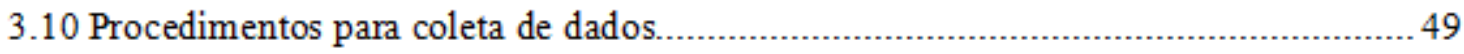

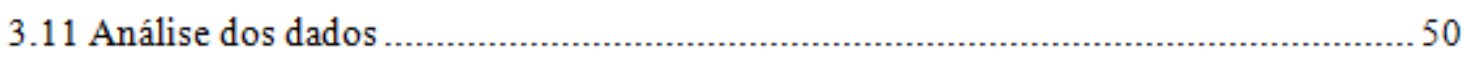

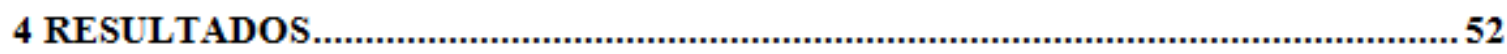

4.1 Caracterização da população do estudo …………..................................................... 53

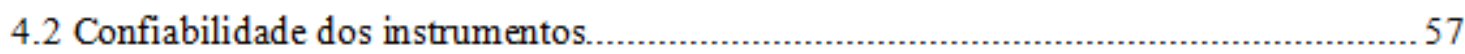


4.3 Análise descritiva das respostas dos técnicos e auxiliares de enfermagem quanto a Sindrome de Bumout, estresse precoce e estratégias de enfrentamento.

4.4 Classificação dos técnicos e auxiliares de enfermagem quanto ao nível da Síndrome de Bumout

4.4 Prevalências da Síndrome de Burnout, estratégias de enfrentamento e estresse precoce 61

4.5 Sindrome de Bumout e suas associações 63

4.5.1 Síndrome de Burnout e as variáveis sociodemográficas, condições de trabalho e saúde. 64

4.5.2 Síndrome de Bumout e as estratégias de enfrentamento. 66

4.5.3 Síndrome de Burnout e o estresse precoce. 66

4.6 As dimensões da Síndrome de Bumout e suas associações. .67

4.6.1 Exaustão emocional, despersonalização, realização pessoal e as variáveis sociodemográficas . 67

4.6.2 Exaustão emocional, despersonalização, realização pessoal e as estratégias de enfrentamento. 70

4.6.3 Exaustão emocional, despersonalização, realização pessoal e o estresse precoce.. 71

4.6 Associação da Síndrome de Bumout e as variáveis independentes. .72

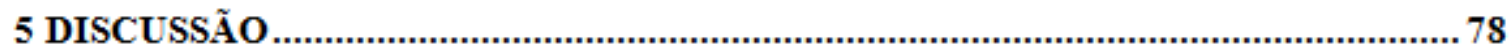

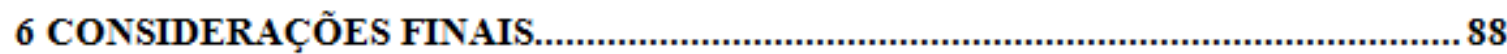

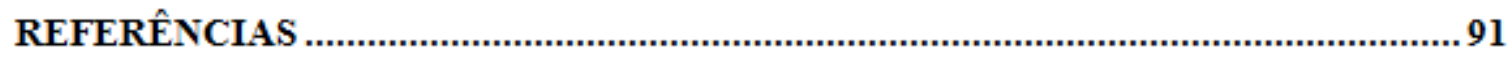

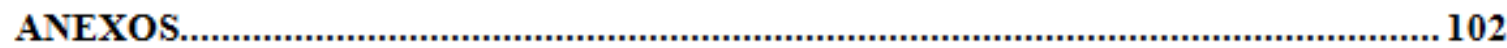

A - Parecer do Comitê de Ética em Pesquisa da EERP .................................................. 103

B - Parecer do Comitê de Ética em Pesquisa do HCFMRP ............................................... 104

C - Escala de Modos de Enfrentamento dos Problemas - EMEP ....................................... 105

D - Maslach Burnout Inventory - MBI..................................................................... 107

E - Childhood Trauma Questionnaire - CTQ …....................................................... 108

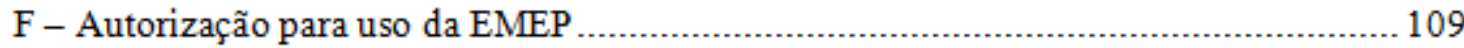

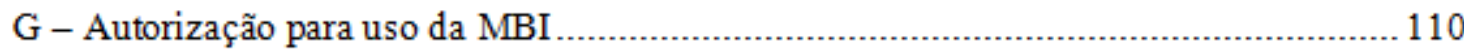

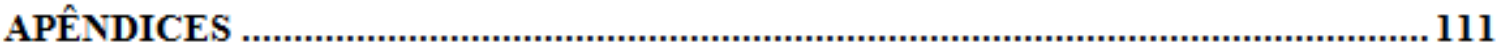

A - Termo de Consentimento Livre e Esclarecido ........................................................... 112

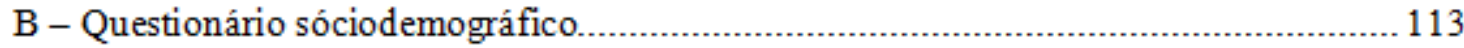


C - Forma de coleta das variáveis do questionário sociodemográfico, de condições de trabalho e saúde

D - Forma de coleta das variáveis da Escala de Modos de Enfrentamento dos Problemas (EMEP)

E - Forma de coleta das variáveis da Maslach Bumout Inventory (MBI) 122

F - Forma de coleta das variáveis da Childhood Trauma Questionnaire (CTQ) 125 
1 INTRODUÇÃO 


\section{INTRODUÇÃ̃O}

\subsection{Apresentação}

Este estudo faz parte de um projeto maior de investigação, intitulado Estresse, esgotamento profissional e estratégias de enfrentamento entre profissionais de saúde. Tal projeto é coordenado pela Dra. Lucilene Cardoso e Dra. Edilaine Cristina da Silva Gherardi Donato, docentes do Departamento de Enfermagem Psiquiátrica e Ciências Humanas da Escola de Enfermagem de Ribeirão Preto da Universidade de São Paulo (EERP-USP), que teve como objetivo analisar a prevalência de estresse (precoce e do trabalho), prevalência de esgotamento profissional e identificar estratégias de enfrentamento entre técnicos e auxiliares de enfermagem.

Assim, o presente estudo teve como objetivos: Analisar a prevalência e associação entre a Síndrome de Burnout, estresse precoce e estratégias de enfrentamento em técnicos e auxiliares de enfermagem.

\subsection{Justificativa do estudo}

O desenvolvimento tecnológico gera benefícios e, em contrapartida, provoca alterações no comportamento do ser humano, interferindo diretamente na sua qualidade de vida. Atualmente, o homem é colocado diante de inúmeras funções e diferentes exigências que podem ultrapassar seu ritmo e levá-lo a desenvolver seu potencial adaptativo e cada vez mais, cresce as responsabilidades que são atribuídas ao trabalhador, o que demanda novas exigências na execução das tarefas e novas competências. Desta forma, torna-se cada vez mais emergente considerar o nível de estresse do trabalhador e a repercussão deste na saúde do mesmo (LAUTERT, 1995; BORGES et al., 2002; SANTOS, ALVES e RODRIGUES, 2009; JODAS e HADDAD, 2009).

O ambiente laboral segue o ritmo destas mudanças e exige adaptação do trabalhador. E este processo de mudanças e adaptações pode tornar-se gerador de conflito e juntamente com outros fatores acometer a saúde do trabalhador, pois é no contexto do trabalho que, 
algumas vezes, os trabalhadores entram em choque, devido à ligação existente entre o compromisso com a profissão e o sistema em que estão inseridos (LAUTERT, 1995; TRINDADE, 2007).

Nesse sentido, estudos evidenciam que o trabalho em saúde é um campo em constante evolução e mudança, sendo uma atividade que pode ocupar grande parcela do tempo na vida do trabalhador e assim comprometer o convício deste indivíduo na sociedade, nem sempre possibilitando sua realização profissional e consequentemente, podendo causar problemas que vão desde a insatisfação até mesmo a exaustão. Além disso, sabe-se que os profissionais de saúde estão também vulneráveis ao estresse, uma vez que sua atividade profissional exige contato intenso com pessoas e enfrentamento de inúmeras situações tensas e críticas (TRIGO, TENG e HALLAK, 2007; TRINDADE, LAUTERT e BECH, 2009). No Brasil, a força de trabalho na saúde é mantida por 1,5 milhão de profissionais da saúde registrados em conselhos profissionais (ALMEIDA FILHO, 2011). Na rede do SUS, principal empregadora do país, 52\% destes profissionais são da enfermagem. O que totaliza 271.809 profissionais e corresponde a 701 para cada habitante do país.

Deste modo, evidencia-se o importante papel da equipe de enfermagem que, em suas práticas diárias, confronta-se com estressores multidimensionais e despendem considerável tempo ao envolvimento com o outro, desenvolvendo o relacionamento interpessoal e dedicando nesta relação grande carga emocional e física, podendo ficar mental e psicologicamente angustiada. Como consequência desta condição, estudos salientam que os profissionais que trabalham ajudando continuamente outras pessoas podem desenvolver várias enfermidades e o estresse crônico pode ser emocionalmente desgastante, levando o profissional a um risco aumentado para o desenvolvimento da Síndrome de Burnout (MASLACH e JACKSON, 1981; TRIGO, TENG e HALLAK, 2007).

O termo Burnout refere-se a uma síndrome de exaustão emocional e cinismo que ocorre frequentemente entre indivíduos que trabalham diretamente com pessoas. O principal aspecto da Síndrome de Burnout é o aumento de sentimentos de exaustão emocional, de modo que os trabalhadores sentem que seus recursos emocionais estão esgotados e desenvolvem atitudes cínicas e negativas. Outro aspecto da síndrome é a tendência da pessoa se avaliar de forma negativa, tanto em relação com seus clientes, como com o local de trabalho. O que gera sentimentos de infelicidade e insatisfação dos trabalhadores com suas realizações no trabalho (MASLACH e JACKSON, 1981; MASLACH \& JACKSON, 1985). 
As consequências desta síndrome atingem tanto o estado de saúde e como o desempenho do trabalhador, pois, passam a existir alterações pessoais e organizacionais relevantes. Sendo as profissões ligadas a áreas que atuam diretamente em contato com pessoas, que envolvem também cunho emocional, mais propensas a desencadeá-la (MASLACH e JACKSON, 1981; MASLACH \& JACKSON, 1985). Alguns autores acreditam que isso acontece, porque o relacionamento interpessoal contínuo requer resposta emocional também contínua (MARTÍNEZ et al., 2007; RITTER, STUMM e KIRCHER, 2009).

O profissional com a Síndrome de Burnout remete ao indivíduo que lida com o público e que se mostra desmotivado, pouco compreensivo, com tratamento distante e desumanizado para com os pacientes. Tais alterações ocasionam tendência ao isolamento, sentimento de onipotência, perda de interesse pelo trabalho ou lazer, absenteísmo, manifestação de ironia e cinismo pelo trabalhador. As consequências da Síndrome de Burnout em nível organizacional e no trabalho são representadas pela diminuição na qualidade do trabalho, faltas constantes, diminuição da produtividade, predisposição a acidentes de trabalho, abandono, absenteísmo e rotatividade (TELLES, 2008; BENEVIDES-PEREIRA, 2010).

Neste contexto, a equipe de enfermagem, que tem como essência de seu trabalho o cuidado permanente à saúde, está cotidianamente exposta ao risco de desenvolver a Síndrome de Burnout. Muitas vezes, este profissional enfrenta grande carga de trabalho voltada ao contato direto com pacientes e familiares, sobrecarga de responsabilidades, dupla jornada e enfrentamento e gerenciamento de crises. No profissional de enfermagem, esta síndrome é prejudicial tanto na esfera individual, como na profissional, pois pode afetar negativamente não apenas sua saúde, mas também a qualidade do cuidado prestado, interferindo assim na prioridade do serviço, que é a habilidade técnica e humanizada no atendimento (LORENS, BENATTI e SABINO, 2010). Autores referem que a redução na qualidade dos serviços pode ser evidenciada por um mau atendimento, em prescrições ou administração de medicamentos e/ou procedimentos equivocados, em negligência, imprudência e imperícia (BENEVIDESPEREIRA, 2010).

Em muitos estudos, a enfermagem é identificada como uma das profissões mais estressantes e de maior incidência da Síndrome de Burnout devido às características intrínsecas à própria atividade laboral, já que está relacionada com o envolvimento direto e indireto com pessoas que necessitam de uma grande demanda de cuidados além de muita paciência, simpatia, empatia e atenção. A convivência com a dor, o sofrimento, a impotência, 
a angústia, o medo, a desesperança, perda e morte, pode ocasionar a estes trabalhadores graves consequências físicas, emocionais, e até mesmo na qualidade do cuidar. Acrescenta-se ainda questões como a indefinição do papel profissional, a sobrecarga, baixa autonomia e autoridade na tomada de decisões como contribuintes para o desenvolvimento da doença. (GIL-MONTE, 2002; SILVA E MELO, 2006; SALOMÉ, MARTINS e ESPÓSITO, 2009; PRETO e PEDRÃO, 2009; MOREIRA et al., 2009; KEBIAN, FURTADO e PAULINO, 2010).

Sabe-se que o ambiente hospitalar pode gerar estresse de várias naturezas e níveis que vão desde a relação com o paciente e seus familiares, dos profissionais e do pessoal de saúde envolvidos. Inclui-se também a vivência da morte, a constatação de que nem sempre os pacientes fazem o que lhes é recomendado, entre outros (MIQUELIM et al., 2004). O mesmo autor ainda completa que os estressores hospitalares variam desde o local de atuação do profissional de enfermagem, bem como o cargo ocupado, o nível de satisfação e até mesmo os clientes atendidos nas unidades. Além disso, sobrecarga de trabalho normalmente justificada por falta de pessoal e estimulada pelo pagamento de horas-extras, ou pela dupla jornada de trabalho, está entre outras situações que geram um estado de estresse crônico.

Apesar da Síndrome de Burnout ser uma condição de saúde já evidenciada por diversos estudos, seu diagnóstico e tratamento não ocorre com frequência nos ambientes de trabalho e, além disso, há pouco reconhecimento da síndrome entre os profissionais e seus gestores, o que dificulta seu enfrentamento.

De acordo com Trindade (2007), a Síndrome de Burnout ainda é desconhecida para muitos trabalhadores, não sendo comum associar o estresse decorrente do trabalho a problemas de saúde ou à doença ocupacional, o que leva o trabalhador a ter que buscar seus próprios mecanismos de enfrentamento para superá-la.

Outros estudos afirmam ainda que pessoas que possuem melhores estratégias de enfrentamento conseguem melhor resolução de seus problemas por, muitas vezes, desenvolverem estratégias mais adequadas para superar o estresse laboral prevenindo o surgimento do Burnout. Assim, a maneira como uma pessoa lida com o estresse e os recursos que ela emprega são fatores presentes na base para o desenvolvimento ou não da Síndrome de Burnout, de modo que as formas de enfrentamento tornam-se assim fatores de proteção (MEARNS e CAIN, 2003; HERNÁNDEZ ZAMORA, CASTEJÓN e FERNÁNDEZ, 2004; MAZON, CARLOTTO e CÂMARA, 2008). 
Considerando todas estas questões, para um melhor enfrentamento desta condição pelos profissionais da saúde, faz-se necessário ampliar os conhecimentos sobre sua prevalência, processos desencadeantes, suas características e consequências, além dos possíveis modos de enfrentamento, com o intuito de promover o cuidado à saúde destes profissionais e melhorar a qualidade do desempenho laboral. Para que se possa atuar preventivamente, considerando os custos elevados relacionados ao mau desempenho dos profissionais, o absenteísmo, a rotatividade, o recrutamento, o treinamento e as doenças que acometem esses profissionais.

Diante do exposto, considera-se relevante o desenvolvimento de um estudo que investigue a Síndrome de Burnout, o estresse precoce e as estratégias de enfrentamento dos problemas utilizadas por técnicos e auxiliares de enfermagem em ambiente hospitalar, para deste modo, contribuir para uma maior reflexão acerca destes fenômenos entre tais profissionais e propor futuras intervenções que melhorem as condições de trabalho dos mesmos.

\subsection{Motivação pessoal}

Durante minha atuação profissional pude vivenciar alguns estressores presentes no ambiente laboral, tais como, sobrecarga de trabalho, baixa remuneração e principalmente falta de reconhecimento. Junto a estes, podem se agregar outros fatores que somados podem acarretar insatisfação por parte do profissional e, consequente, comprometimento da qualidade do serviço prestado e da qualidade de vida desse trabalhador.

Formada em enfermagem, tenho como princípio profissional o cuidado e entendo que este cuidado não deve apenas ser direcionado ao paciente, mas também para todos aqueles que atuam neste contexto, incluindo a pessoa que o exerce.

Assim, seguindo essa linha de pensamento, considero relevante conhecer e identificar o esgotamento profissional entre os profissionais de saúde, para que seja possível planejar estratégias com o intuito de melhorar a qualidade laboral dos profissionais e assim proporcionar uma atenção de qualidade ao receptor desse serviço.

Estudos relacionados ao tema permitem inferir que a Síndrome de Burnout ainda é pouco evidenciada e que o estresse relacionado à prática profissional, acrescido por 
estratégias ineficazes de enfrentamento dos problemas, pode fazer com que os profissionais de saúde desenvolvam a Síndrome de Burnout. As questões que norteiam este estudo são:

- Qual é a prevalência da Síndrome de Burnout entre os auxiliares e técnicos de enfermagem em ambiente hospitalar?

- Qual é a estratégia de enfrentamento mais utilizada por esses profissionais?

- Qual a prevalência de estresse precoce entre esses profissionais?

- Existe alguma associação entre a Síndrome de Burnout e as variáveis sociodemográficas, condições de trabalho e saúde?

- Existe alguma associação entre a Síndrome de Burnout e as estratégias de enfrentamento?

- Existe alguma associação entre a Síndrome de Burnout e o estresse precoce?

\subsection{Referencial teórico}

1.4.1 A relação entre o homem e o trabalho

O mundo do trabalho sofreu mudanças significativas desde seus primórdios. A princípio, o trabalho detinha conotação negativa, considerado uma atividade inferior e sem valor, sendo destinado apenas aos escravos. Com o surgimento da burguesia, iniciou-se a valorização deste trabalho e a crítica à vida ociosa que, a partir dos avanços tecnológicos do século XVII, passagem do feudalismo para o capitalismo, foi refutada para que o trabalho se consolidasse na sociedade. Com o processo de industrialização, o modelo de trabalho mecanizado então se instala, acarretando certa alienação no trabalho. Inúmeras mudanças ocorrem no modelo de gestão trabalhista e nas organizações, culminando no fortalecimento capitalista e consequente aumento da competitividade (ALVIM, 2006).

Assim, observa-se que a relação entre o homem e o trabalho data de muitos anos e que o trabalho sempre ocupou um espaço concreto na vida do indivíduo, pois, garante o suprimento de suas necessidades básicas, sua sobrevivência, sendo também determinante de sua condição social. O trabalho constitui, portanto, uma das formas encontradas pelo homem para viver em sociedade, podendo proporcionar uma maneira de realização pessoal, quando consegue suprir as necessidades tanto internas como externas do indivíduo. O trabalho 
concede ainda um lugar seguro na comunidade humana, sendo a atividade profissional construtora de fonte de satisfação, se for livremente escolhida (FREUD, 1930 apud MENDES, 1999).

Porém, o trabalho pode tornar-se fonte tanto de satisfação quanto de frustração na vida do trabalhador. Algumas vezes podendo ser considerado como um esforço, uma forma de subsistência, obrigação ou até mesmo um mal necessário, tornando-se assim penoso e doloroso. Por outro lado, pode ser considerado como fonte de prazer e uma forma de dignificar o homem (MENDES, 1999; MARINHO, 2005).

Devido às mudanças rápidas que ocorrem na sociedade contemporânea e a consolidação do capitalismo, como sistema econômico hegemônico, o mercado de trabalho é marcado pela competitividade e pelo aumento de busca por atualização profissional, deixando o homem em permanente situação de tensão e desequilíbrio físico e mental.

Ignatti (2012), afirma que o mercado é cada vez mais seletivo quanto à qualificação profissional, porém, não demonstra sinais de melhora de oferta de condições de trabalho e remuneração tanto quanto aposta em tecnologia. Como, por muitos anos, não se considerou a dimensão subjetiva que o trabalho refletia na vida do trabalhador, pela supressão da dimensão humana desta relação entre homem e trabalho, o trabalhador buscou outras formas para manifestá-la, sendo uma delas o adoecimento que se evidencia pela manifestação de sintomas, nem sempre devidamente percebidos e diagnosticados.

Com a queda da produtividade, em que a saúde do trabalhador passou a interferir negativamente em seu trabalho, é que foram surgindo estudos que passaram a considerar a dimensão humana e psíquica envolvida nesta relação (TELLES, HASHIMOTO, 2008).

As primeiras pesquisas surgiram a partir dos anos cinquenta, voltadas às psicopatologias do trabalho e dedicadas aos estudos de tais perturbações ocasionadas pelas atividades laborais (DEJOURS, 1992 apud MENDES, 1999).

Inicialmente, com o reconhecimento de que a organização interfere na saúde mental do trabalhador, a psicopatologia prendeu-se às manifestações orgânicas do indivíduo, dirigindo seu foco de atenção à doença. Posteriormente, com o reconhecimento dos aspectos subjetivos, a atenção deixou de ser voltada à patologia e voltou-se às relações que este estabelece com o trabalho (TELLES, HASHIMOTO, 2008).

Foi somente na década de sessenta que as preocupações com a qualidade de vida no trabalho foram estimuladas (CORREIA, 2000). 
Assim, o interesse em melhorar a qualidade de vida do trabalhador emergiu com o impacto dos problemas de saúde em nível laboral que passaram a ser representativos além de somente preocupantes.

Tamayo (2008), afirma que a preocupação das organizações com as necessidades de saúde de seus empregados é garantia de rendimento para a empresa e sociedade, sendo impossível ignorar tal fato quando se busca desempenho eficaz.

Entende-se que, para que o sujeito desempenhe bem suas atividades, é imprescindível que haja bem estar psicológico dos membros envolvidos no trabalho, fator este também responsável pelo aumento da produtividade e harmonia interna (CORREIA, 2000). Assim, para que o trabalhador tenha boa saúde física e mental, é fundamental direcionar o cuidado também para o profissional, para assim, melhorar sua qualidade laboral e desempenho na qualidade do serviço prestado.

\subsubsection{Conceituando a Síndrome de Burnout}

A concepção de Burnout surgiu nos Estados Unidos em meados dos anos 70, para explicar o processo de deterioração nos cuidados e atenção profissional nos trabalhadores de organizações e teve como autores pioneiros o psicanalista Herbert J. Freudenberger e a psicóloga social Cristina Maslach (PEREIRA e SILVA, 2004).

Este termo foi usado pela primeira vez em 1974 por Freudenberger, que o descreveu como um quadro observado em jovens trabalhadores de uma clínica de dependentes de substâncias químicas na cidade de Nova York onde foi observado que os jovens se mostravam desmotivados e o tratamento tornava-se distante e desumanizado (SCHUWARTZMANN, 2004; MUFORESE, ABRANCHES e NAPOLEÃO, 2005; SANTOS, ALVES e RODRIGUES, 2009; MOREIRA et al, 2009).

De acordo com os autores Muforese, Abranches e Napoleão (2005), o termo Burnout designa aquilo que deixou de funcionar por exaustão energética, expresso por meio de um sentimento de fracasso, causado por um excessivo desgaste de energia e recursos que acomete, geralmente, os profissionais que trabalham em contato direto com pessoas. É uma síndrome psicológica que envolve uma prolongada resposta aos estressores no local de trabalho (MASLACH, 2003). A Síndrome de Burnout manifesta-se através de quatro classes sintomatológicas, sendo: física, psíquica, comportamental e defensiva. 
Na manifestação física de sintomas, o trabalhador apresenta fadiga constante, distúrbio de sono, falta de apetite e dores musculares. Na psíquica é observada falta de atenção, alterações da memória, ansiedade e frustração. A comportamental é identificada quando o indivíduo apresenta-se negligente no trabalho, com irritabilidade ocasional ou instantânea, incapacidade para se concentrar, aumento das relações conflitivas com os colegas, longas pausas para o descanso e cumprimento irregular do horário de trabalho. E na manifestação defensiva de sintomas, o trabalhador tem tendência ao isolamento, sentimento de onipotência, empobrecimento da qualidade do trabalho e atitude cínica (MENEGÁZ, 2004; JODAS \& HADDAD, 2009).

A exaustão é a característica central da Síndrome de Burnout, a manifestação mais óbvia, sendo a principal queixa dos indivíduos que sofrem dessa síndrome. A exaustão emocional corresponde à redução dos recursos emocionais internos causados por demandas interpessoais. A despersonalização reflete o desenvolvimento de atitudes frias, negativas e insensíveis direcionadas aos receptores de um serviço prestado, que torna-se desumanizado, hostil, intolerante e impessoal. Por fim, a sensação de baixa realização profissional evidencia que pessoas que sofrem da síndrome tendem a acreditar que seus objetivos profissionais não foram atingidos e vivenciam uma sensação de insuficiência e baixa autoestima profissional (LIMA et al, 2007; BENEVIDES-PEREIRA, 2010).

As consequências decorrentes da Síndrome de Burnout não são apenas fisiológicas, mas podem ocorrer também abuso de álcool e substâncias, risco de suicídio, transtornos ansiosos e depressivos, além das implicações socioeconômicas como absenteísmo, abandono de especialidade, queda de produtividade, incapacidade temporária e aposentadorias precoces (CURANDI et al, 2003; VIEIRA et al., 2006; FOGAÇA et al, 2008).

Atinge principalmente os profissionais voltados para atividades de cuidado, que envolvem uma relação com o cliente permeada de ambiguidades, como conviver com a tênue distinção entre envolver-se profissional e não pessoalmente na ajuda ao outro (MASLASH \& LEITER, 1997; BORGES et al., 2002; HAHNMARY; CARLOTTO, 2008).

Lima et al (2007), citam um modelo que relaciona a Síndrome de Burnout com os processos de troca interpessoal que se desenvolvem, principalmente, no ambiente do trabalho. Segundo esse modelo, os profissionais que prestam cuidados ou assistência a outras pessoas esperam um retorno, como gratidão, respeito e colaboração. Como essa reciprocidade muitas vezes não ocorre e as expectativas do profissional não são atingidas, ele vivencia um esgotamento de recursos emocionais que o leva a se sentir desmotivado a investir numa boa 
relação com seus clientes. Essa despersonalização pode gerar falhas no trabalho, o que intensifica a sensação de baixa realização pessoal.

A literatura relaciona o desenvolvimento da Síndrome de Burnout aos diversos setores de trabalho existentes no ambiente hospitalar. Os problemas são dos mais variados como condições dos pacientes, prognóstico, pacientes terminais, conflitos com pacientes e familiares, problemas entre a própria equipe de trabalho. (LAUTERT, 1995).

A Organização Mundial de Saúde entende que a Síndrome de Burnout é um risco para o trabalhador e a considera um problema de saúde pública. No Brasil, o Ministério da Saúde reconhece essa síndrome como "síndrome do esgotamento profissional”, um tipo de resposta prolongada a estressores emocionais e interpessoais crônicos presentes no trabalho (CEBRIÀANDREU, 2005; GIL-MONTE, CARLOTTO e CÂMARA, 2010).

Decorrentes da Constituição Federal (BRASIL, 1988), e Lei Orgânica da Saúde (BRASIL, 1990), o Regulamento da Previdência social (BRASIL, 1999), foi aprovado e reconhecida que a Síndrome de Burnout é uma doença relacionada à condição de trabalho, associada à fatores de risco de natureza ocupacional e mental relacionadas ao trabalho (LORENZ, BENATTI e SABINO, 2010).

\subsubsection{O estresse precoce, o estresse laboral e as estratégias de enfrentamento}

Na área da saúde, o termo estresse foi utilizado pela primeira vez em 1926 por Hans Selye, que ao término de diversas pesquisas o explicou como um desgaste geral do organismo, cuja reação psicológica com componentes emocionais, físicos, mentais e químicos a determinados estímulos estranhos levam a irritabilidade, amedrontamento, excitação ou confusão (LIPP, 2000 apud FERREIRA;DE MARTINO, 2009). Assim, Selye definiu o estresse como sendo "um conjunto de reações que ocorrem em um organismo quando este está submetido ao esforço de adaptação” (SEYLE, 1950, p.4667).

Os estímulos capazes de provocar a quebra da homeostase do organismo são chamados de eventos estressores e estes podem ser classificados como externos (relacionados às condições externas que afetam o indivíduo), e internos (determinados completamente pelo próprio indivíduo). $\mathrm{O}$ estado de estresse está relacionado a uma resposta adaptativa e, dessa forma, é um mecanismo normal, necessário e benéfico ao organismo. Cada indivíduo possui 
um nível de tolerância diferente as situações estressantes e a suscetibilidade do indivíduo ao estresse varia de acordo com sua habilidade em lidar com o problema (SILVA, 2005).

Selye desenvolveu, em 1956, um modelo designado Síndrome de Adaptação Geral que divide as manifestações e alterações produzidas pelo sistema biológico em consequência ao estresse em três fases: a fase de alarme ou alerta é referente ao momento inicial onde o organismo identifica o estressor e mobiliza uma resposta orgânica rápida para o enfrentamento; a fase de resistência faz com que o organismo resista independente da permanência ou não do estressor, fazendo com que o organismo se adapte e na fase de exaustão o estressor permanece e o organismo passa a não ser capaz de eliminá-lo ou adaptarse novamente (SELYE, 1950). Uma quarta fase foi identificada por Lipp entre as fases de resistência e exaustão, identificada como fase de quase-exaustão, onde há enfraquecimento e incapacidade do indivíduo em resistir ou adaptar-se ao estressor. Nesta fase pode surgir problemas leves de saúde, porém não incapacitantes. (FERREIRA; DE MARTINO, 2009).

O estresse não incide apenas na vida adulta, ele pode ocorrer também durante a fase de desenvolvimento infantil, sendo assim definido como estresse precoce. Os eventos traumáticos que podem ocorrer durante essa importante fase em que as estruturas cerebrais estão sendo formadas podem gerar consequências negativas e duradouras que poderão permanecer ao longo da vida da criança e repercutir em sua vida adulta (MARTINS et al., 2011).

Estudos mostram que o trauma infantil pode gerar um impacto dramático na saúde mental da criança e gerar dados neuropsicológicos e consequências prejudiciais na vida adulta (GRASSI-OLIVEIRA, STEIN e PEZZI, 2006).

O estresse precoce é definido como uma tensão inicial que é referente a uma variedade de experiências traumáticas que podem ocorrer na infância e os principais tipos encontrados na literatura são: abuso físico, abuso sexual, abuso emocional e a negligência (BERNSTEIN et al.; 2003; ANDA, 2006; AFIFI et al., 2007; MARTINS et al., 2011). Além disso, a morte dos pais ou substitutos, privações materna ou paterna por abandono, separações e divórcio, transtornos psiquiátricos dos pais e abandonos também se caracterizam como estresse precoce (MARTINS et al., 2011).

Abuso físico são agressões físicas cometidas por alguém mais velho que pode resultar em lesões corporais e chegar ao homicídio. Algumas vezes são formas errôneas praticadas para educação dos filhos. Abuso sexual seria qualquer tipo de contato ou comportamento sexual entre uma criança e alguém mais velho como ocorre nos casos de estupro, atentado 
violento ao pudor, sedução ou corrupção de menores. Abuso emocional são agressões verbais que afetam o bem estar ou a moral da criança, de forma depreciativa por parte de um adulto, que humilha, envergonha ou ameaça a mesma causando-lhe grande sofrimento mental. Negligência representa omissão na provisão das necessidades físicas e emocionais e se divide em negligência física quando ocorre falha em termos de fornecimento de alimentação, vestuário, moradia, segurança, supervisão e saúde por parte dos pais ou responsáveis e negligência emocional configura-se pela falha do cuidador em fornecer amor, motivação e suporte, as necessidades básicas emocionais e psicológicas (BERNSTEIN et al.; 2003).

O evento estressante provoca mudanças no padrão de vida do indivíduo, utilizando recursos pessoais disponíveis, além do que o estresse pode ser causa para uma predisposição ou precipitação de uma doença. (TOWNSEND, 2002).

Algumas vezes o trabalho passa a mobilizar sentimentos negativos no trabalhador, podendo levá-lo ao sofrimento e a partir disso, desenvolver recursos para suportar e não adoecer devido às pressões psíquicas da atividade (TRINDADE, 2007). Sabe-se que a enfermagem é uma profissão estressante, geradora de agravos à saúde física e psíquica, que pode confluir para o adoecimento do profissional, quando este enfrenta regularmente: fragmentação das tarefas e relações, estrutura hierárquica pouco flexível, monotonia de atividades, dimensionamento insuficiente de pessoal, elevado absenteísmo e afastamentos, condições inadequadas de trabalho, sobrecarga de tarefas e responsabilidades, alto nível de exigência, excesso de carga horária contínua de trabalho, remuneração deficiente e insatisfação profissional, problemas de relacionamento interpessoal entre indivíduos da mesma classe, exposição a perdas, sofrimento e morte (IGNATTI, 2012). Tal evidência confirma os achados de Ribeira et al., (1993), nos quais 62,30\% do estresse do pessoal de enfermagem provém do próprio trabalho desenvolvido (RIBEIRA et al., 1993 apud LAUTERT, 1995).

E para enfrentar esta situação o profissional muitas vezes necessita desenvolver técnicas de enfrentamento, criando mecanismos de defesa e adaptação ao estresse, uma couraça defensiva e embotada de emoções e sentimentos para promover um distanciamento das pessoas e situações ansiogênicas (IGNATTI, 2012).

O enfrentamento, também denominado "coping”, corresponde a todos os esforços cognitivos e comportamentais que são constantemente alteráveis, para o controle das demandas internas e externas, que excedem ou fadigam o recurso da pessoa. Assim, entende- 
se que os modos de enfrentamento podem mudar ao longo do tempo, de acordo com as características do estressor e as exigências do contexto (SILVA, 2005).

De acordo com Seidl, Tróccoli e Zannon (2001), as estratégias de enfrentamento podem ser classificadas quanto à função e em duas categorias. A primeira categoria refere-se às estratégias focalizadas no problema e a segunda focalizada na emoção. Na primeira o indivíduo busca conhecer o agente estressor e tenta de algum modo modificá-lo ou evitá-lo no futuro, já na segunda procura diminuir a aflição que o estímulo determina, mesmo que a situação estressante não possa ser modificada.

É importante ressaltar que os tipos de estratégias de enfrentamento utilizadas em uma determinada situação variam de acordo com a personalidade ou de experiências vivenciadas pelo indivíduo, bem como as características da situação (LAAL; ALIRAMAIE, 2010). Além do mais, o uso de estratégias protege o indivíduo de danos ou fortalecem sua capacidade em enfrentar situações desafiadoras. (TOWNSEND, 2002).

Segundo Laal e Aliramaie (2010), o enfrentamento pode ter dois tipos de respostas, sendo uma positiva e a outra negativa. Em relação à resposta positiva, os indivíduos podem reduzir o estresse, como exemplo, utilizando-se de técnicas de respiração ou de exercícios de relaxamento. Esse tipo de enfrentamento pode ajudar a pessoa a ganhar maior confiança em si, buscando controlar a realidade além de proporcionar o desenvolvimento da maturidade emocional. Na resposta negativa, a situação implica dano ou algum prejuízo que já ocorreu.

Dessa forma, verifica-se que os indivíduos desenvolvem formas diferentes de enfrentamento, mesmo frente a uma mesma situação conflitante, o que se deve a diversos fatores. Cabe se observar também, que conforme a frequência e a duração das situações estressantes, os recursos tendem ao esgotamento. Por isso, diferentes estudos buscam entender as formas de enfrentamento utilizadas pelos profissionais frente aos fatores conflitantes a fim de que se possa entender a dinâmica laboral e relacional bem como as formas de expressão/posicionamento desses indivíduos favorecendo a melhora da qualidade de vida profissional (TRINDADE, 2007; PRETO e PEDRÃO, 2009).

1.4.4 O exercício da enfermagem e as categorias de auxiliar e técnico em enfermagem

A enfermagem é uma profissão muito antiga no mundo do trabalho e nasceu da necessidade de cuidados para as pessoas saudáveis e doentes. A enfermagem moderna, como 
profissão, se organizou a partir de meados do século XIX, com a atuação de Florence Nightingale e se desenvolveu no Brasil a partir de 1920 (NIGHTINGALE, 1980; BAPTISTA; BARREIRA, 2006).

Horta (1979), citado por Silva (2007), define a profissão de enfermagem como uma ciência e também uma arte na assistência do ser humano, profissão que atente às necessidades básicas do indivíduo e colabora com outros profissionais. Atualmente, a enfermagem ocupa o maior espaço dentro da equipe de saúde brasileira, sendo representada por mais de $50 \%$ da força de trabalho em saúde (ALMEIDA FILHO, 2011).

A regulamentação do exercício da enfermagem foi dada pela Lei n. 7.498 de 25 de junho de 1986, que determina o livre exercício da profissão em todo o território nacional desde que suas atividades sejam exercidas por pessoas legalmente habilitadas e inscritas no Conselho Regional de Enfermagem, nas categorias enfermeiro, técnico de enfermagem e auxiliar de enfermagem (BRASIL, 1986).

De acordo com o Art. 12 da referida lei, cabe ao técnico de enfermagem exercer atividade de nível médio, envolvendo orientação e acompanhamento do trabalho de enfermagem em grau auxiliar e participação no planejamento da assistência de enfermagem, cabendo-lhe especialmente: participar da programação da assistência de enfermagem, executar ações assistenciais de enfermagem, exceto as privativas do enfermeiro, participar da orientação e supervisão do trabalho de enfermagem em grau auxiliar (BRASIL, 1986).

Já o Art. 13 refere-se às atividades específicas do auxiliar de enfermagem, também de nível médio, de natureza repetitiva, envolvendo serviços auxiliares de enfermagem sob supervisão, bem como a participação em nível de execução simples, em processos de tratamento, cabendo-lhes especialmente: observar, reconhecer e descrever sinais e sintomas, executar ações de tratamento simples, prestar cuidados de higiene e conforto ao paciente e participar da equipe de saúde (BRASIL, 1986).

Lembrando-se de que todas essas atividades descritas nos artigos 12 e 13, quando exercidas em instituições de saúde, públicas ou privadas, somente podem ser executadas sob orientação e supervisão de enfermeiro.

A princípio, a organização dos cursos profissionalizantes em enfermagem obedecia a Lei n. 5.692 de 11 de agosto de 1971. Através desta lei, os cursos de auxiliares e técnicos de enfermagem passaram a integrar o sistema educacional do país em nível de segundo grau e podiam ser oferecidos como cursos regulares, tanto integrado como supletivo. Com a LDB, houve repercussões importantes para a estrutura dos cursos profissionalizantes de 
enfermagem, como a separação da educação profissional do ensino médio. O Decreto $\mathrm{n}$. 2.208/97 possibilitou que os cursos tivessem organização própria e independente do ensino médio. Os cursos de auxiliar de enfermagem são operacionalizados em nível de ensino fundamental e os técnicos em nível médio ministrado concomitante ou posterior a este nível de ensino (BRASIL, 1971; BRASIL, 1997; BAGNATO et al., 2007).

O Conselho Federal de Enfermagem - COFEN, a partir das legislações que regulamentam o ensino profissionalizante instituiu a Resolução n. 276/2003 que concede aos auxiliares de enfermagem ingressantes na categoria somente a inscrição profissional provisória e estipula um prazo de cinco anos para que estes se habilitem como técnicos de enfermagem ou prossigam seus estudos cursando a graduação (COFEN, 2003; BAGNATO et al., 2007).

Atualmente alguns hospitais contratam apenas o profissional enfermeiro para desenvolver toda a assistência prestada ao paciente, porém, na grande maioria dos hospitais a equipe de enfermagem é constituída por enfermeiros, técnicos e auxiliares de enfermagem.

O dimensionamento e distribuição dos profissionais são realizados por meio de escala de trabalho. Tendo em vista que os riscos, à vulnerabilidade e os estressores presentes no ambiente hospitalar podem provocar desgaste a esse profissional.

Ressalta-se a importância de se investigar o possível adoecimento do trabalhador e sua associação com o ambiente laboral, enfatizando a devida atenção aos profissionais da saúde, em especial a equipe de enfermagem. 
2 OBJETIVOS 


\section{OBJETIVOS}

\subsection{Objetivo geral}

Analisar a prevalência e associação entre a Síndrome de Burnout, estresse precoce e estratégias de enfrentamento em técnicos e auxiliares de enfermagem.

\subsection{Objetivos específicos}

- Caracterizar a amostra quanto às características sociodemográficas, condições de trabalho e saúde;

- Identificar a prevalência da Síndrome de Burnout entre os trabalhadores de enfermagem;

- Identificar as estratégias de enfrentamento por eles utilizadas;

- Identificar se os trabalhadores de enfermagem sofreram algum tipo de estresse precoce;

- Testar a associação entre a variável de desfecho (Síndrome de Burnout) e as variáveis sociodemográficas, de condições de trabalho e saúde;

- Testar a associação entre a variável de desfecho (Síndrome de Burnout) e as estratégias de enfrentamento;

- Testar a associação entre a variável de desfecho (Síndrome de Burnout) e o estresse precoce.

- Testar a associação entre as dimensões de Síndrome de Burnout e as variáveis sociodemográficas, de condições de trabalho e saúde;

- Testar a associação entre as dimensões de Síndrome de Burnout e as estratégias de enfrentamento;

- Testar a associação entre as dimensões de Síndrome de Burnout e o estresse precoce. 
3 MÉTODOS 


\section{MÉTODOS}

\subsection{Delineamento da pesquisa}

O presente estudo utilizou os recursos da abordagem quantitativa e é do tipo epidemiológico, de corte transversal e descritivo-exploratório.

\subsection{Local de estudo}

A investigação foi desenvolvida em um hospital de grande porte de um município do interior do estado de São Paulo. O referido hospital visa contribuir com o bem estar da população em geral, tendo como princípio qualidade na assistência, no ensino e na pesquisa, sendo reconhecido como centro de referência e tendo linhas de pesquisa de alta qualidade.

Como a coleta de dados ocorreu em todos os setores do hospital, foi realizado um agrupamento das unidades, utilizando-se da classificação de complexidade de acordo com as ações e serviços realizados em cada uma delas. O Conselho Nacional de Secretarias de Saúde (CONASS), que define:

- Atenção básica ou primária: caracteriza-se por um conjunto de ações de saúde, seja no âmbito individual ou coletivo, que abrangem a promoção e a proteção da saúde, a prevenção de agravos, o diagnóstico, o tratamento, a reabilitação e a manutenção da saúde. A atenção básica tem a Saúde da Família como estratégia prioritária para sua organização de acordo com os preceitos do SUS. A atenção básica inclui um rol de procedimentos mais simples e baratos, capazes de atender à maior parte dos problemas comuns de saúde da comunidade.

- Média complexidade composta por ações e serviços que visam atender aos principais problemas e agravos de saúde da população, cuja complexidade da assistência na prática clínica demande a disponibilidade de profissionais especializados e a utilização de recursos tecnológicos para apoio diagnóstico e tratamento. São exemplos de grupos que compõem os procedimentos de média complexidade: procedimentos especializados realizados por profissionais médicos ou outros 
profissionais, cirurgias ambulatoriais especializadas, procedimentos tráumatoortopédicos, ações especializadas em oncologia, patologia clínica, anatomopatologia e citopatologia, radiodiagnóstico, exames ultrassonográficos, diagnose, fisioterapia, terapia especializadas, próteses e órteses e anestesia.

- Alta complexidade: envolve tecnologia e alto custo, objetivando propiciar à população acesso a serviços qualificados. As principais áreas que compõem a alta complexidade são: assistência ao paciente oncológico, cirurgia cardiovascular, cirurgia vascular, cirurgia cardiovascular pediátrica, procedimentos da cardiologia, procedimentos endovasculares extracardíacos, laboratório de eletrofisiologia, assistência em tráumato-ortopedia, procedimentos de neurocirurgia, assistência em otologia, cirurgia de implante coclear, cirurgia das vias aéreas superiores e da região cervical, cirurgia da calota craniana, da face e do sistema estomatognático, procedimentos em fissuras lábio-palatais, procedimentos para avaliação e o tratamento dos transtornos respiratórios do sono, assistência aos pacientes portadores de queimaduras, assistência aos pacientes portadores de obesidade, cirurgia reprodutiva, genética clínica, terapia nutricional, distrofia muscular progressiva, osteogênese imperfeita, fibrose cística e reprodução assistida. São procedimentos com impacto financeiro extremamente alto. (CONASS, 2007).

Assim, as unidades foram distribuídas em serviços de média e alta complexidade:

- Serviços de média complexidade: ambulatórios de psiquiatria, clínica médica, clínica civil, oftalmologia e otorrinolaringologia, ginecologia e obstetrícia, clínica cirúrgica, neurologia e neurocirurgia, ressonância magnética nuclear, endoscopia, tomografia computadorizada, ultrassonografia, serviço de reabilitação, serviço de enfermagem de ambulatório e divisão de enfermagem.

- Serviços de alta complexidade: psiquiatria, dermatologia, neurologia, clínica médica, moléstias infecciosas, pediatria, centro de tratamento intensivo, obstetrícia, ginecologia, berçário, nono andar, décimo andar, ortopedia, cirurgia de cabeça e pescoço, transplante de fígado, clínica civil (enfermarias), transplante de medula óssea, unidade de tratamento de doenças infecciosas, salas de parto, admissão e trabalho de parto, sala de recuperação, recuperação de tórax, laboratório de ginecologia e obstetrícia, bloco cirúrgico, cardiologia, pneumologia, unidade coronariana, transplante renal, apoio anestésico e unidade de transplante renal, centro de atendimento a epilepsia, diálise, unidade metabólica, preparo e esterilização de 
materiais, controle e distribuição de materiais, seção de descontaminação, radioterapia, imunologia, hematologia e quimioterapia.

\subsection{População}

A população da pesquisa abrange todos os técnicos e auxiliares de enfermagem atuantes de um hospital geral do interior de São Paulo.

Sabe-se que uma maior demanda associada a um menor controle do trabalho exercido corresponde a um maior nível de desgaste do trabalhador. Assim, optou-se por realizar o estudo nesta população (técnicos e auxiliares de enfermagem) considerando que estes profissionais apresentam um trabalho que atende as condições acima, ou seja, cumprem uma alta demanda de trabalho e tem pouco controle da função exercida devido ao seu nível de formação e também à supervisão constante do profissional enfermeiro.

Segundo informações do setor de Recursos Humanos, no início da coleta o hospital empregava 987 auxiliares de enfermagem e 148 técnicos em enfermagem, totalizando 1135 funcionários.

\subsection{Critérios de inclusão e exclusão}

Tendo em vista os objetivos da pesquisa, foram incluídos na amostra aqueles profissionais que atenderam ao critério de estar exercendo suas atividades profissionais no mínimo há um ano e de ambos os gêneros. Tal critério temporal foi estabelecido devido o desenvolvimento da Síndrome de Burnout estar relacionada ao ambiente de trabalho, assim, necessitando de um tempo de exposição para que se desenvolva (FREUDENBERGER, 1974 apud BENEVIDES-PEREIRA, 2010).

Quanto aos critérios de exclusão, foram excluídos da pesquisa aqueles profissionais que estavam afastados ou de férias do trabalho durante o período de coleta de dados. 


\subsection{Procedimento amostral}

A amostra do estudo foi constituída por 338 participantes. Para o cálculo do tamanho amostral aplicou-se a fórmula usual proposta por Silva (2001), $\mathrm{N}=\mathrm{Z}^{2}$.p.q / $\mathrm{E}^{2}$, onde:

Z: é o valor da curva normal correspondente ao nível de confiança

p: é a prevalência

$\mathrm{q}=1-\mathrm{p}$

E: é o erro máximo que se está disposto a cometer.

Como são poucas as referências sobre uma prevalência confiável, optou-se pelo valor mais seguro de 50\%. Assim, o tamanho da amostra foi calculado para detectar uma prevalência prevista de $50 \%$ com $95 \%$ de confiança e um erro máximo de $5 \%$. Isto é, o tamanho da amostra deve garantir esta precisão ao detectar uma prevalência no intervalo de $45 \%$ a $55 \%$ com $95 \%$ de probabilidade. Valores da prevalência mais afastados de 50\% resultarão em menor erro ou maior poder da estimativa.

Substituindo os valores $Z=1,96, p=0,50$ e $E=0,05$ obtém-se $n($ inicial $)=384$.

A correção para a população finita foi realizada por meio da expressão: $\mathrm{n}=\mathrm{n}($ inicial $) /\{1+\mathrm{n}($ inicial $) /$ População $\}$, onde $\mathrm{n}($ inicial $)=384$ e população $=1055$, leva ao valor de $n$ (intermediário $)=282$. Assim, admitindo-se recusas e respostas parciais em torno de $20 \%$, o valor final ficou sendo: $\mathrm{n}($ final $)=338$.

\subsection{Proteção de participação do estudo}

Considerando os aspectos éticos referentes à pesquisa envolvendo seres humanos (Resolução 196/96), o presente estudo recebeu autorização do serviço para sua realização, foi submetido à avaliação do Comitê de Ética e Pesquisa da EERP sendo aprovado sob o Parecer 23433 (Anexo A) e logo após, aprovado também pelo Comitê de Ética e Pesquisa do HCFMRP (Anexo B). Foi assegurado aos participantes que as informações obtidas impossibilitariam a identificação dos mesmos. Todos os participantes do estudo foram devidamente esclarecidos sobre a pesquisa, os seus direitos e os cuidados a eles garantidos. Após concordarem em participar, assinaram o Termo de Consentimento Livre e Esclarecido (Apêndice A), em duas vias assinadas pelo pesquisador e participante, sendo uma via do 
pesquisador e a outra via do participante conforme regulamenta os dispositivos da Resolução 196/96 do Conselho Nacional de Saúde (BRASIL, 1996).

\subsection{Coleta de dados}

Os dados foram coletados pelas pesquisadoras envolvidas no projeto, de forma individual, no próprio ambiente laboral. Para a coleta de dados foram utilizados os seguintes instrumentos:

1 - Questionário sociodemográfico, de condições de trabalho e saúde (Apêndice B).

2 - Escala de Modos de Enfrentamento dos Problemas EMEP (Anexo C);

3 - Escala de "Maslach Burnout Inventory" - MBI (Anexo D);

4 - Childhood Traume Questionnaire - CTQ (Anexo E);

3.7.1 Questionário sociodemográfico, de condições de trabalho e saúde

Este questionário foi elaborado pelas pesquisadoras para registrar os dados sociodemográficos e laborais, e assim caracterizar a população em estudo.

Ele é formado por 27 questões que contemplam as seguintes variáveis: Idade; Sexo; Escolaridade; Estado civil; Religião; Tempo de serviço no setor HC; Tempo de serviço na profissão; Número de vínculos empregatícios; Horário de Trabalho; Com quem mora; Número de pessoas que residem no domicílio; Número de filhos; Consulta médica no último ano; Motivo da consulta médica; Tipo de serviço de saúde; Uso de medicamentos; Afastamento do trabalho; Doenças autorreferidas; Uso de álcool e tabaco. 
3.7.2 Escala modos de enfrentamento de problemas - EMEP

Esta escala foi concebida com base no modelo interativo do estresse e conceitua enfrentamento como um conjunto de respostas específicas para determinada situação estressora. Foi desenvolvida por Vitalino e colaboradores em 1985 e a iniciativa de tradução e adaptação para o português foi realizada por Gimenes e Queiroz em 1997, que utilizaram procedimentos de análise semântica e tradução reversa, sem proceder à investigação da estrutura fatorial. A análise fatorial da escala foi investigada por Seidl, Tróccoli e Zanon em 2001, que modificaram apenas a escala de respostas de Likert de quatro pontos substituindo-a por cinco pontos $(1=$ Eu nunca faço isso; $2=\mathrm{Eu}$ faço isso um pouco; $3=$ Eu faço isso às vezes; 4 = Eu faço isso muito; 5 = Eu faço isso sempre) (SEIDL, TRÓCCOLI e ZANNON, 2001).

A EMEP é composta por 45 itens, distribuídos em quatro fatores:

1. Enfrentamento focalizado no problema: constituído por 18 questões $(\alpha=0,84)$ que englobam estratégias comportamentais que representam aproximação em relação ao estressor, voltadas para seu manejo ou solução, bem como estratégias cognitivas direcionadas para a reavaliação e ressignificação do problema, percebendo-o de modo positivo. Fazem parte deste fator as seguintes questões: “40. Eu digo a mim mesmo o quanto já consegui; 39. Eu sairei dessa experiência melhor do que entrei nela; 45. Eu tento não fechar portas atrás de mim. Tento deixar em aberto várias saídas para o problema; 36. Encaro a situação por etapas, fazendo uma coisa de cada vez; 1. Eu levo em conta o lado positivo das coisas; 33. Mudo alguma coisa para que as coisas acabem dando certo; 28. Estou mudando me tornando uma pessoa mais experiente; 32. Eu tento não agir tão precipitadamente ou seguir minha primeira ideia; 42. Eu fiz um plano de ação para resolver o meu problema e o estou cumprindo; 24. Eu sei o que deve ser feito e estou aumentando meus esforços para ser bem sucedido; 17. Eu me concentro nas coisas boas da minha vida; 10. Eu insisto e luto pelo que eu quero; 3 . Eu me concentro em alguma coisa boa que pode vir desta situação; 15. Tento ser uma pessoa mais forte e otimista; 30. Eu fico me lembrando que as coisas poderiam ser piores; 19. Aceito a simpatia e a compreensão de alguém; 14. Encontro diferentes soluções para o meu problema; 16. Eu tento evitar que os meus sentimentos atrapalhem em outras coisas na minha vida". 
2. Enfrentamento focalizado na emoção: constituído por 15 questões $(\alpha=0,81)$ que englobam estratégias cognitivas e comportamentais de esquiva ou negação, expressão de emoções negativas, pensamento fantasioso, autoculpa ou culpabilização de outros, com função paliativa ou de afastamento do problema. Fazem parte deste fator as seguintes questões: “29. Eu culpo os outros; 20. Demonstro raiva para as pessoas que causaram o problema; 13. Desconto em outras pessoas; 25. Eu acho que as pessoas foram injustas comigo; 38. Penso em coisas fantásticas ou irreais (como uma vingança perfeita ou achar muito dinheiro) que me fazem sentir melhor; 23. Eu me sinto mal por não ter podido evitar o problema; 35. Eu imagino e tenho desejos sobre como as coisas poderiam acontecer; 2. Eu me culpo; 5. Procuro um culpado para a situação; 22. Eu percebo que eu mesmo trouxe o problema para mim; 34. Procuro me afastar das pessoas em geral; 37. Descubro quem mais é ou foi responsável; 12. Eu brigo comigo mesmo, eu fico falando comigo mesmo o que devo fazer; 18. Eu desejaria mudar o modo como eu me sinto; 11. Eu me recuso a acreditar que isto esteja acontecendo".

3. Busca de práticas religiosas: constituído por 7 questões $(\alpha=0,74)$ que englobam pensamentos e comportamentos religiosos como modos de enfrentamento e manejo para auxiliar no enfrentamento do estressor. Fazem parte deste fator as seguintes questões: "44. Eu me apego à minha fé para superar esta situação; 6. Espero que um milagre aconteça; 21 . Pratico mais a religião desde que tenho esse problema; 41 . Eu desejaria poder mudar o que aconteceu comigo; 27. Tento esquecer o problema todo; 8 . Eu rezo/oro; 26. Eu sonho ou imagino um tempo melhor do que aquele em que estou".

4. Busca de suporte social: constituído por 5 questões $(\alpha=0,70)$ que englobam a procura de apoio social emocional ou instrumental para ajudar a lidar com o problema. Fazem parte deste fator as seguintes questões: “31. Converso com alguém que possa fazer alguma coisa para resolver o meu problema; 9. Converso com alguém sobre como estou me sentindo; 43. Converso com alguém para obter informações sobre a situação; 7. Peço conselho a um parente ou a um amigo que eu respeite; 4. Eu tento guardar meus sentimentos para mim mesmo".

As respostas são dadas em escala de Likert de cinco pontos ( 1 = nunca faço isso a $5=$ faço isso sempre). Os escores são obtidos pela média aritmética e quanto mais altos, maior a frequência de utilização da estratégia de enfrentamento. Apenas o item quatro possui análise 
fatorial negativa, sendo necessário inverter os escores antes do cálculo (SEIDL; TRÓCOOLI; ZANNON, 2001). Ressalta-se que houve contato e autorização da respectiva autora, responsável pela análise fatorial, para utilização da mesma (Anexo F).

\subsubsection{Maslach Burnout Inventory (MBI)}

Elaborado em 1981 por Maslach e Jackson, o Maslach Burnout Inventory (MBI) é um dos instrumentos de auto-avaliação mais utilizados em todo o mundo para medir a Síndrome de Burnout. Os itens do MBI foram projetados para medir hipóteses de aspectos da síndrome que caracterizam um trabalhador com Síndrome de Burnout. Os itens foram escritos na forma de declarações sobre sentimentos pessoais e atitudes (MASLACH e JACKSON, 1981). Foi traduzido e adaptado para o português por Lautert (1995), sendo a versão atual do MBI é formada por 22 itens (afirmações) tipo Likert de cinco pontos, dividida em três subescalas: exaustão emocional ( 9 itens, $\alpha=0,88$ ), despersonalização ( 5 itens, $\alpha=0,65$ ) e realização pessoal ( 8 itens, $\alpha=0,94)$ (TELLES, 2008).

As questões referentes à "exaustão emocional" investigam sentimentos de se estar emocionalmente exausto e esgotado com o trabalho. Compõem esta subescala as seguintes afirmações: “1. Eu me sinto emocionalmente exausto pelo meu trabalho; 2. Eu me sinto esgotado ao final de um dia de trabalho; 3 . Eu me sinto cansado quando me levanto de manhã e tenho que encarar outro dia de trabalho; 6. Trabalhar o dia inteiro é realmente um grande esforço para mim; 8. Eu me sinto esgotado com meu trabalho; 13. Eu me sinto frustrado com meu trabalho; 14. Eu sinto que estou trabalhando demais no meu emprego; 16. Trabalhar diretamente com pessoas me deixa muito estressado; 20. No meu trabalho, eu me sinto como se estivesse no final do meu limite".

A “despersonalização" descreve respostas impessoais e fazem parte desta subescala as seguintes afirmações: "5. Eu sinto que eu trato alguns dos meus pacientes como se eles fossem objetos; 10. Eu sinto que me tornei mais insensível com as pessoas desde que comecei este trabalho; 11. Eu sinto que este trabalho está me endurecendo emocionalmente; 15 . Eu não me importo realmente com o que acontece com alguns dos meus pacientes; 22. Eu sinto que os pacientes me culpam por alguns dos seus problemas".

A “realização pessoal" descreve os sentimentos ao nível da capacidade e sucessos alcançados no trabalho com pessoas, esta última inversamente correlacionada com a 
Síndrome. Fazem parte as seguintes afirmações: “4. Eu posso entender facilmente o que sentem os meus pacientes acerca das coisas que acontecem no dia a dia; 7. Eu trato de forma adequada os problemas dos meus pacientes; 9. Eu sinto que estou influenciando positivamente a vida de outras pessoas através do meu trabalho; 12. Eu me sinto muito cheio de energia; 17. Eu posso criar facilmente um ambiente tranquilo com os meus pacientes; 18. Eu me sinto estimulado depois de trabalhar lado a lado com os meus pacientes; 19. Eu tenho realizado muitas coisas importantes neste trabalho; 21. No meu trabalho, eu lido com os problemas emocionais com calma”.

O cálculo dos escores dos indivíduos é realizado através da atribuição de valores relativos à frequência. $\mathrm{O}$ escore total bruto dos sujeitos é obtido através dos somatórios de cada item do inventário. O escore do sujeito em cada uma das dimensões (exaustão, realização pessoal e despersonalização) também é computado pelo somatório dos pontos dos itens relativos a cada uma das dimensões.

A Síndrome de Burnout é centralizada como variável contínua, neste estudo, os níveis variaram entre baixo e alto. Um nível baixo de Burnout reproduz-se em escores baixos nas subescalas de "exaustão emocional" e "despersonalização" e escores elevados na "realização pessoal". Já um nível alto traduz-se em escores altos para as subescalas de "exaustão emocional" e "despersonalização", e escores baixos na "realização pessoal". (RAMIREZ et al., 1995; BENEVIDES-PEREIRA, 2010).

Destaca-se que houve contato e autorização da respectiva autora, responsável pela validação do inventário, para utilização do mesmo (Anexo G).

\subsubsection{Childhood Trauma Questionnaire (CTQ)}

Com o intuito de investigar traumas infantis, foi desenvolvido por Bernstein e colaboradores em 1994 um questionário auto-aplicável constituído por 70 questões denominado Childhood Trauma Questionnaire (CTQ) que investiga cinco componentes traumáticos: abuso físico, abuso emocional, abuso sexual, negligência física e negligência emocional. Possui também uma escala de controle de minimização/negação das respostas de forma a avaliar tendências dos entrevistados para minimizar ou até negar a experiência de abuso (SCHER et al., 2001; BERNSTEIN et al., 2003; VILLANO et al., 2004; GRASSIOLIVEIRA, STEIN e PEZZI, 2006). 
Uma versão breve do CTQ composta por 28 itens foi modificada por Bernstein e colaboradores em 2003 e validada, mantendo as mesmas propriedades da versão original, porém, sendo de mais rápida aplicação. O questionário foi então traduzido e adaptado para o português por Grassi-Oliveira e colaboradores em 2006. Foram realizadas análises fatoriais exploratórias e confirmatórias em relação à validade do constructo que evidenciaram que os itens do CTQ constituem os cinco fatores distintos correspondentes às cinco dimensões. Foram obtidos fortes indicadores de consistência interna de todas as subescalas, calculadas a partir do alfa de Cronbach variando de $\alpha=0,66$ para negligência física a $\alpha=0.92$ para abuso sexual. Foi realizado o teste-reteste para confirmar a confiabilidade do CTQ mostrando-se bastante estável (SCHER et al., 2001; VILLANO et al., 2004; GRASSI-OLIVEIRA, STEIN e PEZZI, 2006).

O CTQ é constituído por 28 assertivas relacionadas com situações ocorridas na infância em uma escala de Likert de cinco pontos. É considerado o instrumento mais utilizado em pesquisas, na área forense e na área clínica. Cada dimensão é constituída por cinco afirmações cuja resposta varia de $1=$ nunca até $5=$ muito frequentemente (GRASSIOLIVEIRA, STEIN e PEZZI, 2006).

A dimensão abuso emocional é definida como as agressões verbais direcionadas à criança no sentido de valor ou bem-estar ou qualquer comportamento humilhante a ela direcionada por um adulto ou pessoa mais velha. Fazem parte desta dimensão as seguintes assertivas: "3. As pessoas da minha família me chamaram de coisas do tipo "estúpido (a)", "preguiçoso (a)" ou "feio (a)"; 8. Eu achei que meus pais preferiam que eu nunca tivesse nascido; 14. Pessoas da minha família disseram coisas que me machucaram ou me ofenderam; 18. Eu senti que alguém da minha família me odiava e 25 . Eu acredito que fui maltratado (a) emocionalmente".

Abuso físico é definido pelas agressões corporais sofridas por uma criança cometidas por um adulto ou pessoa mais velha, representando um risco ou que resultou em ferimentos. As assertivas correspondentes a esta dimensão são: "9. Eu apanhei tanto de alguém da minha família que tive de ir ao hospital ou consultar um médico; 11. Alguém da minha família me bateu tanto que me deixou com machucados roxos; 12. Eu apanhei com cinto, vara, corda ou outras coisas que machucaram; 15. Eu acredito que fui maltratado (a) fisicamente e 17. Eu apanhei tanto que um professor, vizinho ou médico chegou a notar”.

O contato sexual ou conduta entre uma criança com menos de 18 anos de idade e uma pessoa adulta ou mais velha define a dimensão abuso sexual. Faz parte desta dimensão as 
assertivas: "20. Tentaram me tocar ou me fizeram tocar de uma maneira sexual; 21. Ameaçaram me machucar ou contar mentiras sobre mim se eu não fizesse algo sexual; 23 . Tentaram me forçar a fazer algo sexual ou assistir coisas sobre sexo; 24. Alguém me molestou e 27. Eu acredito que fui abusado (a) sexualmente".

A negligência emocional é definida como a falha dos cuidadores para atender as necessidades emocionais e psicológicas básicas das crianças, incluindo amor, cuidados e apoio. As assertivas que compõem esta dimensão são: "5. Houve alguém na minha família que ajudou a me sentir especial ou importante; 7. Eu me senti amado (a); 13. As pessoas da minha família cuidavam umas das outras; 19. As pessoas da minha família se sentiam unidas e 28. Minha família foi uma fonte de força e apoio".

A dimensão negligência física é definida como o fracasso dos cuidadores para oferecer à criança necessidades físicas básicas, como alimento, abrigo, roupas, segurança e saúde (a supervisão dos pais também é incluída nesta dimensão, caso coloque a segurança da criança em risco). Constituem esta dimensão as seguintes assertivas: "1. Eu não tive o suficiente para comer; 2. Eu soube que havia alguém para me cuidar e proteger; 4. Meus pais estiveram muito bêbados ou drogados para poder cuidar da família; 6. Eu tive que usar roupas sujas e 26. Houve alguém para me levar ao médico quando eu precisei”.

As assertivas “10. Não houve nada que eu quisesse mudar na minha família; 16. Eu tive uma ótima infância e 22. Eu tive a melhor família do mundo", correspondem a escala de controle de minimização/negação da experiência de abuso (BERNSTEIN et al., 2003).

A pontuação é feita através do somatório de pontos referente a cada assertiva de cada dimensão, totalizando ao final cinco escores. Para o indivíduo ser classificado com presença de estresse precoce na infância é necessário que pontue nas classificações de moderadosevero ou severo-extremo. As classificações da CTQ estão descritas de acordo com os pontos de corte sugeridos Bernstein et al. (2003) no quadro abaixo:

\begin{tabular}{|l|c|c|c|c|}
\hline \multirow{2}{*}{ Subtipos } & \multicolumn{4}{c|}{ Classificação } \\
\cline { 2 - 5 } & Não à mínimo & $\begin{array}{c}\text { Leve à } \\
\text { Moderado }\end{array}$ & $\begin{array}{c}\text { Moderado à } \\
\text { Severo }\end{array}$ & $\begin{array}{c}\text { Severo à } \\
\text { Extremo }\end{array}$ \\
\hline Abuso Emocional & $5-8$ & $9-12$ & $13-15$ & $\geq 16$ \\
\hline Abuso Físico & $5-7$ & $8-9$ & $10-12$ & $\geq 13$ \\
\hline Abuso Sexual & 5 & $6-7$ & $8-12$ & $\geq 13$ \\
\hline Negligência Emocional & $5-9$ & $10-14$ & $15-17$ & $\geq 18$ \\
\hline Negligência Física & $5-7$ & $8-9$ & $10-12$ & $\geq 13$ \\
\hline
\end{tabular}

Figura 1 - Classificação dos subtipos de Estresse Precoce de acordo com a gravidade.

Fonte: Traduzido e adaptado de Bernstein et al., 2003. 


\subsection{Permissão para uso dos instrumentos}

A permissão para o uso das escalas EMEP e MBI foi obtida junto às professoras Dra. Eliane Maria Freury Seidl e Dra. Liana Lautert respectivamente, em e-mails recebidos nas datas 18 e 30 de abril de 2012 (Anexos F e G).

\subsection{Estudo piloto}

Sabe-se que durante o desenvolvimento de uma pesquisa podem surgir imprevistos os quais podem interromper a continuação do estudo até que modificações sejam feitas.

Além disso, é importante a familiarização do pesquisador com os instrumentos de coleta e também verificar se as orientações para o preenchimento são de fácil entendimento (RICHARDSON, 2012). Quando ocorrem modificações nos instrumentos após iniciar a coleta os dados coletados estes devem ser descartados (POLIT; BECK; HUNGLER, 2004). Por esse motivo, realizou-se o estudo piloto com os vinte primeiros participantes. Após a análise dos dados, não foram detectadas necessidades de mudanças na proposta inicial para a abordagem dos participantes e coleta dos dados, assim, estes foram incluídos no estudo e foi dada continuidade na coleta.

\subsection{Procedimentos para coleta de dados}

Foi solicitada no setor de recursos humanos do hospital, uma relação com o nome completo dos profissionais, data de admissão, carga horária semanal de trabalho, tipo de contrato e setor em que está alocado. De posse das listas, os profissionais que tinham o tempo de serviço maior que um ano foram organizados em uma planilha no software Microsoft Excel $^{\underline{R}}$, classificados em ordem alfabética. O processamento da aleatorização da amostra foi feito através do programa SPSS versão 16.0. Os profissionais aleatorizados foram então convidados a participar do estudo, não sendo possível a reposição em caso de recusa. 
A coleta ocorreu durante o segundo semestre de 2012, após aprovação pelos Comitês de Ética em Pesquisa da Instituição de Ensino e do campo de estudo.

Antes da abordagem do participante era solicitada autorização para o enfermeiro responsável da unidade. Foram fornecidos a cada participante esclarecimentos quanto à natureza da pesquisa, objetivos, procedimentos, garantias éticas e solicitada a sua colaboração voluntária. Os instrumentos foram autoaplicados e preenchidos pelos participantes logo após os esclarecimentos da pesquisadora em sala reservada para isto. $\mathrm{O}$ tempo de coleta foi em média de 30 minutos.

A coleta de dados foi efetuada pela pesquisadora e ocorreu da seguinte forma:

a) Após os esclarecimentos, o participante assinou duas cópias do TCLE, ficando uma cópia com o pesquisador e outra com ele;

b) $\mathrm{O}$ participante respondeu ao questionário sociodemográfico sendo o preenchimento deste feito pela pesquisadora;

c) O participante foi orientado a pensar em uma situação profissional que ocorreu no ambiente de trabalho, e que tenha sido motivo de preocupação e estresse. Após anotação da situação, era lida a primeira afirmação da escala e as possíveis respostas. Após confirmação de entendimento por parte do participante, este seguia com o preenchimento da EMEP;

d) Posteriormente foi preenchido a MBI onde o participante assinalou qual a frequência das afirmativas listadas;

e) Por último foi preenchido o CTQ, também assinalando a frequência de ocorrência de cada afirmação.

Não foi discutido o conteúdo das questões ou seu significado, nem a escala de respostas. Quando o participante queixava-se de dúvida, foi orientado para reler a questão com atenção e explicado a importância de sua própria interpretação para o preenchimento.

\subsection{Análise dos dados}

Para o processamento das respostas, os dados coletados foram codificados e tabulados pela própria pesquisadora em uma planilha do Microsoft Windows Excel, em dupla digitação, sendo a segunda digitação realizada por colaboradores. Na sequência foi realizada a validação do banco de dados com o uso do software estatístico EpiData. 
Realizou-se a estatística descritiva das características da população e das variáveis estudadas através de distribuição de frequências, números absolutos e percentuais, média, mínimo e máximo.

Calculou-se o Alfa de Cronbach para verificar a consistência interna e confiabilidade das escalas EMEP, MBI e CTQ para a amostra em estudo. O Alfa de Cronbach é um coeficiente de correlação que tem como premissa para sua análise que os itens que constituem os instrumentos sejam positivamente relacionados entre si. Alguns fatores interferem nos coeficientes do Alfa de Cronbach, tais como a extensão e a variância do teste (WALTZ; STRIKLAND; LENS, 2005). Os valores do Alfa de Cronbach podem variar de 0 a 1 , sendo os valores entre o intervalo de 0,70 a 0.90 considerados aceitáveis (CUMMINGS; STWART; RULLEY, 2003).

Posteriormente procedeu-se à análise da escala MBI, considerando escores superiores e iguais ao percentil 75 nas subescalas de Exaustão Emocional e Despersonalização, e percentil até 25 na subescala Realização Pessoal, conforme estudo de validação do MBI no Brasil (LAUTERT, 1995). Assim, criou-se grupos dicotômicos, ou seja, um grupo composto com participantes que apresentaram escores compatíveis à Síndrome de Burnout e outro com participantes que não apresentaram o desfecho.

Foram testadas as associações entre o desfecho principal (Síndrome de Burnout) e as variáveis sociodemográficas, condições de trabalho e saúde, estratégias de enfrentamento e estresse precoce, por meio de testes de associação, realizando-se testes Qui-quadrado, com coeficiente de correlação de Pearson e regressão logística considerando nível de significância de 0,05 .

Prosseguiu-se com a regressão bivariada para determinar quais variáveis seriam utilizadas na regressão múltipla. As variáveis obtidas na regressão bivariada com $\mathrm{p} \leq 0,25$ foram incluídas no modelo de acordo com a hierarquia estabelecida no modelo teórico e definida no modelo de análise mostrada na figura 1. Para o controle de confusão foram mantidas aquelas com $\mathrm{p} \leq 0,25$, e foram consideradas significantes as associações com $\mathrm{p}<$ 0,05 . 

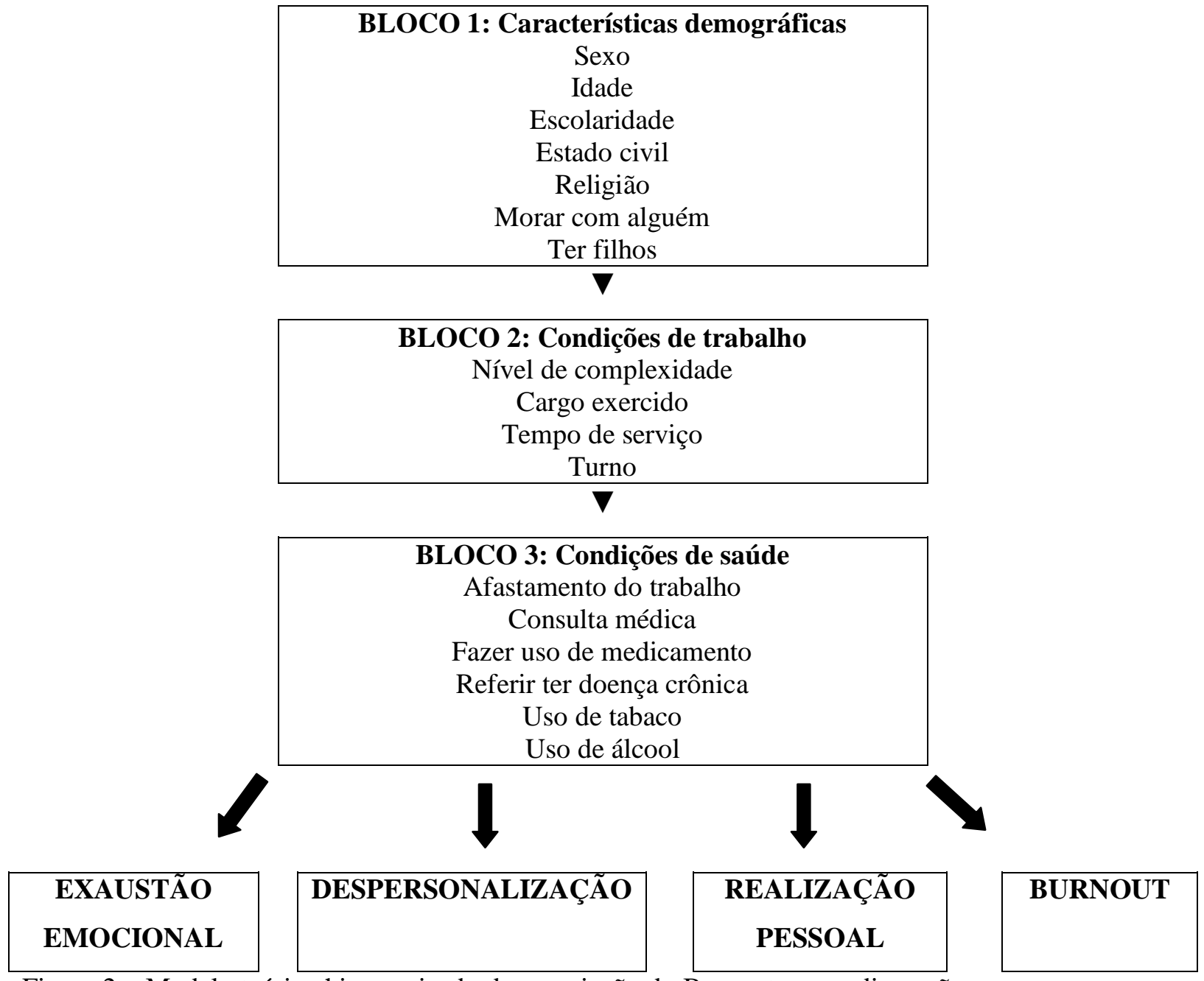

Figura 2 - Modelo teórico hierarquizado de associação do Burnout e suas dimensões. Fonte: Dados da pesquisa, 2012. 
4 RESULTADOS 


\section{RESULTADOS}

\subsection{Caracterização da população do estudo}

Foram convidados a participar do estudo 338 profissionais de enfermagem divididos entre auxiliares e técnicos de enfermagem. Houve $8,2 \%$ de recusas, sendo o total final de participantes igual a 310 .

Conforme pode-se verificar na Tabela 1, a população constituiu-se, em sua maioria, por mulheres $(76,1 \%)$, na faixa etária acima de 41 a 50 anos $(28,1 \%)$, idade variando de 20 a 68 anos e média de 47,19 (DP 10,94) anos, ensino médio completo $(67,4 \%)$, casado ou com companheiro $(58,1 \%)$, com filhos $(74,5 \%)$ e que seguem a religião católica $(53,2 \%)$.

Tabela 1 - Distribuição de frequência dos técnicos e auxiliares de enfermagem segundo as variáveis demográficas. Ribeirão Preto; 2012.

\begin{tabular}{|c|c|c|}
\hline Variável & $\mathbf{N}^{*}$ & $\%$ \\
\hline $\begin{array}{l}\text { Sexo } \\
\text { Masculino } \\
\text { Feminino }\end{array}$ & $\begin{array}{c}74 \\
236\end{array}$ & $\begin{array}{l}23,9 \\
76,1\end{array}$ \\
\hline $\begin{array}{l}\text { Faixa Etária } \\
<30 \text { anos } \\
31 \text { a } 40 \text { anos } \\
41 \text { a } 50 \text { anos } \\
51 \text { a } 60 \text { anos } \\
>60 \text { anos }\end{array}$ & $\begin{array}{l}18 \\
82 \\
87 \\
82 \\
41\end{array}$ & $\begin{array}{r}5,8 \\
26,5 \\
28,1 \\
26,5 \\
13,1\end{array}$ \\
\hline $\begin{array}{l}\text { Escolaridade } \\
\text { Fundamental completo } \\
\text { Médio incompleto } \\
\text { Médio completo } \\
\text { Superior incompleto } \\
\text { Superior completo }\end{array}$ & $\begin{array}{c}10 \\
19 \\
209 \\
42 \\
30\end{array}$ & $\begin{array}{c}3,2 \\
6,1 \\
67,4 \\
13,6 \\
9,7\end{array}$ \\
\hline $\begin{array}{l}\text { Estado Civil } \\
\text { Casado ou com companheiro } \\
\text { Solteiro } \\
\text { Divorciado } \\
\text { Viúvo }\end{array}$ & $\begin{array}{c}180 \\
77 \\
48 \\
5\end{array}$ & $\begin{array}{c}58,1 \\
24,6 \\
15,6 \\
1,7\end{array}$ \\
\hline $\begin{array}{l}\text { Filhos } \\
\text { Não tem filhos } \\
\text { Tem filhos }\end{array}$ & $\begin{array}{c}79 \\
231\end{array}$ & $\begin{array}{l}25,5 \\
74,5\end{array}$ \\
\hline $\begin{array}{l}\text { Religião } \\
\text { Católico } \\
\text { Evangélico } \\
\text { Protestante } \\
\text { Espírita } \\
\text { Agnóstico } \\
\text { Outros }\end{array}$ & $\begin{array}{c}165 \\
69 \\
6 \\
44 \\
23 \\
3\end{array}$ & $\begin{array}{c}53,2 \\
22,6 \\
1,8 \\
14,2 \\
7,3 \\
0,9\end{array}$ \\
\hline
\end{tabular}

$* \mathrm{~N}$ total $=310$

Fonte: Dados da pesquisa, 2012. 
A Tabela 2 mostra que a maioria possui a formação profissional de auxiliares de enfermagem (63,9\%), exercem o cargo de auxiliares de enfermagem $(85,5 \%)$, em serviços de alta complexidade (88,7\%), com tempo de serviço em média de 12,6 (DP 8,75) anos, média de tempo na profissão de 15,9 (DP 8,83) anos, com um único vínculo empregatício $(79,4 \%$ ) e trabalham até 30 horas semanais $(78,0 \%)$.

Tabela 2 - Distribuição de frequência dos técnicos e auxiliares de enfermagem segundo as variáveis de condições de trabalho. Ribeirão Preto; 2012.

\begin{tabular}{|c|c|c|}
\hline Variável & $\mathbf{N}^{*}$ & $\%$ \\
\hline $\begin{array}{l}\text { Formação } \\
\text { Auxiliar de Enfermagem } \\
\text { Técnico de Enfermagem } \\
\text { Enfermeiro }\end{array}$ & $\begin{array}{c}198 \\
107 \\
5\end{array}$ & $\begin{array}{c}63,9 \\
34,5 \\
1,6\end{array}$ \\
\hline $\begin{array}{l}\text { Cargo exercido no serviço } \\
\text { Auxiliar de Enfermagem } \\
\text { Técnico de Enfermagem } \\
\text { Outros }\end{array}$ & $\begin{array}{c}265 \\
39 \\
6\end{array}$ & $\begin{array}{c}85,5 \\
12,6 \\
1,9\end{array}$ \\
\hline $\begin{array}{l}\text { Tipo de serviço } \\
\text { Média complexidade } \\
\text { Alta complexidade }\end{array}$ & $\begin{array}{c}35 \\
275\end{array}$ & $\begin{array}{l}11,3 \\
88,7\end{array}$ \\
\hline $\begin{array}{l}\text { Turno } \\
\text { Diurno } \\
\text { Noturno }\end{array}$ & $\begin{array}{c}238 \\
72\end{array}$ & $\begin{array}{l}76,8 \\
23,2\end{array}$ \\
\hline $\begin{array}{l}\text { Tempo de serviço no local d } \\
\text { Até } 5 \text { anos } \\
6 \text { a } 10 \text { anos } \\
11 \text { a } 15 \text { anos } \\
16 \text { a } 20 \text { anos } \\
21 \text { a } 25 \text { anos } \\
\text { Acima de } 26 \text { anos }\end{array}$ & $\begin{array}{l}84 \\
50 \\
95 \\
31 \\
22 \\
28\end{array}$ & $\begin{array}{l}27,1 \\
16,1 \\
30,7 \\
10,0 \\
7,1 \\
9,0\end{array}$ \\
\hline $\begin{array}{l}\text { Tempo de serviço na profiss } \\
\text { Até } 5 \text { anos } \\
6 \text { a } 10 \text { anos } \\
11 \text { a } 15 \text { anos } \\
16 \text { a } 20 \text { anos } \\
21 \text { a } 25 \text { anos } \\
\text { Acima de } 26 \text { anos }\end{array}$ & $\begin{array}{l}33 \\
61 \\
86 \\
48 \\
34 \\
48\end{array}$ & $\begin{array}{l}10,6 \\
19,7 \\
27,7 \\
15,5 \\
11,0 \\
15,5\end{array}$ \\
\hline $\begin{array}{l}\text { Número de vínculos empreg } \\
\text { Único } \\
\text { Dois vínculos }\end{array}$ & $\begin{array}{c}246 \\
64\end{array}$ & $\begin{array}{l}79,4 \\
20,6\end{array}$ \\
\hline $\begin{array}{l}\text { Carga horária semanal de t } \\
\text { Até } 30 \text { horas semanais } \\
\text { Acima de } 30 \text { horas semanais }\end{array}$ & $\begin{array}{c}242 \\
68\end{array}$ & $\begin{array}{l}78,0 \\
22,0\end{array}$ \\
\hline
\end{tabular}

Com relação aos aspectos de saúde dos participantes verifica-se na Tabela 3 que a maioria referiu ter passado por consulta médica no último ano $(88,4 \%)$, o motivo principal foi 
consulta de rotina $(35,8 \%)$, realizado em serviço público $(72,6 \%)$. Ao ser questionado se houve afastamento do trabalho no último ano, $50 \%$ da amostra mencionou que sim, sendo o principal motivo à ocorrência de doenças $(51,0 \%)$.

Tabela 3 - Distribuição de frequência dos técnicos e auxiliares de enfermagem segundo as variáveis de condições de saúde. Ribeirão Preto; 2012.

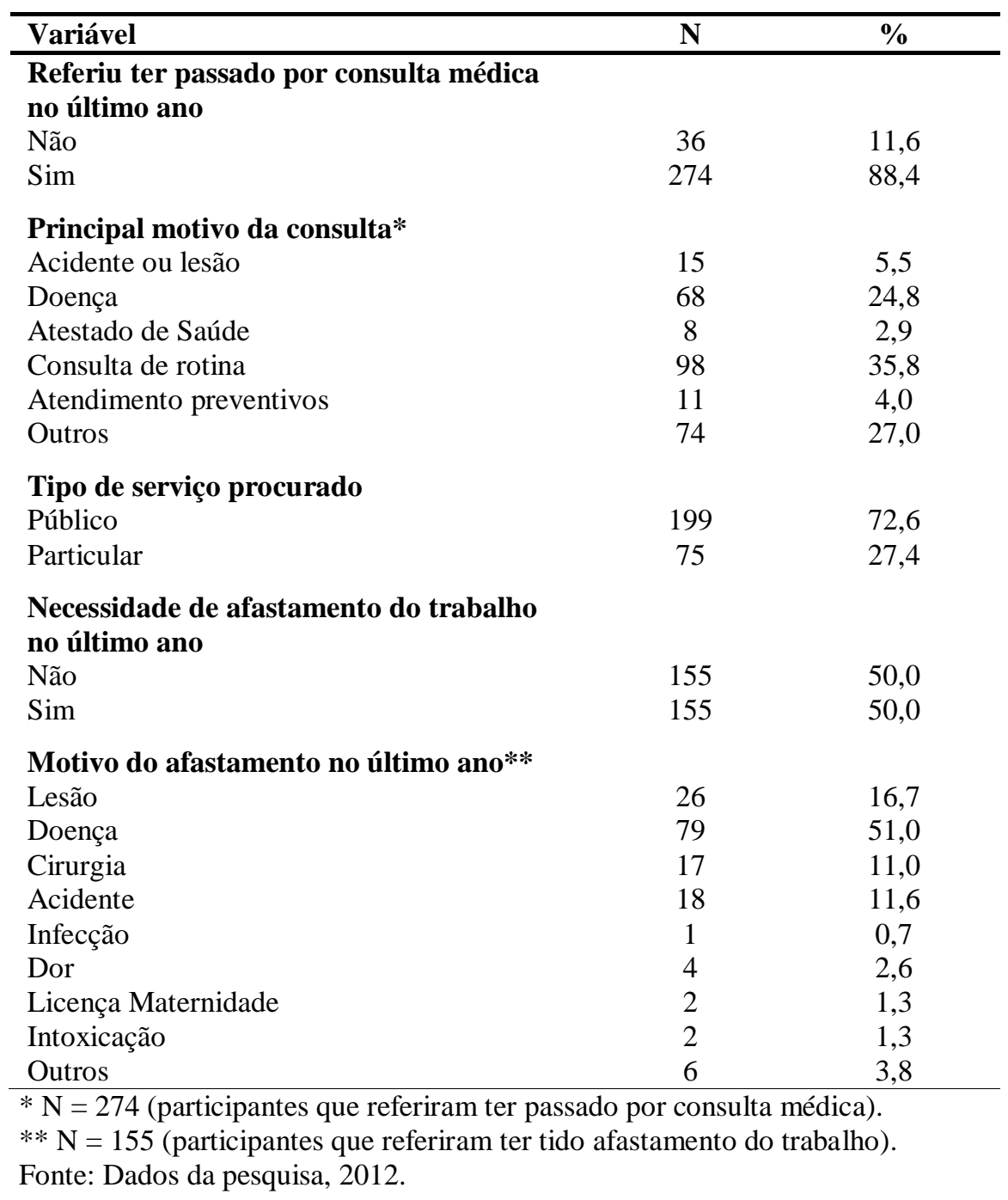

A Tabela 4 apresenta que $51 \%$ dos participantes fazem uso de medicamentos sendo estes para sanar problemas de múltiplos sistemas (31,7\%). Dos $11,3 \%$ de participantes que referiram fazer uso de tabaco, a maioria fuma até 10 cigarros por dia $(48,6 \%)$ há mais de 20 anos $(51,4 \%)$. Entre a população, $75,2 \%$ relata não fazer uso de bebidas alcoólicas, e entre os que fazem uso, a maioria consome apenas uma vez por semana $(68,8 \%)$. 
Tabela 4 - Distribuição de frequência dos técnicos e auxiliares de enfermagem segundo o uso de medicamentos, tabaco e álcool. Ribeirão Preto; 2012.

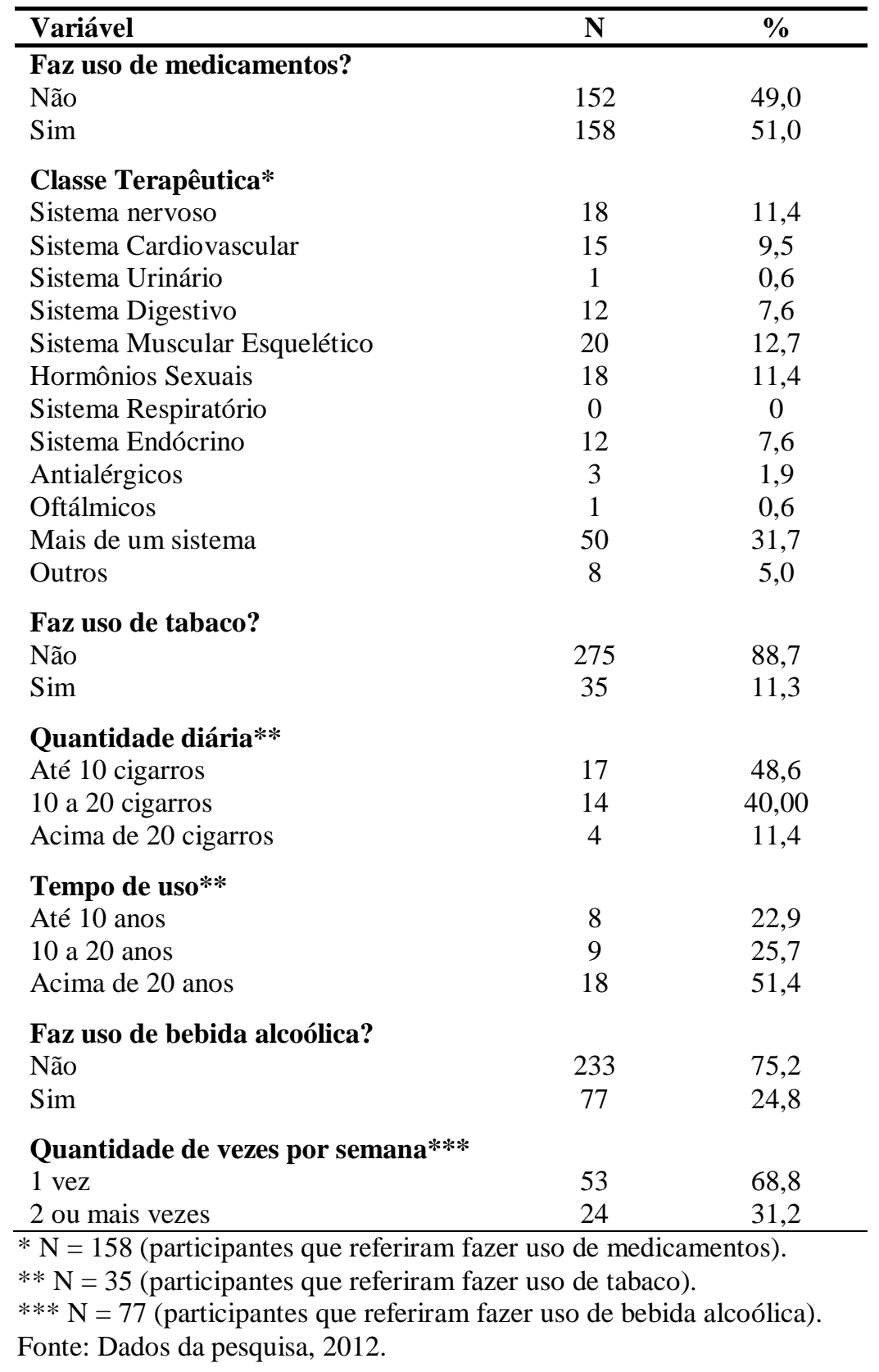

A Tabela 5 relaciona a doença autorreferida, se houve prescrição medicamentosa e em caso afirmativo se o tratamento foi seguido. Percebe-se um padrão de diminuição em relação à porcentagem de participantes na sequencia das perguntas: se algum médico já disse que você tem alguma das doenças abaixo relacionadas, houve prescrição medicamentosa e se o participante seguiu o tratamento. A única exceção ocorreu em relação à hipertensão, dos 50 participantes que relataram ter recebido o diagnóstico, 45 disseram ter recebido prescrição para tratamento farmacológico, mas 47 fazem uso de algum medicamento. As doenças mais autorreferidas foram às doenças de coluna ou costas, gastrite e ansiedade. 
Tabela 5 - Distribuição de frequência dos técnicos e auxiliares de enfermagem segundo doenças autorreferidas, prescrição e tratamento medicamentoso. Ribeirão Preto; 2012.

\begin{tabular}{|c|c|c|c|c|c|c|}
\hline \multirow{3}{*}{ Doença autorreferida } & \multicolumn{2}{|c|}{$\begin{array}{l}\text { Algum médico já disse que } \\
\text { você tem? }\end{array}$} & \multicolumn{2}{|c|}{$\begin{array}{l}\text { Houve prescrição de } \\
\text { medicação? }\end{array}$} & \multicolumn{2}{|c|}{ Fez o tratamento? } \\
\hline & Não & Sim & Não & Sim & Não & Sim \\
\hline & $\mathbf{N}(\%)$ & $\mathbf{N}(\%)$ & $\mathbf{N}(\%)$ & $\mathbf{N}(\%)$ & $\mathbf{N}(\%)$ & $\mathbf{N}(\%)$ \\
\hline Doença de Coluna ou Costas & $192(61,9)$ & $118(38,1)$ & $237(76,5)$ & $73(23,5)$ & $246(79,4)$ & $64(20,6)$ \\
\hline Diabetes & $289(93,2)$ & $21(6,8)$ & $292(94,2)$ & $18(5,8)$ & $291(93,9)$ & $19(6,1)$ \\
\hline Hipertensão & $260(83,9)$ & $50(16,1)$ & $265(85,5)$ & $45(14,5)$ & $263(84,8)$ & $47(15,2)$ \\
\hline $\begin{array}{l}\text { Doença do coração ou } \\
\text { cardiovascular }\end{array}$ & $294(94,8)$ & $16(5,2)$ & $302(97,4)$ & $8(2,6)$ & $302(97,4)$ & $8(2,6)$ \\
\hline Depressão & $248(80,0)$ & $62(20,0)$ & $254(81,9)$ & $56(18,1)$ & $259(83,5)$ & $51(16,5)$ \\
\hline Tendinite ou tendossinovite & $243(78,4)$ & $67(21,6)$ & $260(83,9)$ & $50(16,1)$ & $263(84,8)$ & $47(15,2)$ \\
\hline Gastrite & $233(75,2)$ & $77(24,8)$ & $244(78,7)$ & $66(21,3)$ & $248(80,0)$ & $62(20,0)$ \\
\hline $\begin{array}{l}\text { Úlcera no estômago ou } \\
\text { duodeno }\end{array}$ & $299(96,5)$ & $11(3,5)$ & $299(96,5)$ & $11(3,5)$ & $300(96,8)$ & $10(3,2)$ \\
\hline Doença de pele & $272(87,7)$ & $38(12,3)$ & $277(89,4)$ & $33(10,7)$ & $279(90,0)$ & $31(10,0)$ \\
\hline Ansiedade & $237(76,5)$ & $73(23,5)$ & $254(81,9)$ & $56(18,1)$ & $259(83,5)$ & $51(16,5)$ \\
\hline Distúrbios do sono & $259(83,6)$ & $51(16,4)$ & $277(89,4)$ & $33(10,6)$ & $284(91,6)$ & $26(8,4)$ \\
\hline Distúrbios sexuais & $301(97,1)$ & $9(2,9)$ & $306(98,7)$ & $4(1,3)$ & $307(99,0)$ & $3(1,0)$ \\
\hline
\end{tabular}

Fonte: Dados da pesquisa, 2012.

\subsection{Confiabilidade dos instrumentos}

Primeiramente investigou-se a confiabilidade dos instrumentos utilizados por meio do cálculo de consistência interna coeficiente do Alfa de Cronbach de todos os itens, por dimensões e da escala total. De forma geral, os instrumentos apresentaram coeficientes que caracterizam os indicadores como confiáveis. Na escala MBI as dimensões exaustão emocional e realização pessoal apresentaram os maiores coeficientes e no geral a escala pontuou 0,86. Na EMEP os maiores coeficientes incidiram para as estratégias focalizadas no problema, seguido pelas estratégias focalizadas na emoção e busca de práticas religiosas. $\mathrm{O}$ coeficiente de alfa de Cronbach geral da escala foi de 0,85. Já na CTQ para a população estudada foi obtido o coeficiente de 0,85 para a escala geral e observa-se que as subescalas abuso sexual e negligência emocional apresentaram os maiores coeficientes de Cronbach. A relação completa dos coeficientes consta no Apêndice $\mathbf{C}$. 


\subsection{Análise descritiva das respostas dos técnicos e auxiliares de enfermagem quanto a Síndrome de Burnout, estresse precoce e estratégias de enfrentamento}

Apresentam-se as respostas dos profissionais de enfermagem com relação aos itens da MBI. Verifica-se que as médias nos itens da escala variaram de 1,3 a 4,3, sendo a menor média na questão número cinco, com mínimo de um ponto e máximo de cinco pontos e a maior média na questão número sete, com mínimo de dois pontos e máximo de cinco pontos. Considerando por dimensão, conforme Tabela 6 , realização pessoal apresentou a maior média com mínimo de vinte pontos e máximo de quarenta pontos.

Com relação às estratégias de enfrentamento, as médias dos escores das questões da EMEP variaram de 1,6 a 4,3. A menor média ocorreu na questão número treze e a maior média ocorreu na questão número dezessete. Verifica-se que entre os fatores, as estratégias focalizadas no problema apresentaram a maior média, seguidas pelos fatores de busca por práticas religiosas e busca de suporte social.

Nas respostas dos profissionais aos itens de avaliação do estresse precoce, observou-se que as médias em seus itens variaram de 0,1 a 2,1, nas questões dez, quatorze e dezenove respectivamente. A Tabela abaixo mostra que o subtipo com maior média foi negligência emocional, seguido pelos subtipos de abuso emocional e negligência física.

Tabela 6 - Descrição dos escores médios das respostas dos técnicos e auxiliares de enfermagem em cada dimensão das escalas MBI, EMEP e CTQ. Ribeirão Preto; 2012.

\begin{tabular}{llcccc}
\hline Escala & Dimensões/Fatores/Subtipos & Mínimo & Máximo & Média & $\begin{array}{c}\text { Desvio } \\
\text { Padrão }\end{array}$ \\
\hline MBI* & Exaustão Emocional & 9 & 43 & 24,3 & 6,41 \\
& Despersonalização & 5 & 19 & 9,05 & 3,07 \\
& Realização Pessoal & 20 & 40 & 30,5 & 4,16 \\
EMEP** & Estratégias focalizadas no problema & 1,94 & 5 & 3,7 & 0,54 \\
& Estratégias focalizadas na emoção & 1 & 3,8 & 2.3 & 0,56 \\
& Busca de práticas religiosas & 1 & 5 & 3,3 & 0,79 \\
& Busca por suporte social & 1 & 5 & 3,1 & 0,82 \\
CTQ****as & Abuso Emocional & 5 & 25 & 7,9 & 3,57 \\
& Abuso Físico & 5 & 21 & 6,8 & 2,60 \\
& Abuso Sexual & 5 & 23 & 5,5 & 1,98 \\
& Negligência Emocional & 5 & 25 & 9,4 & 4,42 \\
& Negligência Física & 5 & 20 & 7,1 & 2,77 \\
\hline
\end{tabular}

* $\mathrm{MBI}$ - Maslach Burnout Inventory: dividida em 3 dimensões

** EMEP - Escala de Modos de Enfrentamento dos Problemas: dividida em 4 fatores

*** CTQ - Childhood Trauma Questionnaire: dividida em 3 subtipos

Fonte: Dados da pesquisa, 2012. 


\subsection{Classificação dos técnicos e auxiliares de enfermagem quanto ao nível da Síndrome de Burnout}

Conforme estudo de validação da MBI no Brasil (LAUTERT, 1995), procedeu-se à análise da escala MBI considerando alto nível escores superiores e iguais ao percentil 75 nas subescalas de Exaustão Emocional e Despersonalização, e baixo nível escores inferiores ao percentil até 25 na subescala Realização Pessoal.

Após a divisão por níveis e associação entre as três dimensões, criaram-se grupos dicotômicos, ou seja, um grupo composto com participantes que apresentaram escores compatíveis à Síndrome de Burnout e outro com participantes que não apresentaram o desfecho.

A tabela 7 mostra as faixas de corte das três dimensões da MBI. O escore 27 foi utilizado como nota de corte para a dimensão exaustão emocional neste estudo, sendo o que mais se aproxima do percentil 75 que foi utilizado pela autora Lautert (1995). Assim, 71,6\% dos participaram tiveram um escore até 27, que significa um baixo/moderado nível de exaustão emocional e, 28,4\% apresentaram nível alto nesta dimensão, com escores variando de 28 a 43.

$\mathrm{Na}$ dimensão despersonalização a nota de corte utilizada foi o escore 10, o mais próximo ao percentil 75 . Verifica-se que $68,4 \%$ dos participantes tiveram escore variando de 5 a 10, ou seja, apresentaram um nível baixo/moderado de despersonalização. Já os 31,6\% restante, pontuaram entre 11 e 19 e apresentaram um nível alto nesta mesma dimensão.

Percebe-se que 22,9\% dos participantes tiveram escore até 27 na dimensão realização pessoal. Este percentual é o que mais se aproximou do percentil 25 utilizado pela autora na referida dimensão. O escore 27 foi utilizado como nota de corte neste estudo. Assim, os participantes que pontuaram um escore de 20 a 27 apresentaram baixo/moderado nível realização pessoal $(22,9 \%)$ e os que pontuaram um escore entre 28 e 40 apresentaram um nível alto nesta dimensão $(77,1 \%)$. 
Tabela 7 - Distribuição dos técnicos e auxiliares de enfermagem de acordo com os escores e percentis na escala MBI por dimensões. Ribeirão Preto; 2012.

\begin{tabular}{|c|c|c|c|c|c|c|c|c|c|c|c|c|c|c|}
\hline \multicolumn{5}{|c|}{ Exaustão Emocional } & \multicolumn{5}{|c|}{ Despersonalização } & \multicolumn{5}{|c|}{ Realização Pessoal } \\
\hline Escore & $\mathbf{N}$ & $\%$ & $\% *$ & $\begin{array}{c}\% * \\
*\end{array}$ & Escore & $\mathbf{N}$ & $\%$ & $\% *$ & $\begin{array}{c}\% * \\
*\end{array}$ & Escore & $\mathbf{N}$ & $\%$ & $\% *$ & $\begin{array}{c}\% * \\
*\end{array}$ \\
\hline 9 & 1 & 0,3 & 0,3 & & 5 & 49 & 15,8 & 15,8 & & 20 & 2 & 0,7 & 0,7 & \\
\hline 12 & 9 & 2,9 & 3,2 & & 6 & 33 & 10,7 & 26,5 & & 21 & 3 & 1,0 & 1,6 & \\
\hline 13 & 5 & 1,6 & 4,8 & & 7 & 26 & 8,4 & 34,8 & & 22 & 2 & 0,7 & 2,3 & \\
\hline 14 & 2 & 0,7 & 5,5 & & 8 & 32 & 10,3 & 45,2 & & 23 & 6 & 1,9 & 4,2 & \\
\hline 15 & 6 & 1,9 & 7,4 & & 9 & 40 & 12,9 & 58,1 & & 24 & 11 & 3,6 & 7,7 & \\
\hline 16 & 7 & 2,3 & 9,7 & & 10 & 32 & 10,3 & 68,4 & & 25 & 12 & 3,9 & 11,6 & \\
\hline 17 & 9 & 2,9 & 12,6 & & & & & & 68,4 & 26 & 20 & 6,5 & 18,1 & \\
\hline 18 & 12 & 3,9 & 16,5 & & 11 & 30 & 9,7 & 78,1 & & 27 & 15 & 4,8 & 22,9 & \\
\hline 19 & 20 & 6,5 & 22,9 & & 12 & 25 & 8,1 & 86,1 & & & & & & 22,9 \\
\hline 20 & 15 & 4,8 & 27,7 & & 13 & 18 & 5,8 & 91,9 & & 28 & 29 & 9,4 & 32,3 & \\
\hline 21 & 17 & 5,5 & 33,2 & & 14 & 10 & 3,2 & 95,2 & & 29 & 32 & 10,3 & 42,6 & \\
\hline 22 & 21 & 6,8 & 40,0 & & 15 & 7 & 2,3 & 97,4 & & 30 & 30 & 9,7 & 52,3 & \\
\hline 23 & 29 & 9,4 & 49,4 & & 16 & 4 & 1,3 & 98,7 & & 31 & 23 & 7,4 & 59,7 & \\
\hline 24 & 24 & 7,7 & 57,1 & & 17 & 1 & 0,3 & 99,0 & & 32 & 25 & 8,1 & 67,7 & \\
\hline 25 & 14 & 4,5 & 61,6 & & 18 & 2 & 0,7 & 99,7 & & 33 & 21 & 6,8 & 74,5 & \\
\hline 26 & 17 & 5,5 & 67,1 & & 19 & 1 & 0,3 & 100,0 & & 34 & 20 & 6,5 & 81,0 & \\
\hline \multirow[t]{2}{*}{27} & 14 & 4,5 & 71,6 & & & & & & 31,6 & 35 & 19 & 6,1 & 87,1 & \\
\hline & & & & 71,6 & & & & & & 36 & 16 & 5,2 & 92,3 & \\
\hline 28 & 14 & 4,5 & 76,1 & & & & & & & 37 & 6 & 1,9 & 94,2 & \\
\hline 29 & 12 & 3,9 & 80,0 & & & & & & & 38 & 12 & 3,9 & 98,1 & \\
\hline 30 & 12 & 3,9 & 83,9 & & & & & & & 39 & 4 & 1,3 & 99,4 & \\
\hline 31 & 4 & 1,3 & 85,2 & & & & & & & 40 & 2 & 0,7 & 100,0 & \\
\hline 32 & 7 & 2,3 & 87,4 & & & & & & & & & & & 77,1 \\
\hline 33 & 8 & 2,6 & 90,0 & & & & & & & & & & & \\
\hline 34 & 5 & 1,6 & 91,6 & & & & & & & & & & & \\
\hline 35 & 10 & 3,2 & 94,8 & & & & & & & & & & & \\
\hline 36 & 2 & 0,7 & 95,5 & & & & & & & & & & & \\
\hline 37 & 6 & 1,9 & 97,4 & & & & & & & & & & & \\
\hline 38 & 2 & 0,7 & 98,1 & & & & & & & & & & & \\
\hline 39 & 1 & 0,3 & 98,4 & & & & & & & & & & & \\
\hline 40 & 2 & 0,7 & 99,0 & & & & & & & & & & & \\
\hline 41 & 1 & 0,3 & 99,4 & & & & & & & & & & & \\
\hline 42 & 1 & 0,3 & 99,7 & & & & & & & & & & & \\
\hline 43 & 1 & 0,3 & 11,0 & & & & & & & & & & & \\
\hline & & & & 28,4 & & & & & & & & & & \\
\hline
\end{tabular}

* Percentual acumulado

** Percentual por faixa de corte

MBI - Maslach Burnout Inventory

Fonte: Dados da pesquisa, 2012. 


\subsection{Prevalências da Síndrome de Burnout, estratégias de enfrentamento e estresse precoce}

A prevalência da Síndrome de Burnout entre os técnicos e auxiliares de enfermagem de um hospital geral foi de 7,4\%. Conforme pode ser observado na Tabela 8, denotada pela ocorrência de alteração nas três dimensões da escala MBI. Cabendo ressaltar também que 45,2\% dos técnicos e auxiliares de enfermagem apresentaram alterações em uma ou duas dimensões, o que os classifica em processo de desenvolvimento da síndrome.

Tabela 8 - Distribuição de técnicos e auxiliares de enfermagem segundo alteração nas dimensões que avaliam a Sindrome de Burnout. Ribeirão Preto; 2012.

\begin{tabular}{lcc}
\hline Indicadores & N & \% \\
\hline Ausência de alteração nas três dimensões & 147 & 47,4 \\
Alteração em apenas uma das dimensões & 92 & 29,8 \\
Alteração em duas dimensões & 48 & 15,4 \\
Alteração nas três dimensões & 23 & 7,4 \\
Total & 310 & 100,0 \\
\hline
\end{tabular}

Fonte: Dados da pesquisa, 2012.

Um importante resultado observado entre os técnicos e auxiliares de enfermagem é que 52,6\% deles estão com Síndrome de Burnout ou em processo de desenvolvimento da mesma, observando que tiveram alteração em pelo menos uma das dimensões. Tais alterações podem ser descritas conforme segue:

- 30 participantes apresentaram alto nível em exaustão emocional, baixo/moderado nível em despersonalização e alto nível em realização pessoal;

- 44 participantes apresentaram baixo nível em exaustão emocional, alto nível em despersonalização e alto nível em realização pessoal;

- 18 participantes apresentaram baixo nível em exaustão emocional, baixo nível em despersonalização e baixo nível em realização pessoal;

- 18 participantes apresentaram alto nível em exaustão emocional, alto nível em despersonalização e alto nível em realização pessoal;

- 17 participantes apresentaram alto nível em exaustão emocional, baixo/moderado nível em despersonalização e baixo/moderado nível em realização pessoal; 
- 13 participantes apresentaram baixo/moderado nível em exaustão emocional, alto nível de despersonalização e baixo/moderado nível em realização pessoal.

Observa-se pela Tabela 9 a distribuição dos técnicos e auxiliares de enfermagem segundo as estratégias de enfrentamento. Nota-se que o tipo de estratégia mais utilizada foi a focalizada no problema seguida pela busca por práticas religiosas e busca por suporte social.

Tabela 9 - Distribuição de técnicos e auxiliares de enfermagem segundo o tipo de estratégias de enfrentamento utilizada. Ribeirão Preto; 2012.

\begin{tabular}{lcc}
\hline Fatores & $\mathbf{N}$ & $\mathbf{\%}$ \\
\hline Estratégias focalizadas no problema & 186 & 60,0 \\
Estratégias focalizadas na emoção & 4 & 1,3 \\
Estratégias de busca por práticas religiosas & 66 & 21,3 \\
Estratégias de busca por suporte social & 54 & 17,4 \\
Total & 310 & 100,0 \\
\hline Fonte: Dados da pesquisa, 2012. & &
\end{tabular}

A prevalência de estresse precoce foi igual a 31,3\%, denotado pela ocorrência de pelo menos um subtipo de estresse precoce. Observou-se que 1,6\% apresentaram todos os tipos de estresse precoce, $29,7 \%$ de um a quatro subtipos e $68,7 \%$ não apresentaram estresse precoce.

Os participantes que pontuaram escores classificados como Moderado-Severo e/ou Severo-Extremo indicando algum tipo de estresse precoce $(31,3 \%)$, estão assim distribuídos:

- 51 participantes apresentaram um dos cinco subtipos com pontuação que indicou classificação de um trauma Moderado-Severo ou Severo-Extremo;

- 20 participantes apresentaram dois dos cinco subtipos com pontuação que indicou classificação de um trauma Moderado-Severo ou Severo-Extremo;

- 12 participantes apresentaram três dos cinco subtipos com pontuação que indicou classificação de um trauma Moderado-Severo ou Severo-Extremo;

- 9 participantes apresentaram quatro dos cinco subtipos com pontuação que indicou classificação de um trauma Moderado-Severo ou Severo-Extremo;

- 5 participantes apresentaram todos os cinco subtipos com pontuação que indicou classificação de traumas Moderado-Severo ou Severo-Extremo.

A Tabela 10 mostra a distribuição dos participantes de acordo com o subtipo de estresse precoce e sua classificação. Considerando os cinco subtipos de estresse precoce, 
verifica-se que $35,9 \%$ dos participantes foram classificados com um trauma considerado Moderado-Severo e 24,5\% dentro do nível Severo-Extremo.

Tabela 10 - Distribuição de frequência dos técnicos e auxiliares de enfermagem com presença ou ausência de estresse precoce segundo os subtipos do mesmo. Ribeirão Preto; 2012.

\begin{tabular}{lccccc}
\hline \multirow{2}{*}{$\begin{array}{l}\text { AUBTIPOS DE } \\
\text { ESTRESSE PRECOCE }\end{array}$} & \multicolumn{2}{c}{ PRECOCE } & \multicolumn{2}{c}{ PRESENÇA DE } & \\
& $\begin{array}{c}\text { Mão à } \\
\text { Níno }\end{array}$ & $\begin{array}{c}\text { Leve à } \\
\text { Moderado } \\
\text { N }(\%)\end{array}$ & $\begin{array}{c}\text { Moderado à } \\
\text { Severo } \\
\text { N }(\%)\end{array}$ & $\begin{array}{c}\text { Severo à } \\
\text { Extremo } \\
\text { N }(\%)\end{array}$ & TOTAL \\
\hline Abuso Emocional & $211(68,3)$ & $62(20,1)$ & $19(6,2)$ & $17(5,5)$ & $309^{*}$ \\
Abuso Físico & $240(77,4)$ & $33(10,7)$ & $21(6,8)$ & $16(5,2)$ & 310 \\
Abuso Sexual & $277(89,6)$ & $8(2,6)$ & $18(5,8)$ & $6(1,9)$ & $309^{*}$ \\
Negligência Emocional & $192(61,9)$ & $78(25,2)$ & $18(5,8)$ & $22(7,1)$ & 310 \\
Negligência Física & $203(65,5)$ & $57(18,4)$ & $35(11,3)$ & $15(4,8)$ & 310 \\
\hline * missing & & & & & \\
Fonte: Dados da pesquisa, 2012. & & & & &
\end{tabular}

Resumindo, percebe-se que 31,3\% dos participantes apresentaram estresse precoce em algum dos cinco subtipos, sendo que 5 dentre eles sofreram abusos emocional, físico e sexual e também negligências emocional e física durante o período da infância.

\subsection{Síndrome de Burnout e suas associações}

4.5.1 Síndrome de Burnout e as variáveis sociodemográficas, condições de trabalho e saúde

Na tabela 11, nota-se que a Síndrome de Burnout mostrou-se estatisticamente significativa entre os participantes que referiram morar sozinho e não ter filhos.

Tabela 11 - Associação entre Síndrome de Burnout e as características sociodemográficas entre técnicos e auxiliares de enfermagem de um hospital geral. Ribeirão Preto; 2012.

\begin{tabular}{lccc}
\hline \multirow{2}{*}{ Características } & \multicolumn{2}{c}{ Síndrome de Burnout } \\
& $\begin{array}{c}\text { Ausência } \\
\text { N (\%) }\end{array}$ & $\begin{array}{c}\text { Presença } \\
\mathbf{N}(\%)\end{array}$ & Valor de p \\
\hline Sexo & & & \\
Masculino & $71(95,9)$ & $3(4,1)$ & 0,21 \\
Feminino & $216(91,5)$ & $20(8,5)$ &
\end{tabular}

Faixa etária 


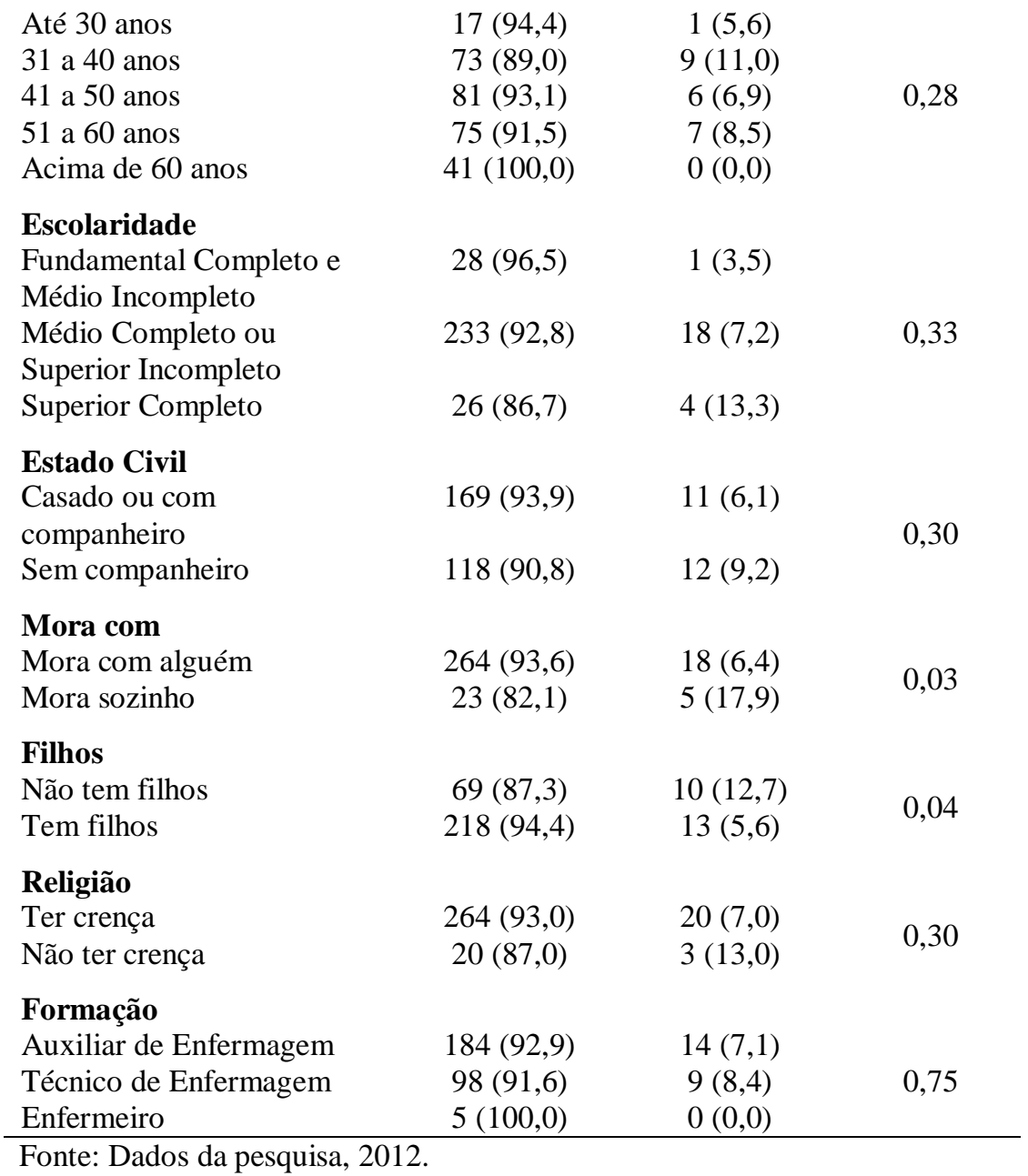

Na tabela 12, verifica-se que a Síndrome de Burnout mostrou-se estatisticamente significativa entre os participantes que referiram ter passado por consulta médica no último ano.

Tabela 12 - Associação entre Síndrome de Burnout e as condições de trabalho e saúde entre técnicos e auxiliares de enfermagem de um hospital geral. Ribeirão Preto; 2012.

\begin{tabular}{|c|c|c|c|}
\hline \multirow[b]{2}{*}{ Características } & \multicolumn{2}{|c|}{ Síndrome de Burnout } & \multirow[b]{2}{*}{ Valor de $p$} \\
\hline & $\begin{array}{c}\text { Ausência } \\
\mathbf{N}(\%) \\
\end{array}$ & $\begin{array}{c}\text { Presença } \\
\text { N }(\%) \\
\end{array}$ & \\
\hline \multicolumn{4}{|l|}{ Cargo Exercido } \\
\hline Auxiliar de Enfermagem & $247(93,2)$ & $18(6,8)$ & \multirow{3}{*}{0,51} \\
\hline Técnico de Enfermagem & $35(89,7)$ & $4(10,3)$ & \\
\hline Outros & $5(83,3)$ & $1(16,7)$ & \\
\hline \multicolumn{4}{|l|}{ Setor } \\
\hline Média Complexidade & $33(94,3)$ & $2(5,7)$ & \multirow{2}{*}{0,68} \\
\hline Alta Complexidade & $254(92,4)$ & $21(7,6)$ & \\
\hline \multicolumn{4}{|l|}{ Turno } \\
\hline Diurno & $221(92,9)$ & $17(7,1)$ & \multirow{2}{*}{0,74} \\
\hline Noturno & $66(92,6)$ & $6(8,4)$ & \\
\hline
\end{tabular}

Tempo de serviço no local de estudo 
Até 5 anos

De 6 à 10 anos

De 11 à 15 anos

De 16 à 20 anos

De 21 à 25 anos

Acima de 26 anos

Tempo de serviço na profissão

Até 5 anos

De 6 à 10 anos

De 11 à 15 anos

De 16 à 20 anos

De 21 à 25 anos

Acima de 26 anos

$\begin{array}{cc}78(92,9) & 6(7,1) \\ 43(86,0) & 7(14,0) \\ 89(93,7) & 6(6,3) \\ 30(96,8) & 1(3,2) \\ 19(86,4) & 3(13,6) \\ 28(100,0) & 0(0,0)\end{array}$

$31(93,9) \quad 2(6,1)$

$54(88,5) \quad 7(11,5)$

$80(93,0) \quad 6(7,0)$

$44(91,7) \quad 4(8,3)$

$30(88,2) \quad 4(11,8)$

$48(100,0) \quad 0(0,0)$

0,27

$233(92,2) \quad 19(7,8)$

$64(94,1) \quad 4(5,9)$

0,58

Acima de 30 horas

Passou por consulta médica no último ano

Não

Sim

$35(97,2) \quad 1(2,8)$

$252(92,0)$

$22(8,0)$

0,26

Faz uso de algum medicamento

Não

Sim

$141(92,8) \quad 11(7,2)$

$146(92,4) \quad 12(7,6)$

0,85

Houve afastamento do trabalho no último ano

Não

Sim

$148(95,5)$

$139(89,7)$

$7(4,5)$

$16(10,3)$

0,05

Tabagista

Não

$255(92,7) \quad 20(7,3)$

$32(91,4) \quad 3(8,6)$

0,78

Sim

$214(91,9)$

$73(94,8)$

$19(8,1)$

$4(5,2)$

0,39

Sim

$81(95,3)$

$206(91,6)$

$4(4,7)$

$19(8,4)$

0,26

Fonte: Dados da pesquisa, 2012

4.5.2 Síndrome de Burnout e as estratégias de enfrentamento

Conforme tabela 13, nota-se que os participantes com Síndrome de Burnout não utilizam as estratégias focalizadas no problema. Houve forte correlação entre os participantes com Burnout e que utilizam de estratégias de busca por suporte social. 
Tabela 13 - Associação entre Síndrome de Burnout e as estratégias de enfrentamento entre técnicos e auxiliares de enfermagem de um hospital geral. Ribeirão Preto; 2012.

\begin{tabular}{llccc}
\hline \multirow{2}{*}{ Estratégias } & & \multicolumn{2}{c}{ Burnout } \\
& & Ausência & Presença & Valor de \\
N $(\%)$ & $\mathbf{N}(\%)$ & p \\
\hline Estratégias focalizadas no problema & Não utilizada & $109(87,9)$ & $15(12,1)$ & 0,01 \\
& Utilizada & $178(95,7)$ & $8(4,3)$ & \\
Estratégias focalizadas na emoção & Não utilizada & $284(92,8)$ & $22(7,2)$ & 0,18 \\
& Utilizada & $3(75,0)$ & $1(25,0)$ & \\
Estratégias de busca por práticas religiosas & Não utilizada & $227(93,0)$ & $17(7,0)$ & 0,56 \\
& Utilizada & $60(90,9)$ & $6(9,1)$ & \multirow{2}{*}{ Estratégias de busca por suporte social } \\
& Não utilizada & $241(94,1)$ & $15(5,9)$ & 0,02 \\
& Utilizada & $46(85,2)$ & $8(14,8)$ & \multirow{2}{*}{} \\
\hline
\end{tabular}

Fonte: Dados da pesquisa, 2012.

Destaca-se ainda que não houve associação significativa entre os participantes com Síndrome de Burnout e as estratégias focalizadas na emoção ou de busca por práticas religiosas.

\subsubsection{Síndrome de Burnout e o estresse precoce}

Nota-se pela tabela 14 que não houve diferença estatisticamente significativa entre a Síndrome de Burnout e os subtidos de estresse precoce.

Tabela 14 - Associação entre Síndrome de Burnout e os subtipos de estresse precoce entre técnicos e auxiliares de enfermagem de um hospital geral. Ribeirão Preto; 2012.

\begin{tabular}{|c|c|c|c|c|}
\hline \multicolumn{2}{|c|}{ Estresse Precoce } & \multicolumn{2}{|c|}{ Síndrome de Burnout } & \multirow{3}{*}{ Valor de $p$} \\
\hline & & \multirow{2}{*}{$\begin{array}{c}\text { Ausência } \\
\mathrm{N}(\%)\end{array}$} & \multirow{2}{*}{$\begin{array}{c}\text { Presença } \\
\mathrm{N}(\%)\end{array}$} & \\
\hline & & & & \\
\hline Abuso & Não-Mínimo & $199(94,3)$ & $12(5,7)$ & \multirow{4}{*}{0,39} \\
\hline \multirow[t]{3}{*}{ Emocional } & Mínimo-Moderado & $55(88,7)$ & $7(11,3)$ & \\
\hline & Moderado-Severo & $17(89,5)$ & $2(10,5)$ & \\
\hline & Severo-Extremo & $15(88,2)$ & $2(11,8)$ & \\
\hline \multirow[t]{4}{*}{ Abuso Físico } & Não-Mínimo & $224(93,3)$ & $16(6,7)$ & \multirow{4}{*}{0,79} \\
\hline & Mínimo-Moderado & $30(90,9)$ & $3(9,1)$ & \\
\hline & Moderado-Severo & $19(90,5)$ & $2(9,5)$ & \\
\hline & Severo-Extremo & $14(87,5)$ & $2(12,5)$ & \\
\hline \multirow[t]{4}{*}{ Abuso Sexual } & Não-Mínimo & $258(93,1)$ & $19(6,9)$ & \multirow{4}{*}{0,29} \\
\hline & Mínimo-Moderado & $8(100,0)$ & $0(0,0)$ & \\
\hline & Moderado-Severo & $15(83,3)$ & $3(16,7)$ & \\
\hline & Severo-Extremo & $5(83,3)$ & $1(16,7)$ & \\
\hline Negligência & Não-Mínimo & $179(93,2)$ & $13(6,8)$ & 0,80 \\
\hline Física & Mínimo-Moderado & $71(91,0)$ & $7(9,0)$ & \\
\hline
\end{tabular}




\begin{tabular}{llccc} 
& Moderado-Severo & $16(88,9)$ & $2(11,1)$ & \\
& Severo-Extremo & $21(95,5)$ & $1(4,5)$ & \\
Negligência & Não-Mínimo & $188(92,6)$ & $15(7,4)$ & \\
Emocional & Mínimo-Moderado & $51(89,5)$ & $6(10,5)$ & 0,60 \\
& Moderado-Severo & $34(97,1)$ & $1(2,9)$ & \\
& Severo-Extremo & $14(93,3)$ & $1(6,7)$ & \\
\hline
\end{tabular}

Fonte: Dados da pesquisa, 2012.

\subsection{As dimensões da Síndrome de Burnout e suas associações}

4.6.1 Exaustão emocional, despersonalização, realização pessoal e as variáveis sociodemográficas

Identifica-se, pela tabela 15, que a Exaustão Emocional mostrou-se mais significativa entre as mulheres, que possuem ensino superior completo, que residem sozinhas e que não tem filhos.

Com a Despersonalização houve associações, porém, com tendência à forte significância entre os participantes que referiram não possuir uma crença religiosa.

A dimensão de Realização Pessoal revelou-se mais significativa entre os participantes que referiram morar sozinhos.

Tabela 15 - Associação entre Exaustão Emocional, Despersonalização, Realização Pessoal e as características sociodemográficas entre técnicos e auxiliares de enfermagem de um hospital geral. Ribeirão Preto; 2012.

\begin{tabular}{|c|c|c|c|c|c|c|c|c|c|}
\hline \multirow[b]{2}{*}{ Características } & \multicolumn{2}{|c|}{ Exaustão Emocional } & \multirow[b]{2}{*}{$\begin{array}{l}\text { Valor } \\
\text { de p }\end{array}$} & \multicolumn{2}{|c|}{ Despersonalização } & \multirow[b]{2}{*}{$\begin{array}{l}\text { Valor } \\
\text { de p }\end{array}$} & \multicolumn{2}{|c|}{ Realização Pessoal } & \multirow[b]{2}{*}{$\begin{array}{l}\text { Valor } \\
\text { de p }\end{array}$} \\
\hline & $\begin{array}{l}\text { Ausência } \\
\text { N (\%) }\end{array}$ & $\begin{array}{c}\text { Presença } \\
\text { N }(\%)\end{array}$ & & $\begin{array}{c}\text { Ausência } \\
\text { N (\%) }\end{array}$ & $\begin{array}{c}\text { Presença } \\
\text { N }(\%)\end{array}$ & & $\begin{array}{l}\text { Ausência } \\
\text { N (\%) }\end{array}$ & $\begin{array}{c}\text { Presença } \\
\text { N }(\%)\end{array}$ & \\
\hline $\begin{array}{l}\text { Sexo } \\
\text { Masculino } \\
\text { Feminino }\end{array}$ & $\begin{array}{c}61(82,4) \\
161(68,2)\end{array}$ & $\begin{array}{l}13(17,6) \\
75(31,8)\end{array}$ & 0,02 & $\begin{array}{c}48(64,9) \\
164(69,5)\end{array}$ & $\begin{array}{l}26(35,1) \\
72(30,5)\end{array}$ & 0,46 & $\begin{array}{c}62(83,8) \\
177(75,0)\end{array}$ & $\begin{array}{l}12(16,2) \\
59(25,0)\end{array}$ & 0,12 \\
\hline $\begin{array}{l}\text { Faixa etária } \\
\text { Até } 30 \text { anos } \\
31 \text { a } 40 \text { anos } \\
41 \text { a } 50 \text { anos } \\
51 \text { a } 60 \text { anos } \\
\text { Acima de } 60 \text { anos }\end{array}$ & $\begin{array}{l}14(77,8) \\
60(73,2) \\
57(65,5) \\
60(73,2) \\
31(75,6)\end{array}$ & $\begin{array}{c}4(22,2) \\
22(26,8) \\
30(34,5) \\
22(26,8) \\
10(24,4)\end{array}$ & 0,65 & $\begin{array}{l}10(55,6) \\
54(65,8) \\
60(69,0) \\
56(68,3) \\
32(78,1)\end{array}$ & $\begin{array}{c}8(44,4) \\
28(34,2) \\
27(31,0) \\
26(31,7) \\
9(21,9)\end{array}$ & 0,50 & $\begin{array}{l}15(83,3) \\
64(78,1) \\
61(70,1) \\
63(76,8) \\
36(87,8)\end{array}$ & $\begin{array}{c}3(16,7) \\
18(21,9) \\
26(29,9) \\
19(23,2) \\
5(12,2)\end{array}$ & 0,24 \\
\hline $\begin{array}{l}\text { Escolaridade } \\
\text { Fundamental Completo } \\
\text { ou Médio Incompleto } \\
\text { Médio Completo ou } \\
\text { Superior Incompleto } \\
\text { Superior Completo }\end{array}$ & $\begin{array}{l}19(65,5) \\
187(74,5) \\
16(53,3)\end{array}$ & $\begin{array}{l}10(34,5) \\
64(25,5) \\
14(46,7)\end{array}$ & 0,04 & $\begin{array}{l}22(75,9) \\
167(66,5) \\
23(76,7)\end{array}$ & $\begin{array}{l}7(24,1) \\
84(33,5) \\
7(23,3)\end{array}$ & 0,35 & $\begin{array}{l}20(69,0) \\
196(78,1) \\
23(76,7)\end{array}$ & $\begin{array}{l}9(31,0) \\
55(21,9) \\
7(23,3)\end{array}$ & 0,54 \\
\hline $\begin{array}{l}\text { Estado Civil } \\
\text { Casado ou com }\end{array}$ & $132(73,3)$ & $48(26,7)$ & 0,43 & $130(72,2)$ & $50(27,8)$ & 0,09 & $145(80,6)$ & $35(19,4)$ & 0,09 \\
\hline
\end{tabular}




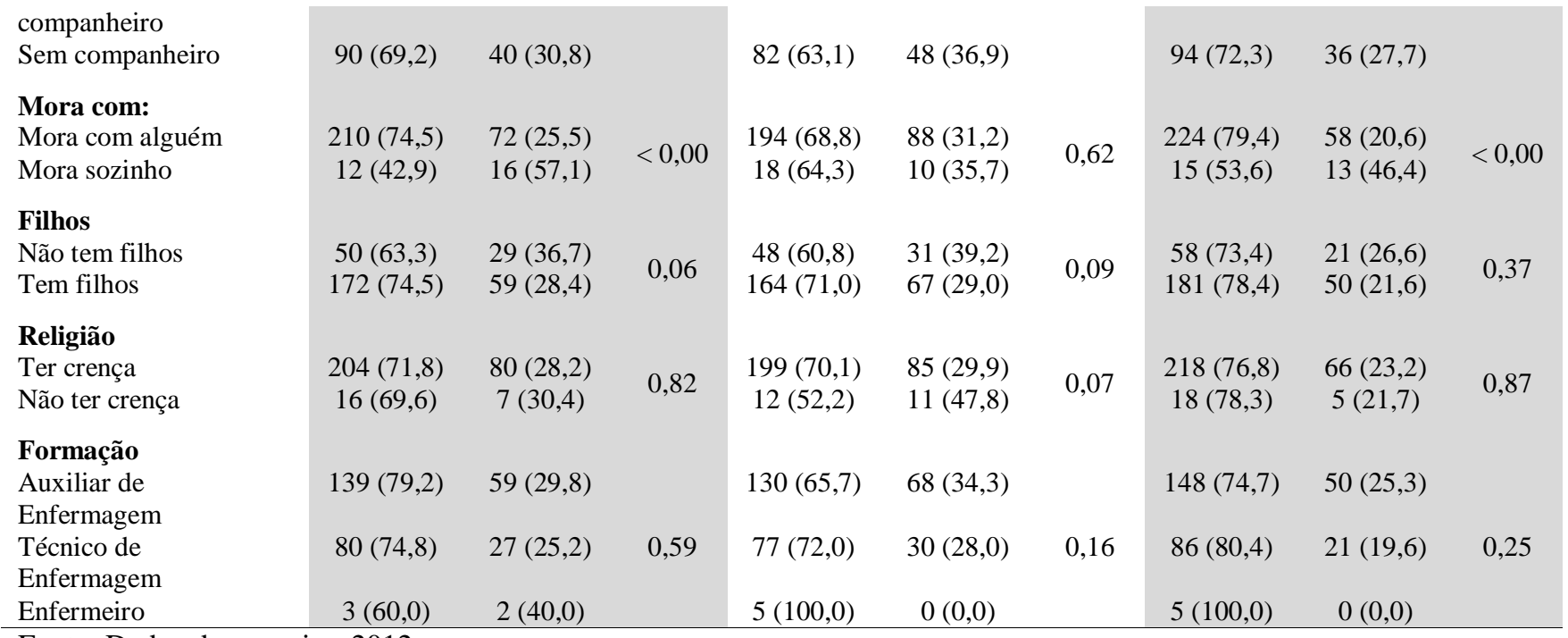

Fonte: Dados da pesquisa, 2012.

Identifica-se, pela tabela 16, que a Exaustão Emocional mostrou-se mais significativa entre os participantes que trabalham na faixa entre 06 e 10 anos no referido serviço, que referiram ter tido afastamento do trabalho no último ano e ter doença crônica.

A Despersonalização mostrou-se mais significativa entre os profissionais que referiram ter passado por consulta médica no último ano. Houve outras associações, porém, com tendência à forte significância entre os participantes que referem fazer uso de bebida alcoólica.

A dimensão de Realização Pessoal revelou-se mais significativa entre os participantes que referiram trabalhar no mesmo serviço na faixa de 21 a 25 anos. Houve uma tendência a significância com os participantes que referiram afastamento do emprego no último ano.

Tabela 16 - Associação entre Exaustão Emocional, Despersonalização, Realização Pessoal e as condições de trabalho e saúde entre técnicos e auxiliares de enfermagem de um hospital geral. Ribeirão Preto; 2012.

\begin{tabular}{|c|c|c|c|c|c|c|c|c|c|}
\hline \multirow[b]{2}{*}{ Características } & \multicolumn{2}{|c|}{ Exaustão Emocional } & \multirow[b]{2}{*}{$\begin{array}{l}\text { Valor } \\
\text { de p }\end{array}$} & \multicolumn{2}{|c|}{ Despersonalização } & \multirow[b]{2}{*}{$\begin{array}{l}\text { Valor } \\
\text { de p }\end{array}$} & \multicolumn{2}{|c|}{ Realização Pessoal } & \multirow[b]{2}{*}{$\begin{array}{l}\text { Valor } \\
\text { de p }\end{array}$} \\
\hline & $\begin{array}{c}\text { Ausência } \\
\text { N (\%) }\end{array}$ & $\begin{array}{c}\text { Presença } \\
\text { N }(\%)\end{array}$ & & $\begin{array}{c}\text { Ausência } \\
\mathbf{N}(\%)\end{array}$ & $\begin{array}{c}\text { Presença } \\
\text { N }(\%)\end{array}$ & & $\begin{array}{l}\text { Ausência } \\
\mathbf{N}(\%)\end{array}$ & $\begin{array}{c}\text { Presença } \\
\text { N }(\%)\end{array}$ & \\
\hline $\begin{array}{l}\text { Cargo Exercido } \\
\text { Auxiliar de } \\
\text { Enfermagem }\end{array}$ & $191(72,1)$ & $74(27,9)$ & & $178(67,2)$ & $87(32,8)$ & & $208(78,5)$ & $57(21,5)$ & \\
\hline $\begin{array}{l}\text { Técnico de } \\
\text { Enfermagem }\end{array}$ & $29(74,4)$ & $10(25,6)$ & 0,11 & $30(76,9)$ & $9(23,1)$ & 0,47 & $28(71,8)$ & $11(28,2)$ & 0,18 \\
\hline Outros & $2(33,3)$ & $4(66,7)$ & & $4(66,7)$ & $2(33,3)$ & & $3(50,0)$ & $3(50,0)$ & \\
\hline $\begin{array}{l}\text { Setor } \\
\text { Média Complexidade } \\
\text { Alta Complexidade }\end{array}$ & $\begin{array}{c}26(74,3) \\
196(71,3)\end{array}$ & $\begin{array}{c}9(25,7) \\
79(28,7)\end{array}$ & 0,71 & $\begin{array}{c}22(62,9) \\
190(69,1)\end{array}$ & $\begin{array}{l}13(37,1) \\
85(30,9)\end{array}$ & 0,45 & $\begin{array}{c}28(80,0) \\
211(76,7)\end{array}$ & $\begin{array}{c}7(20,0) \\
64(23,3)\end{array}$ & 0,66 \\
\hline $\begin{array}{l}\text { Turno } \\
\text { Diurno } \\
\text { Noturno }\end{array}$ & $\begin{array}{c}173(72,7) \\
49(68,1)\end{array}$ & $\begin{array}{l}65(27,3) \\
23(31,9)\end{array}$ & 0,45 & $\begin{array}{c}167(70,2) \\
45(62,5)\end{array}$ & $\begin{array}{l}71(29,8) \\
27(37,5)\end{array}$ & 0,22 & $\begin{array}{c}180(75,6) \\
59(81,9)\end{array}$ & $\begin{array}{l}58(24,4) \\
13(18,1)\end{array}$ & 0,26 \\
\hline $\begin{array}{l}\text { Tempo de serviço no } \\
\text { local de estudo } \\
\text { Até } 5 \text { anos }\end{array}$ & $72(85,7)$ & $12(14,3)$ & $<0,00$ & $55(65,5)$ & $29(34,5)$ & 0,56 & $30(90,9)$ & $3(9,1)$ & 0,02 \\
\hline
\end{tabular}




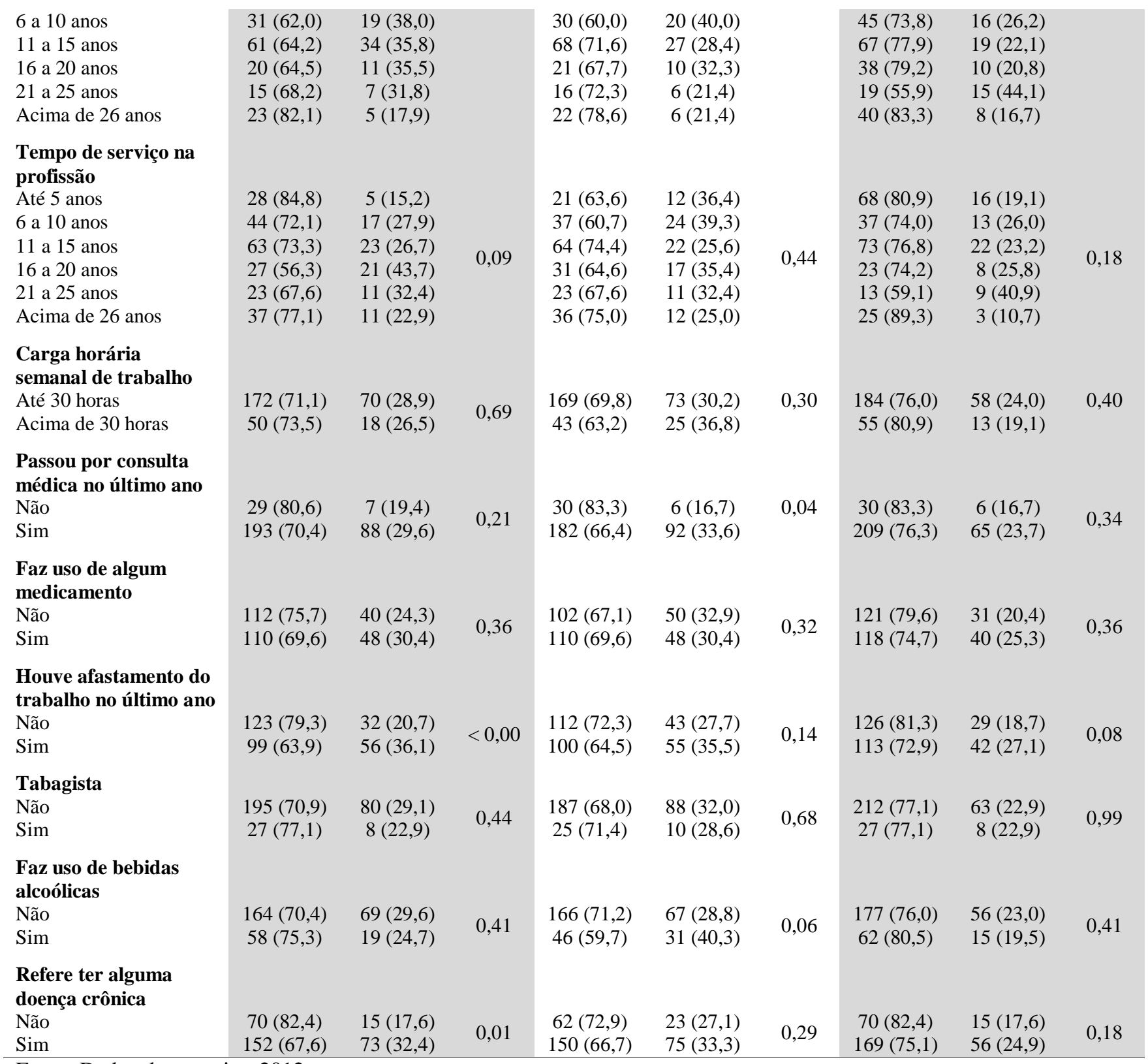

Fonte: Dados da pesquisa, 2012.

4.6.2 Exaustão emocional, despersonalização, realização pessoal e as estratégias de enfrentamento

Verifica-se, pela tabela 17, que as pessoas com alta Exaustão Emocional utilizam de estratégias focalizadas no problema seguidas ou busca por práticas religiosas. Nota-se também que não houve diferença significativa entre os participantes com despersonalização e as estratégias de enfrentamento. Pessoas com baixa Realização Pessoal utilizam de estratégias focalizadas no problema e de busca por práticas religiosas. 
Tabela 17 - Associação entre as dimensões do Burnout e as estratégias de enfrentamento entre técnicos e auxiliares de enfermagem de um hospital geral. Ribeirão Preto; 2012.

\begin{tabular}{lccc}
\hline & \multicolumn{2}{c}{ Dimensão } & Valor de p \\
Estratégia & Baixo/Moderado & Alto & N(\%) \\
\hline & Exaustão Emocional & \\
Focalizada no Problema & $149(67,1)$ & $37(42,1)$ & \\
Focalizada na Emoção & $2(0,9)$ & $2(2,3)$ & $<0,00$ \\
Busca por Práticas Religiosas & $32(14,4)$ & $34(38,6)$ & \\
Busca por Suporte Social & $39(17,6)$ & $15(17,1)$ & \\
& Despersonalização & \\
Focalizada no Problema & $135(63,7)$ & $51(52,0)$ & \\
Focalizada na Emoção & $1(0,5)$ & $3(3,1)$ & \\
Busca por Práticas Religiosas & $42(19,8)$ & $24(24,5)$ & \\
Busca por Suporte Social & $34(16,0)$ & $20(20,4)$ & \\
& Realização Pessoal & \\
Focalizada no Problema & $159(66,5)$ & $27(38,0)$ & \\
Focalizada na Emoção & $1(0,4)$ & $3(4,2)$ & \\
Busca por Práticas Religiosas & $46(19,3)$ & $20(28,2)$ & \\
Busca por Suporte Social & $33(13,8)$ & $21(29,6)$ & \\
\hline Fonte: Dados da pesquisa & & & \\
\hline
\end{tabular}

Fonte: Dados da pesquisa, 2012.

4.6.3 Exaustão emocional, despersonalização, realização pessoal e o estresse precoce

$\mathrm{Na}$ tabela 18, verifica-se que os participantes com alta exaustão emocional não sofreram estresse precoce. Nota-se ainda que não houve diferença estatisticamente significativa entre despersonalização e o estresse precoce e, também entre realização pessoal e o estresse precoce.

Tabela 18 - Associação entre as dimensões da Síndrome de Burnout e estresse precoce entre técnicos e auxiliares de enfermagem de um hospital geral. Ribeirão Preto; 2012.

\begin{tabular}{lccc}
\hline \multirow{2}{*}{$\begin{array}{l}\text { Estresse } \\
\text { Precoce }\end{array}$} & $\begin{array}{c}\text { Dimensão } \\
\text { Baixa/Moderada }\end{array}$ & $\begin{array}{c}\text { Alto } \\
\text { N }(\%)\end{array}$ & Valor de p \\
\hline \multirow{4}{*}{$\begin{array}{c}\text { Exaustão Emocional } \\
\text { Pusência }\end{array}$} & $165(74,3)$ & $48(54,5)$ & \\
Presença & $57(25,7)$ & $40(45,4)$ & $<0,00$ \\
& \multicolumn{4}{c}{ Despersonalização } \\
Ausência & $152(71,7)$ & $61(62,2)$ & \\
Presença & $60(28,3)$ & $37(37,8)$ & 0,09 \\
& \multicolumn{2}{c}{ Realização Pessoal } \\
Ausência & $167(69,9)$ & $46(64,8)$ & \\
Presença & $72(30,1)$ & $25(35,2)$ & 0,41 \\
\hline
\end{tabular}

Fonte: Dados da pesquisa, 2012. 


\subsection{Associação da Síndrome de Burnout e as variáveis independentes}

A tabela 19 mostra os valores brutos das razões de prevalência da Síndrome de Burnout segundo as variáveis independentes e os valores ajustados das razões de prevalência de Burnout segundo as variáveis independentes. Na análise bivariada destacaram-se as maiores prevalências entre os participantes que moram sozinhos $(\mathrm{OR}=3,19$; IC 95\% 1,04 9,38), que tem filhos ( $\mathrm{OR}=2,43$; IC 95\% 1,02 - 5,79) e que referiram ter tido afastamento do trabalho no último ano $(\mathrm{OR}=2,43$; IC 95\% 0,97 - 6,09).

$\mathrm{Na}$ análise multivariável a única variável que permaneceu estatisticamente significante foi com quem mora. Houve uma tendência a significância com a variável ter tido afastamento do trabalho no último ano. As chances de desenvolver Síndrome de Burnout ocorre 3,19 vezes mais naqueles que moram sozinhos e 2,26 vezes mais naqueles que tiveram afastamento do trabalho no último ano. As demais variáveis não se associaram com o desfecho após a análise ajustada.

Tabela 19 - Regressão logística entre Síndrome de Burnout e as variáveis sociodemográficas, de condições de trabalho e de saúde entre técnicos e auxiliares de enfermagem de um hospital geral. Ribeirão Preto, 2012.

\begin{tabular}{|c|c|c|c|c|c|}
\hline & \multirow[b]{2}{*}{ Variável } & \multicolumn{2}{|c|}{ Bruta } & \multicolumn{2}{|c|}{ Ajustada } \\
\hline & & OR* (IC 95\%) & $\begin{array}{l}\text { Valor } \\
\text { de } \mathbf{p}^{* *}\end{array}$ & OR* (IC 95\%) & $\begin{array}{l}\text { Valor de } \\
\text { p** }\end{array}$ \\
\hline 1 & $\begin{array}{l}\text { Sexo } \\
\text { Masculino } \\
\text { Feminino }\end{array}$ & $\begin{array}{l}1 \\
2,19(0,63-7,59)\end{array}$ & 0,22 & $\begin{array}{l}1 \\
2,53(0,71-9,00)\end{array}$ & 0,15 \\
\hline 1 & $\begin{array}{l}\text { Faixa etária } \\
\text { Até } 40 \text { anos } \\
\text { Acima de } 40 \text { anos }\end{array}$ & $\begin{array}{l}1 \\
0,74(0,30-1,81)\end{array}$ & 0,50 & $\begin{array}{l}1 \\
0,74(0,29-1,88)\end{array}$ & 0,53 \\
\hline 1 & $\begin{array}{l}\text { Escolaridade } \\
\text { Superior completo } \\
\text { Superior incompleto e Médio } \\
\text { completo } \\
\text { Médio incompleto e Fundamental } \\
\text { completo }\end{array}$ & $\begin{array}{l}1 \\
0,50(0,16-1,60) \\
0,23(0,02-2,21)\end{array}$ & $\begin{array}{l}0,24 \\
0,20\end{array}$ & $\begin{array}{l}1 \\
0,56(0,17-1,84) \\
0,25(0,03-2,41)\end{array}$ & $\begin{array}{l}0,34 \\
0,23\end{array}$ \\
\hline & $\begin{array}{l}\text { Estado Civil } \\
\text { Com companheiro } \\
\text { Sem companheiro } \\
\text { Religião } \\
\text { Sim } \\
\text { Não }\end{array}$ & $\begin{array}{l}1 \\
1,56(0,67-3,66) \\
1 \\
1,98(0,54-7,23)\end{array}$ & 0,30 & & \\
\hline 1 & $\begin{array}{l}\text { Mora com } \\
\text { Mora com alguém } \\
\text { Mora sozinho }\end{array}$ & $\begin{array}{l}1 \\
3,19(1,04-9,38)\end{array}$ & 0,03 & $\begin{array}{l}1 \\
3,19(1,08-9,38)\end{array}$ & 0,03 \\
\hline
\end{tabular}




\section{Tem filhos}

Tem filhos

Não tem filhos

\section{Cargo}

Auxiliar de Enfermagem

Técnico de Enfermagem

\section{Tempo no serviço}

2 Até 15 anos

Acima de 15 anos

Tipo de Serviço

Média Complexidade

Alta Complexidade

\section{Turno}

Diurno

Noturno

Passou por consulta médica

Não

Sim

Faz uso de medicamentos

Não

Sim

Teve afastamento do trabalho

3 Não

Sim

Fumante

Não

Sim

Ingere bebida alcoólica

Não

Sim

\section{Ter doença crônica}

3 Não

Sim

* Razão de Prevalência

** Valor de p de Wald

*** Não entrou no modelo ajustado, pois teve o valor de $\mathrm{p}>0,25$ na análise bruta.

Fonte: Dados da pesquisa, 2012.

A tabela 20 mostra os valores brutos das razões de prevalência da exaustão emocional segundo as variáveis independentes e os valores ajustados das razões de prevalência de exaustão emocional segundo as variáveis independentes. Na análise bivariada destacaram-se as maiores prevalências entre as mulheres ( $\mathrm{OR}=2,18$; IC 95\% 1,31-4,22), com ensino médio completo ou superior incompleto $(\mathrm{OR}=0,39$; IC $95 \% 0,18-0,84)$, que moram sozinhos $(\mathrm{OR}=3,89 ;$ IC 95\% 1,76 - 8,61), que não tem filhos $(\mathrm{OR}=1,69 ;$ IC 95\% $0,98-$ $2,92)$, ter tido afastamento do trabalho no último ano (OR $=2,17$; IC 95\% 1,31 - 3,62) e ter doença crônica $(\mathrm{OR}=2,24 ; \mathrm{IC} 95 \%$ 1,20 - 4,18). 
$\mathrm{Na}$ análise multivariável permaneceram estatisticamente significantes as variáveis: sexo, escolaridade, com quem mora e afastamento do trabalho no último ano.

Deste modo, observa-se que as chances de desenvolver exaustão emocional, ocorre 2,55 vezes mais nas mulheres. Aqueles que possuem ensino médio completo apresentam $61 \%$ de chances de desenvolver exaustão emocional, morar sozinho apresenta 3,39\% de chances e, ter tido afastamento do trabalho apresenta $2,17 \%$.

A variável "tipo de serviço" não foi levada em consideração, pois seu intervalo de confiança foi grande e a amostra é pequena não sendo possível aprofundamento. As demais variáveis não se associaram com o desfecho após a análise ajustada.

Tabela 20 - Regressão multivariada entre a Exaustão Emocional e as variáveis sociodemográficas, de condições de trabalho e de saúde entre técnicos e auxiliares de enfermagem de um hospital geral. Ribeirão Preto, 2012.

\begin{tabular}{|c|c|c|c|c|c|}
\hline & \multirow[b]{2}{*}{ Variável } & \multicolumn{2}{|c|}{ Bruta } & \multicolumn{2}{|c|}{ Ajustada } \\
\hline & & OR* (IC 95\%) & $\begin{array}{l}\text { Valor } \\
\text { de } p^{* *}\end{array}$ & OR* (IC 95\%) & $\begin{array}{l}\text { Valor de } \\
\mathbf{p}^{* *}\end{array}$ \\
\hline 1 & $\begin{array}{l}\text { Sexo } \\
\text { Masculino } \\
\text { Feminino }\end{array}$ & $\begin{array}{l}1 \\
2,18(1,31-4,22)\end{array}$ & 0,02 & $\begin{array}{l}1 \\
2,55(1,28-5,08)\end{array}$ & 0,01 \\
\hline 1 & $\begin{array}{l}\text { Faixa Etária } \\
\text { Até } 40 \text { anos } \\
\text { Acima de } 40 \text { anos }\end{array}$ & & & $\begin{array}{l}1 \\
1,06(0,58-1,92)\end{array}$ & 0,85 \\
\hline 1 & $\begin{array}{l}\text { Escolaridade } \\
\text { Superior completo } \\
\text { Médio completo ou Superior } \\
\text { incompleto } \\
\text { Fundamental completo ou Médio } \\
\text { incompleto }\end{array}$ & $\begin{array}{l}1 \\
0,39(0,18-0,84) \\
0,60(0,21-1,72)\end{array}$ & $\begin{array}{l}0,02 \\
0,34\end{array}$ & $\begin{array}{l}1 \\
0,43(0,20-0,96) \\
0,59(0,20-1,74)\end{array}$ & $\begin{array}{l}0,04 \\
0,34\end{array}$ \\
\hline & $\begin{array}{l}\text { Estado Civil } \\
\text { Com companheiro } \\
\text { Sem companheiro } \\
\text { Religião } \\
\text { Sim } \\
\text { Não }\end{array}$ & $\begin{array}{l}1 \\
1,22(0,74-2,01) \\
1 \\
1,11(0,44-2,81)\end{array}$ & 0,82 & $* * *$ & \\
\hline 1 & $\begin{array}{l}\text { Mora com } \\
\text { Mora com alguém } \\
\text { Mora sozinho }\end{array}$ & $\begin{array}{l}1 \\
3,89(1,76-8,61)\end{array}$ & $<0,00$ & $\begin{array}{l}1 \\
1,55(1,20-2,01)\end{array}$ & $<0,00$ \\
\hline & $\begin{array}{l}\text { Tem filhos } \\
\text { Tem filhos } \\
\text { Não tem filhos }\end{array}$ & $\begin{array}{l}1 \\
1,69(0,98-2,92)\end{array}$ & 0,06 & $* * *$ & \\
\hline & $\begin{array}{l}\text { Cargo } \\
\text { Auxiliar de Enfermagem } \\
\text { Técnico de Enfermagem }\end{array}$ & $\begin{array}{l}1 \\
0,90(0,41-1,91)\end{array}$ & 0,77 & $* * *$ & \\
\hline 2 & $\begin{array}{l}\text { Tempo no serviço } \\
\text { Até } 15 \text { anos } \\
\text { Acima de } 15 \text { anos }\end{array}$ & $\begin{array}{l}1 \\
1,53(0,92-2,53)\end{array}$ & 0,10 & 1 & 0,27 \\
\hline
\end{tabular}




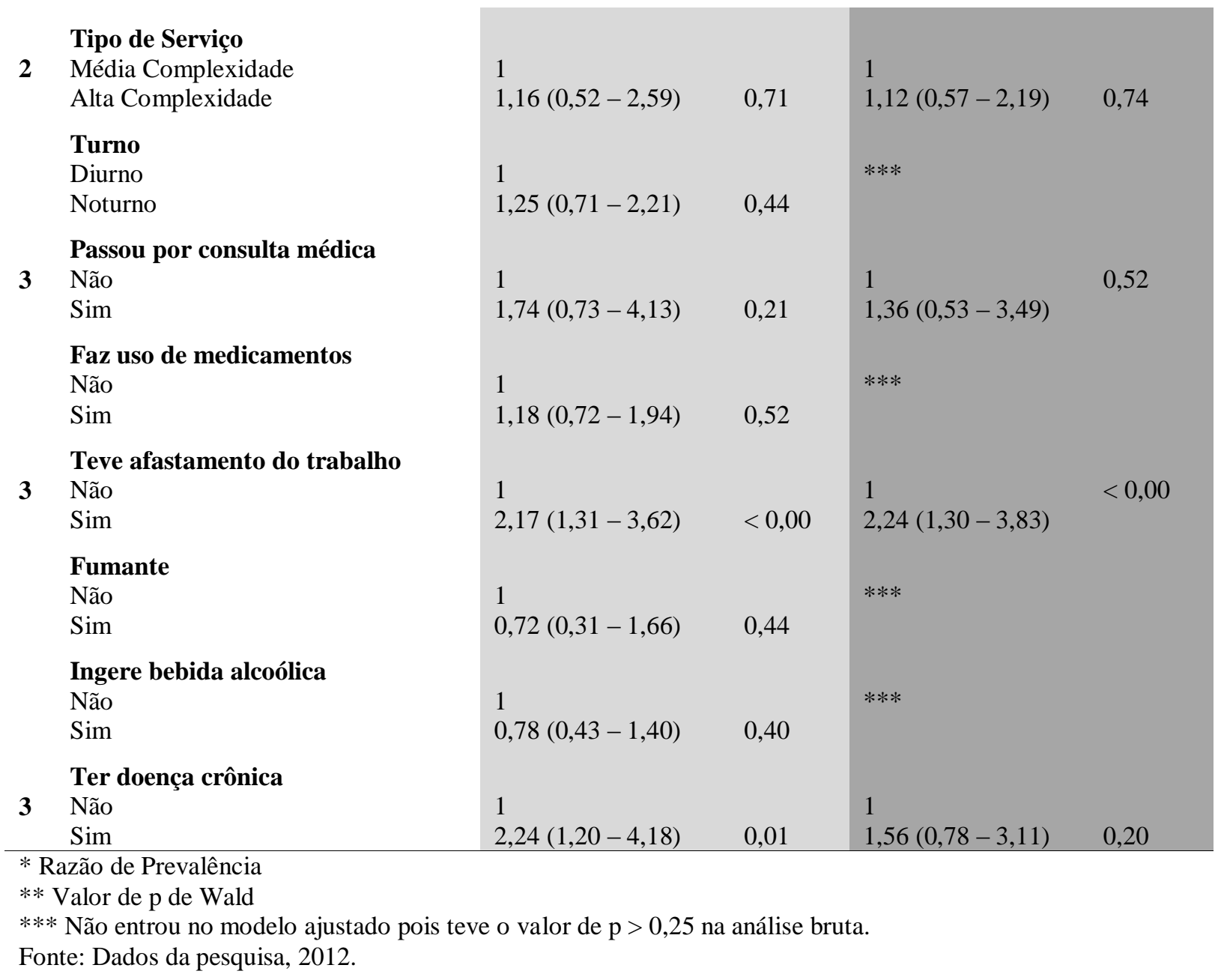

A tabela 21 mostra os valores brutos das razões de prevalência de despersonalização segundo as variáveis independentes e os valores ajustados das razões de prevalência de despersonalização segundo as variáveis independentes. Na análise bivariada destacaram-se as maiores prevalências entre os participantes que referiram ter passado por consulta médica no último ano $(\mathrm{OR}=2,53$; IC 95\% 1,02 - 6,29) e referir fazer uso de álcool $(\mathrm{OR}=1,67$; IC 95\% $0,98-2,86)$.

$\mathrm{Na}$ análise multivariável permaneceu estatisticamente significante a variável ter referido passar por consulta médica no último ano. Tendeu a significância as variáveis: religião e estado civil. As chances de desenvolver despersonalização ocorre 3,28 vezes mais nos participantes que passaram por consulta médica, 2,25 vezes mais naqueles que não possuem crença religiosa e $56 \%$ dos que não possuem companheiro. As demais variáveis não se associaram com o desfecho após a análise ajustada. 
Tabela 21 - Regressão multivariada entre a Despersonalização e as variáveis sociodemográficas, de condições de trabalho e de saúde entre técnicos e auxiliares de enfermagem de um hospital geral. Ribeirão Preto, 2012.

\begin{tabular}{|c|c|c|c|c|c|}
\hline & \multirow[b]{2}{*}{ Variável } & \multicolumn{2}{|l|}{ Bruta } & \multicolumn{2}{|c|}{ Ajustada } \\
\hline & & OR* (IC 95\%) & $\begin{array}{l}\text { Valor } \\
\text { de } \mathbf{p}^{* *}\end{array}$ & OR* (IC 95\%) & $\begin{array}{l}\text { Valor de } \\
\text { p }^{* *}\end{array}$ \\
\hline 1 & $\begin{array}{l}\text { Sexo } \\
\text { Masculino } \\
\text { Feminino }\end{array}$ & $\begin{array}{l}1 \\
0,81(0,47-1,40)\end{array}$ & 0,46 & $\begin{array}{l}1 \\
0,86(0,48-1,51)\end{array}$ & 0,59 \\
\hline & $\begin{array}{l}\text { Faixa Etária } \\
\text { Até } 40 \text { anos } \\
\text { Acima de } 40 \text { anos }\end{array}$ & & & $* * *$ & \\
\hline 1 & $\begin{array}{l}\text { Escolaridade } \\
\text { Superior completo } \\
\text { Superior incompleto e Médio } \\
\text { completo }\end{array}$ & $\begin{array}{l}1 \\
1,65(0,68-4,01)\end{array}$ & 0,27 & $\begin{array}{l}1 \\
1,93(0,77-4,79)\end{array}$ & 0,16 \\
\hline & $\begin{array}{l}\text { Médio incompleto e Fundamental } \\
\text { completo }\end{array}$ & $1,05(0,31-3,47)$ & 0,94 & $1,45(0,42-5,03)$ & 0,56 \\
\hline 1 & $\begin{array}{l}\text { Estado Civil } \\
\text { Com companheiro } \\
\text { Sem companheiro }\end{array}$ & $\begin{array}{l}1 \\
1,51(0,94-2,47)\end{array}$ & 0,09 & $\begin{array}{l}1 \\
1,56(0,95-2,54)\end{array}$ & 0,08 \\
\hline 1 & $\begin{array}{l}\text { Religião } \\
\text { Sim } \\
\text { Não }\end{array}$ & $\begin{array}{l}1 \\
2,14(0,91-5,05)\end{array}$ & 0,08 & $\begin{array}{l}1 \\
2,15(0,91-5,05)\end{array}$ & 0,08 \\
\hline & $\begin{array}{l}\text { Mora com } \\
\text { Mora com alguém } \\
\text { Mora sozinho }\end{array}$ & $\begin{array}{l}1 \\
1,22(0,54-2,76)\end{array}$ & 0,62 & $* * *$ & \\
\hline 1 & $\begin{array}{l}\text { Tem filhos } \\
\text { Tem filhos } \\
\text { Não tem filhos }\end{array}$ & $\begin{array}{l}1 \\
1,58(0,92-2,70)\end{array}$ & 0,09 & $\begin{array}{l}1 \\
1,37(0,78-2,40)\end{array}$ & 0,27 \\
\hline 2 & $\begin{array}{l}\text { Cargo } \\
\text { Auxiliar de Enfermagem } \\
\text { Técnico de Enfermagem }\end{array}$ & $\begin{array}{l}1 \\
0,61(0,28-1,35)\end{array}$ & 0,22 & $\begin{array}{l}1 \\
0,79(0,42-1,51)\end{array}$ & 0,48 \\
\hline & $\begin{array}{l}\text { Tempo no serviço } \\
\text { Até } 15 \text { anos } \\
\text { Acima de } 15 \text { anos }\end{array}$ & $\begin{array}{l}1 \\
0,86(0,52-1,42)\end{array}$ & 0,55 & $* * *$ & \\
\hline & $\begin{array}{l}\text { Tipo de Serviço } \\
\text { Média Complexidade } \\
\text { Alta Complexidade }\end{array}$ & $\begin{array}{l}1 \\
0,76(0,36-1,57)\end{array}$ & 0,46 & $* * *$ & \\
\hline 2 & $\begin{array}{l}\text { Turno } \\
\text { Diurno } \\
\text { Noturno }\end{array}$ & $\begin{array}{l}1 \\
1,41(0,81-2,45)\end{array}$ & 0,22 & $\begin{array}{l}1 \\
1,49(0,84-2,64)\end{array}$ & 0,17 \\
\hline 3 & $\begin{array}{l}\text { Passou por consulta médica } \\
\text { Não } \\
\text { Sim }\end{array}$ & $\begin{array}{l}1 \\
2,53(1,02-6,29)\end{array}$ & 0,05 & $\begin{array}{l}1 \\
3,28(1,25-8,59)\end{array}$ & 0,02 \\
\hline & $\begin{array}{l}\text { Faz uso de medicamentos } \\
\text { Não } \\
\text { Sim }\end{array}$ & $\begin{array}{l}1 \\
0,86(0,53-1,39)\end{array}$ & 0,52 & $* * *$ & \\
\hline 3 & $\begin{array}{l}\text { Teve afastamento do trabalho } \\
\text { Não } \\
\text { Sim }\end{array}$ & $\begin{array}{l}1 \\
1,43(0,89-2.32)\end{array}$ & 0,14 & $1,51(0,89-2,55)$ & 0,13 \\
\hline
\end{tabular}




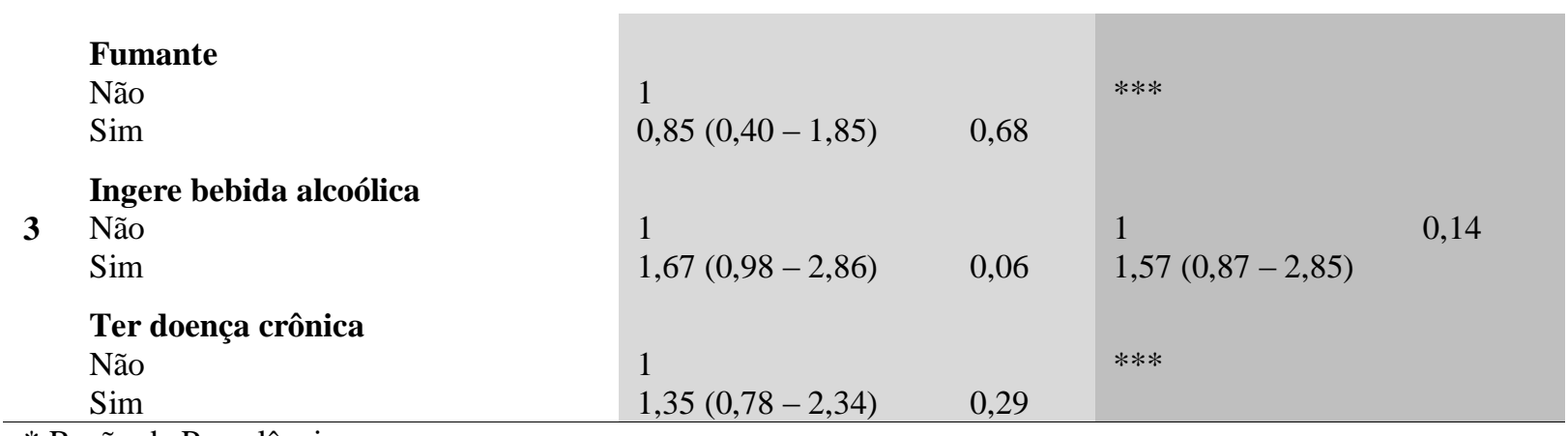

* Razão de Prevalência

** Valor de $\mathrm{p}$ de Wald

*** Não entrou no modelo ajustado pois teve o valor de $\mathrm{p}>0,25$ na análise bruta.

Fonte: Dados da pesquisa, 2012.

A tabela 22 mostra os valores brutos das razões de prevalência de realização pessoal segundo as variáveis independentes e os valores ajustados das razões de prevalência de realização pessoal segundo as variáveis independentes. Na análise bivariada destacou-se a maior prevalência entre os participantes que moram sozinhos $(\mathrm{OR}=3,35$; IC 95\% 1,51 $7,43)$.

Na análise multivariável a única variável que permaneceu estatisticamente significante foi a com que mora. A variável "sexo" tendeu a significância. As chances de não desenvolver realização pessoal ocorre 3,35 vezes mais naqueles que moram sozinhos e $86 \%$ nas mulheres. As demais variáveis não se associaram com o desfecho após a análise ajustada.

Tabela 22 - Regressão multivariada entre a Realização Pessoal e as variáveis sociodemográficas, de condições de trabalho e de saúde entre técnicos e auxiliares de enfermagem de um hospital geral. Ribeirão Preto, 2012

\begin{tabular}{|c|c|c|c|c|c|}
\hline & \multirow[b]{2}{*}{ Variável } & \multicolumn{2}{|c|}{ Bruta } & \multicolumn{2}{|c|}{ Ajustada } \\
\hline & & OR* (IC 95\%) & $\begin{array}{l}\text { Valor } \\
\text { de } \mathbf{p}^{* * *}\end{array}$ & OR* (IC 95\%) & $\begin{array}{l}\text { Valor de } \\
\mathbf{p}^{* *}\end{array}$ \\
\hline 1 & $\begin{array}{l}\text { Sexo } \\
\text { Masculino } \\
\text { Feminino }\end{array}$ & $\begin{array}{l}1 \\
1,72(0,87-3,42)\end{array}$ & 0,12 & $\begin{array}{l}1 \\
1,86(0,92-3,77)\end{array}$ & 0,08 \\
\hline 1 & $\begin{array}{l}\text { Faixa etária } \\
\text { Até } 40 \text { anos } \\
\text { Acima de } 40 \text { anos }\end{array}$ & $\begin{array}{l}1 \\
1,37(0,74-2,52)\end{array}$ & 0,31 & $\begin{array}{l}1 \\
1,33(0,71-2,49)\end{array}$ & 0,37 \\
\hline & $\begin{array}{l}\text { Escolaridade } \\
\text { Superior completo } \\
\text { Superior incompleto e Médio } \\
\text { completo } \\
\text { Médio incompleto e Fundamental } \\
\text { completo }\end{array}$ & $\begin{array}{l}1 \\
0,92(0,38-2,26) \\
1,48(0,47-4,70)\end{array}$ & $\begin{array}{l}0,86 \\
0,51\end{array}$ & & \\
\hline 1 & $\begin{array}{l}\text { Estado Civil } \\
\text { Com companheiro } \\
\text { Sem companheiro }\end{array}$ & $\begin{array}{l}1 \\
1,59(0,93-2,70)\end{array}$ & 0,09 & $\begin{array}{l}1 \\
1,23(0,68-2,21)\end{array}$ & 0,49 \\
\hline & Religião & & & & \\
\hline
\end{tabular}


Sim

Não

\section{Mora com}

1 Mora com alguém

Mora sozinho

Tem filhos

Tem filhos

Não tem filhos

\section{Cargo}

Auxiliar de Enfermagem

Técnico de Enfermagem

\section{Tempo no serviço}

2 Até 15 anos

Acima de 15 anos

Tipo de Serviço

Média Complexidade

Alta Complexidade

Turno

Diurno

Noturno

Passou por consulta médica

Não

Sim

Faz uso de medicamentos

Não

Sim

Teve afastamento do trabalho

3 Não

Sim

Fumante

Não

Sim

Ingere bebida alcoólica

Não

Sim

Ter doença crônica

3 Não

Sim

Razão de Prevalência

** Valor de p de Wald

*** Não entrou no modelo ajustado pois teve o valor de $\mathrm{p}>0,25$ na análise bruta.

Fonte: Dados da pesquisa, 2012.

$1,21(0,51-2,91) \quad 0,66$
1

$0,92(0,33-2,57) \quad 0,87$

1

$3,35(1,51-7,43) \quad<0,00 \quad 3,35(1,51-7,43)$

$<0,00$

1

$1,31(0,73-2,36) \quad 0,37$

1

$1,43(0,67-3,05) \quad 0,35$

$1,43(0,83-2,45) \quad 0,19 \quad 1,36(0,74-2,51)$

0,33

1

1

$0,68(0,35-1,33) \quad 0,27$

1

$1,56(0,62-3,90) \quad 0,35$

1

$1,28(0,75-2,18) \quad 0,37$

1

$1,61(0,94-2,76) \quad 0,08 \quad 1,58(0,91-2,75)$

0,10

1

$1,00(0,43-2,30) \quad 0,99$

1

$0,76(0,40-1,45) \quad 0,41$

$1 \quad 1 \quad 0,64$ 
5 DISCUSSÃO 


\section{DISCUSSÃO}

Neste estudo foi investigada a prevalência e associação da Síndrome de Burnout, do estresse precoce e das estratégias de enfrentamento entre técnicos e auxiliares de enfermagem, dada a relevância desta temática. As inferências de que há associação entre a Síndrome de Burnout e estresse precoce, estratégias de enfrentamento, características sociodemográficas, condições de trabalho e saúde foram testadas e algumas foram comprovadas em alguns pontos, conforme descrito a seguir.

Com relação à Síndrome de Burnout, a prevalência foi de 7,4\%, o que indica alto nível de Burnout, ou seja, participantes que pontuaram um escore alto em exaustão emocional, alto em despersonalização e baixo em realização pessoal. Resultados semelhantes foram obtidos em outros estudos, com prevalência de $6,7 \%, 12 \%, 9 \%$ e $9,1 \%$, realizados com equipe de enfermagem, professores, médicos e outros profissionais da área de saúde (DAL PAI, 2011; MUÑOZ e GUTIÉRREZ, 2011; MAGNABOSCO et. al., 2009; RODRIGUES, 2006).

Estudo, realizado na Espanha com auxiliares de enfermagem que exercem a função de profissionais sanitários, mostrou uma prevalência de Burnout de 22,5\%. Além disso, percebeu-se que os altos valores de exaustão emocional e despersonalização estavam significativamente relacionados com baixa satisfação no trabalho revelando elevado nível de mal-estar psíquico. Em compensação, os que apresentavam alto nível de realização profissional apresentavam correlação negativa com os distúrbios somáticos, ou seja, satisfeitos com suas atividades ocupacionais e com menos problemas de saúde (OLZA 1999 citada por BENEVIDES-PEREIRA, 2010).

No presente estudo, apesar de a prevalência ter sido menor do que se esperava entre os técnicos e auxiliares do hospital geral investigados, percebe-se, que mais da metade da amostra apresentou alguma alteração em uma das dimensões da Síndrome de Burnout, o que chama a atenção, pois indica que já está ocorrendo alterações que poderão levar o trabalhador a desenvolver a síndrome.

A exemplo disso, a literatura evidencia a exaustão emocional como traço fundamental da Síndrome de Burnout, sendo considerada sua característica principal, pois é a percepção de uma sobrecarga de trabalho tanto qualitativa como quantitativa onde o sujeito sente que as exigências são maiores que seus recursos emocionais e sua capacidade e vigor para o trabalho, embora a síndrome possa não estar desenvolvida ainda (MARINHO, 2005). 
Assim, percebe-se a importância dos resultados como indicadores em que $28,4 \%$ dos participantes pontuaram alto nível em exaustão emocional e requerem cuidados quanto a essa dimensão.

A segunda fase do Burnout, dimensão Despersonalização, indica que o indivíduo já não tem mais interesse e responsabilidade pela função exercida e não se importa com o que acontece com o outro. Neste estudo, tal dimensão foi pontuada por $31,6 \%$ dos técnicos e auxiliares de enfermagem, o que indica que podem estar ocorrendo alterações das relações pessoais no trabalho, tanto com o paciente como com o colega, passando a acontecer de forma "coisificada".

Cabe ressaltar que para um trabalho de qualidade é necessário tempo, esforço, compromisso e criatividade, quesitos que um indivíduo desgastado já não está disposto a oferecer espontaneamente. No caso da dimensão Realização Pessoal, níveis baixos são negativos e indicam sentimentos de incompetência e alteração nessa dimensão e, conforme os resultados deste estudo, a baixa realização pessoal está presente em $22,9 \%$ dos técnicos e auxiliares de enfermagem.

Quando pensamos em estratégias de enfrentamento, nota-se que cada pessoa busca uma maneira de lidar com os estressores, voltada para a redução dos mesmos. Neste estudo, a estratégia mais utilizada entre a amostra foi a focalizada no problema, esta estratégia representa uma condução de aproximação que é desempenhada pelo indivíduo em relação ao estressor no sentido de solucionar o problema, lidar ou manejar com a situação estressora. Indica também que há esforços cognitivos voltados para a reavaliação do problema, percebendo-o de modo positivo (SEIDL, TRÓCOLI e ZANNON, 2001).

Tal resultado indica que, encarar os problemas com o intuito de resolvê-los, é a melhor maneira de lidar com os estressores que surgem não apenas no ambiente de trabalho mais também na vida pessoal. Estudos realizados com outras populações, como portadores de HIV, pacientes com Insuficiência Renal Crônica Terminal, mestrandos em Ciências da Saúde e pacientes com câncer, corroboram tais resultados (FARIA e SEIDL, 2006; BERTOLIN, 2007; SANTOS e ALVES JUNIOR, 2007; SANTANA, ZANIN e MANIGLIA, 2008).

O estresse precoce por sua vez foi prevalente em $31 \%$ dos técnicos e auxiliares de enfermagem, ou seja, em pessoas teoricamente saudáveis e produtivas. Ressalta-se que o estudo com estresse precoce tem priorizado como população alvo indivíduos com algum tipo de adoecimento, o que limitou comparações. Estudo conduzido por Martins e colaboradores (2011), com pacientes atendidos em um hospital dia mostrou que o estresse precoce foi 
prevalente em mais de $70 \%$ da amostra e teve forte associação com risco de suicídio e esquizofrenia. Porém, sendo o estresse um grave problema de ordem mundial, evidencia-se a relevância de se investigar tal temática, visto que a literatura comprova a associação do estresse precoce com dificuldades em lidar com o estresse na vida adulta e também com o risco aumentado para o adoecimento mental.

A literatura traz ainda outras associações de acordo com cada subtipo de estresse precoce. De forma geral, os estudos mostram que o estresse precoce está associado com ansiedade, transtornos do humor, transtornos psiquiátricos, esquizofrenia, vítimas de abuso sexual são mais prováveis de cometer abuso em crianças, estresse, transtornos de conduta, tentativas de suicídio, transtorno obsessivo-compulsivo, transtornos alimentares, sintomas psiquiátricos, depressão e transtorno de personalidade borderline (MARTINS et al., 2011). Sendo que estudos sobre o estresse precoce também em indivíduos "saudáveis" visando o desenvolvimento de intervenções preventivas ao adoecimento relacionado a este fenômeno, podem favorecer a produção de importantes resultados. Porém, ao contrário do que se esperava, não houve diferença estatisticamente significativa ao associar-se a variável Síndrome de Burnout com o estresse precoce entre os técnicos e auxiliares de enfermagem.

Visando alcançar os objetivos propostos, neste estudo, a verificação de associação entre a Síndrome de Burnout e as demais variáveis resultou em importantes evidências. A literatura demonstra que a Síndrome de Burnout está associada a algumas variáveis (características pessoais, organizacionais, do trabalho e sociais), não sendo estas necessariamente desencadeantes da síndrome, mas sim facilitadoras ou inibidoras da reação aos agentes estressores (Gil-Monte e Peiró citado por BENEVIDES-PEREIRA, 2010).

Dentre as características pessoais que podem estar associadas à Síndrome de Burnout destacam-se a idade, sexo, nível educacional, filhos, personalidade, sentido de coerência, motivação e idealismo. As características organizacionais são: ambiente físico, mudanças organizacionais, normas institucionais, clima, burocracia, comunicação, autonomia, recompensas e segurança. Em relação ao trabalho as características citadas são: tipo de ocupação, tempo de profissão e na instituição, turnos, sobrecarga, relacionamentos com os colegas e com o cliente, conflito de papel, ambiguidade de papel, suporte organizacional, satisfação, controle, responsabilidade, pressão, possibilidade de progresso, percepção de iniquidade, conflito com valores pessoais e falta de feedback. Já as características sociais são de suporte social e familiar, cultura e prestígio (BENEVIDES-PEREIRA, 2010). 
Neste estudo, ao testar-se a associação entre a Síndrome de Burnout e as variáveis sociodemográficas, condições de trabalho e saúde, percebeu-se forte associação entre os participantes que referiram morar sozinhos, não ter filhos e ter tido afastamento do serviço no último ano. Outro resultado importante foi obtido ao proceder para a regressão logística, com o intuito de aprofundar os resultados obtidos e modelar a probabilidade de um evento ocorrer como função de outros fatores. Evidenciando que a Síndrome de Burnout possui 3,19 vezes mais chances de ocorrer naqueles que moram sozinhos e 2,26 vezes mais chances de ocorrer naqueles que tiveram afastamento do trabalho no último ano.

Outros estudos, realizados com professores, corroboram com tais resultados por mostrar maiores valores na síndrome em solteiros, viúvos ou divorciados, e a relação de ter filhos possibilitar melhores estratégias de enfrentamento em situações conflitivas e também um aumento entre afastamento do trabalho à medida que ocorre avanço da síndrome (BENEVIDES-PEREIRA, 2010).

Tais resultados deixam clara a importância de se ter vínculos afetivos e que estes funcionam como suporte para o enfrentamento dos problemas, sendo uma maneira de dividir os problemas e não guardá-los para si. Neste sentido, embora ter filhos exija cuidados e atenção, em vez de sobrecarga a maternidade pode trazer realização pessoal e satisfação.

Apesar de a literatura indicar associação entre a Síndrome de Burntou e as variáveis sexo, idade e estado civil, tanto neste estudo, como no estudo de Marinho (2005), não houve correlação significativa entre tais variáveis.

A associação entre a Sindrome de Burnout e as estratégias de enfrentamento mostrou forte significância entre os participantes com a síndrome e que não utilizavam as estratégias focalizadas nos problemas. Houve também associação entre os participantes com a síndrome e que utilizavam estratégias de busca por suporte social. Entre os participantes que usam de estratégias focalizadas no problema a maioria não está com Burnout, o que indica que estas estratégias colaboram para que a situação de conflito seja resolvida e não permaneça como fator de estresse. Da mesma forma, entre os participantes que utilizam das estratégias de busca por suporte social, parte deles apresenta a síndrome.

Tal achado pode ser justificado pela literatura que mostra que, pessoas mais passivas, que optam por permanecer na defensiva, possuem maiores chances de adoecimento do que as pessoas que tendem a ser mais ativas, que buscam a resolução dos problemas e possuem de certa forma uma proteção para o desenvolvimento da Síndrome de Burnout (MASLACH, SCHAUFELI e LEITER, 2001). 
$\mathrm{Na}$ análise da associação entre as dimensões da Síndrome de Burnout (Exaustão Emocional, Despersonalização e Realização Pessoal) e as variáveis sociodemográficas, condições de trabalho e saúde, estratégias de enfrentamento e estresse precoce foram evidenciados resultados importantes.

Evidenciou-se que, neste estudo, a Exaustão Emocional mostrou-se mais significativa entre as mulheres, que possuem ensino superior completo, residem sozinhas, não possuem filhos, trabalham no mesmo serviço, entre 6 e 10 anos, referiram ter tido afastamento do trabalho no último ano e ter alguma doença crônica. O que foi reforçado, após análise de regressão logística, confirmando que as chances de desenvolver Exaustão Emocional ocorre 2,55 vezes mais nas mulheres, $61 \%$ mais naqueles que possuem ensino médio completo, 3,39 vezes mais nos que moram sozinhos e 2,17 vezes mais naqueles que tiveram afastamento do trabalho no último ano.

Além disso, mulheres são mais vulneráveis ao estresse que os homens e, também, estão mais sujeitas a desenvolver diversos transtornos psiquiátricos (HEGADOREN, 2006; KINRYS e WYGANT, 2005; RENNÓ JR et al., 2012).

Um resultado também relevante neste estudo foi a verificação de que as chances de não se obter Realização Pessoal ocorre 3,35 vezes mais naqueles que moram sozinhos e $86 \%$ em mulheres.

Estudos evidenciam a maior incidência de exaustão emocional e baixa realização pessoal no sexo feminino, explicado pela ocorrência de dupla jornada de trabalho em que a maioria está sujeita, a profissional e a do lar. Por outro lado, pode-se também considerar a questão da interferência entre as características da profissão com o gênero, que nesse caso é a enfermagem e o gênero feminino.

O nível educacional também é citado na literatura como um fator que possui associação com a Síndrome de Burnout, especialmente na dimensão Exaustão Emocional em que os grupos com maiores graus de escolaridade encontram-se com maior exaustão emocional, justificado pelas expectativas profissionais ou maior nível de responsabilidade (MASLACH, SCHAUEFELI e LEITER, 2001).

Leatt e Schneck (1985) relacionam o nível educacional com a percepção de cansaço e Alvarez e Fernandez (1991) associaram a falta de adequada formação dos profissionais à Síndrome de Burnout (LEATT; SCHNECK, 1985 apud LAUTERT, 1995; ALVAREZ; FERNANDEZ, 1991 apud LAUTERT, 1995). 
Com relação à associação entre Exaustão Emocional e a variável tempo de serviço no mesmo local, na literatura, não há consenso sobre tal associação. Há autor que descreve a Síndrome de Burnout como um processo de desgaste que aumenta com o tempo (OUBIÑA, 1995 citado por BENEVIDES-PEREIRA, 2010) e autor que aponta que a maior incidência ocorre nos que ingressam no mercado de trabalho (SCHAUFELI, 1999 citado por BENEVIDES-PEREIRA, 2010).

Neste estudo, avaliando-se que os resultados demonstraram que, a Exaustão Emocional, foi mais frequente em técnicos e auxiliares de enfermagem com tempo de serviço de 6 e 10 anos e, permaneceu presente entre os profissionais com tempo de serviço de 11 a 20 anos, considera-se que o processo de Exaustão Emocional pode realmente estar relacionado com o aumento do tempo de serviço no mesmo local.

Cabe ressaltar que ao mesmo tempo em que o profissional adquire mais conhecimento com o tempo, acaba acarretando desencantamento por suas atividades, seja pela crescente frustração e mal-estar que seu trabalho proporciona, falta de reconhecimento ou baixa remuneração, podendo levar ao adoecimento ou ao abandono da profissão (BENEVIDESPEREIRA, 2010).

Por outro lado, Obiña (1995) e Schaufeli (1999) citados por Benevides-Pereira (2010), referem que o transcorrer dos anos de experiência propiciam estratégias de enfrentamento eficazes na atividade profissional para algumas pessoas, enquanto para outras o tempo leva a uma acentuação das dificuldades e ao desgaste, deixando o trabalhador mais vulnerável ao adoecimento.

Maiores níveis de Exaustão Emocional estiveram associados com não possuir filhos. Tal ocorrência pode ser explicada pelo desenvolvimento de um equilíbrio entre a experiência da paternidade e as experiências profissionais, possibilitando melhores estratégias de enfrentamento das situações e estressores ocupacionais para os que experienciam a vivência de serem pais (BENEVIDES-PEREIRA, 2010).

Cabe observar que, morar sozinho demonstrou forte associação tanto com a dimensão Exaustão Emocional como com a dimensão Realização Pessoal e Despersonalização. Morar sozinho relacionou-se com maiores níveis de Exaustão Emocional e Despersonalização e menores de Realização Pessoal, ou seja, conviver com alguém demonstrou ser um fator protetor em relação ao desenvolvimento da Síndrome de Burnout entre técnicos e auxiliares de enfermagem. Estudos evidenciam que ter um relacionamento afetivo saudável e estável e qualidade de vida torna-se benéfico à prevenção da Síndrome de Burnout (LAUTERT, 1995; 
LIPP e TANGANELLI, 2002; CARREIRO et al., 2013). Assim, estar realizado na esfera pessoal acaba interferindo positivamente na dimensão profissional.

A despersonalização reflete no indivíduo o desenvolvimento de atitudes frias, negativas e insensíveis direcionadas tanto aos receptores de um serviço prestado como também aos colegas. Tais atitudes tornam-se desumanizadas, hostis, intolerantes e impessoais (BENEVIDES-PEREIRA, 2010). Neste estudo, as chances de desenvolver Despersonalização ocorreram 3,28 vezes mais nos participantes que passaram por consulta médica, 2,25 vezes mais naqueles que não possuem crença religiosa e 56\% dos que não possuem companheiro. Além de estar associada também aos que referiram fazer uso de bebidas alcoólicas.

Entende-se que quando o indivíduo está na fase de despersonalização, em que passa a agir de maneira coisificada, é natural que sua crença seja abalada e até perdida, e assim, uma forma de tentar fugir da realidade é através do uso de bebidas alcoólicas ou outras substâncias. Há evidências que o uso de álcool pode ser determinado por diversos fatores, tanto psicológicos quanto fisiológicos, porém o estresse é considerado um fator maior para a iniciação e continuação do uso de álcool (BRADY e SONNE, 1999).

As dimensões da Síndrome de Burnout e o estresse precoce associaram-se apenas entre os participantes com alto nível de Exaustão Emocional e o estresse precoce. Do total de participantes que pontuaram alto nível de Exaustão Emocional, praticamente a metade sofreu estresse precoce. A literatura evidencia que a ocorrência de estresse precoce pode influenciar negativamente a maneira como uma pessoa na fase adulta enfrenta os estressores cotidianos (MARINHO, 2005), o que pode estar relacionado à utilização de ineficazes estratégias de enfrentamento. Neste contexto, o estresse precoce pode influenciar nos recursos emocionais do indivíduo e assim alterar sua capacidade e vigor para o trabalho.

Embora não tenha sido objetivo principal deste estudo avaliar questões de categorização profissional, ressalta-se haver considerável número de técnicos exercendo cargos de auxiliares de enfermagem no serviço. Neste estudo, 64\% dos técnicos de enfermagem atuavam como auxiliares. Tal estranhamento decorre da orientação do COFEN para gradual extinção desta última categoria profissional (COFEN, 2003).

Sendo a baixa remuneração um fator evidenciado na literatura como estressor e relacionado à ocorrência da Síndrome de Burnout, ter profissionais atuando em cargo diferente de sua formação e com menor remuneração, torna tal situação importante a reflexão. Embora seja uma estratégia economicamente interessante ao serviço, submeter o profissional a atividades inferiores a sua qualificação profissional tem sido evidenciado como fator 
possivelmente associado à baixa realização profissional e consequentemente ao desenvolvimento da Síndrome de Burnout. (BENEVIDES-PEREIRA, 2010).

Porém, neste estudo, não houve associação entre formação e cargo exercido com a Síndrome de Burnout.

A enfermagem como categoria profissional sempre foi marcada por profissionais que conciliavam mais de um vínculo empregatício, conforme se pode verificar no estudo de Pafaro e Martino (2004), realizado com enfermeiros de um hospital de oncologia, 70,8\% dos trabalhadores possuíam dupla jornada de trabalho tendo como justificativa os baixos salários e a necessidade de complementação da renda familiar. Mas, no presente estudo, a maioria dos técnicos e auxiliares de enfermagem possuía apenas um vínculo empregatício.

Dados semelhantes podem ser verificados nos estudos de Dal Pai (2011), Meneghini et al. (2011) e Pereira et al. (2009), também realizados com estes profissionais. Neste estudo, dedicar-se apenas a um vínculo empregatício pode estar relacionado à oportunidade oferecida pelo próprio serviço para que o profissional consiga aumentar seu salário através de plantões extras na própria unidade em que trabalha.

Cabe ressaltar, porém, que embora o profissional não precise se deslocar até outro serviço, terá um aumento da carga horária de trabalho, o que poderá desencadear desgaste do profissional. Grande parcela dos técnicos e auxiliares de enfermagem deste estudo disseram desempenhar até 60 horas semanais de trabalho. Estudos evidenciam que a sobrecarga de horas de trabalho pode estar relacionada ao adoecimento. (CARREIRO et al, 2013).

Nos últimos anos percebeu-se uma crescente preocupação em relação à qualidade de vida e bem-estar do profissional. $\mathrm{O}$ foco deixou de ser o modelo curativista e passou a ser a promoção à saúde, pois, entendeu-se que é mais barato investir na promoção à saúde do que na recuperação da mesma. Destaca-se que a metade da amostra mencionou ter afastado do trabalho no último ano sendo o principal motivo à ocorrência de doenças.

Achados de Silva e Marziale (2000) mostrou em seu estudo que a maioria dos trabalhadores de enfermagem em ambiente hospitalar falta pelo menos uma vez ao trabalho sendo $75 \%$ por motivo de doença, e o maior número de atestados relacionou-se ao sistema respiratório, justificado por frequentes exposições da equipe de enfermagem a agentes biológicos e químicos que podem causar infecções no trato respiratório.

Estudo com população semelhante mostrou que as doenças mais referidas foram hipertensão, infecção urinária e alergias (SANTOS e ARAÚJO, 2003). O que difere dos resultados do presente estudo, os quais evidenciaram que, entre os técnicos e auxiliares de 
enfermagem, a doença de coluna ou costas foi a mais citada pelos participantes, seguida por gastrite, ansiedade e tendinite ou tendossinovite.

Em síntese, observou-se com os resultados deste estudo que estes profissionais de enfermagem estão sujeitos a fatores estressores cotidianos, alguns relacionados ao ambiente de trabalho, outros a características pessoais e também com experiências precoces que de alguma forma podem estar influenciando a maneira como utilizam suas estratégias para o enfrentamento dos problemas.

As limitações sentidas em relação ao estudo referem-se às abordagens dos profissionais durante o horário de trabalho. Embora quase que a totalidade dos participantes demonstrou interesse em participar da pesquisa, coletar dados durante o expediente do profissional pode fazer com que este tenha respondido aos instrumentos com maior rapidez e preocupação, pois interromper o trabalho por determinado tempo pode acarretar em acúmulo de serviço ou até mesmo interferir em seu horário de descanso.

Percebe-se que a relevância deste estudo concentra-se na junção de dois pontos distintos, a temática e a população alvo.

Não há na literatura estudos em que foram investigadas associações entre o estresse precoce, a Síndrome de Burnout e as estratégias de enfrentamento. Da mesma forma, a maioria dos estudos é voltada para os mais diversos profissionais da área da saúde, porém, muito poucos foram direcionados especificamente aos técnicos e auxiliares de enfermagem.

Como pesquisadora, realizar este estudo proporcionou uma aproximação com o tema e maior interação com os profissionais. Foi possível vivenciar e presenciar a rotina dos participantes, perceber a maneira como agem com os colegas de trabalho e por diversas vezes foi necessário agir como ouvinte. Nas interações, ficou evidente a necessidade do profissional em conversar e desabafar sobre os problemas vivenciados em seu trabalho.

Outro fator limitador sentido, foi em relação ao tipo de abordagem escolhido. A abordagem quantitativa é bastante prática e estratégica, porém é também limitadora. Principalmente quando foi evidenciada a necessidade que os participantes demonstraram em relação a conversar sobre seus problemas. Talvez com uma abordagem quantiqualitativa, a entrevista poderia ter colhido mais informações que seriam importantes para a maior compreensão destes fenômenos.

Cabe ressaltar ainda, a gratidão demonstrada por alguns profissionais pelo simples fato da pesquisa estar sendo focada neles. Estes perceberam o quão necessário é investigar os 
problemas sentidos por esta categoria profissional e viram uma oportunidade para esclarecer sobre seus problemas e demonstraram interesse pelos resultados do estudo.

A experiência vivenciada pela pesquisadora somada aos resultados obtidos neste estudo evidenciam a necessidade de desenvolver estratégias voltadas a resolução dos problemas evidenciados e assim melhorar as condições laborais. 
6 CONSIDERAÇÕES FINAIS 


\section{CONSIDERAÇÕES FINAIS}

Apesar de a maioria dos participantes utilizarem de estratégias de enfrentamento que visam solucionar os estressores no ambiente de trabalho, os técnicos e auxiliares de enfermagem estão consideravelmente sujeitos ao desenvolvimento da Síndrome de Burnout e grande parte destes sofreram determinado tipo de estresse precoce que pode estar refletindo em sua forma de enfrentamento dos problemas.

Os resultados deste estudo indicam considerável prevalência da Síndrome de Burnout entre estes trabalhadores e preocupante risco para o desenvolvimento desta para grande parte deles. O estresse precoce, presente em significante parcela destes trabalhadores, embora não associado à Síndrome de Burnout neste estudo, também demonstrou ser um fenômeno importante, principalmente se consideradas as possíveis consequências à saúde destas pessoas e também ao modo de enfrentamento dos problemas na vida adulta.

As estratégias de enfrentamento mais utilizadas foram aquelas focalizadas no problema, indicando que estes profissionais utilizam de estratégias voltadas para a resolução dos fatores estressantes.

Algumas limitações foram percebidas no decorrer do estudo e um ponto que merece ser destacado é inexistência de estudos com análise em conjunto das três variáveis pesquisadas. Quando pesquisado especificamente sobre o estresse precoce, não há pesquisas com tal abordagem na referida população, indicando ser um tema recentemente pesquisado e que merece maior aprofundamento. Em relação aos estudos sobre a Síndrome de Burnout, há grande quantidade de estudos, porém a maioria dos autores não analisou as dimensões de maneira conjunta como recomendado pela autora do instrumento.

Em relação ao tema principal deste estudo, a Síndrome de Burnout, esta é mais estudada com outras categorias profissionais, considerando ser relevante para a área maior investigação com esta determinada população (técnicos e auxiliares de enfermagem).

Os resultados, ora apresentados, evidenciam a necessidade de desenvolver intervenções que visem capacitar os profissionais a desenvolver melhores estratégias de enfrentamento diante dos estressores presentes no ambiente laboral e pessoal. Espera-se com os resultados deste estudo, ampliar o conhecimento científico e assim beneficiar os trabalhadores do setor da saúde, estimulando iniciativas e ações de proteção e promoção da saúde do trabalhador no ambiente laboral. 
Além disso, os resultados podem evidenciar a necessidade de implementação de estratégias voltadas para a resolução de eventuais problemas operacionais de acordo com as característica e necessidades de cada setor dos serviços de saúde, visando não somente a qualidade de vida desses trabalhadores, mas também do serviço prestado. Gerando assim, benefícios não somente aos profissionais, mas também para a população em geral que é receptora deste serviço. 


\section{REFERÊNCIAS $\mathbf{S}^{1}$}

1. AFIFI, T. O.; ENNS, M. W.; COX, B. J.; GRAAF, R de; HAVE, M.; SAREEN, J. Child abuse and health-related quality of life in adulthood. The Journal of Nervous and Mental Disease, Chicago, v. 195, n. 10, p. 797-804, 2007.

2. AlMEIDA, M. F. de.; BARATA, R. B.; MONTERO, C. V.; SILVA, Z. P. da. Prevalência de doenças crônicas autorreferidas e utilização de serviços de saúde, PNAD/1998, Brasil. Ciência \& Saúde Coletiva, Rio de Janeiro, v. 7, n. 4, p. 743-756, 2002.

3. ALMEIDA FILHO, N. Ensino superior e os serviços de saúde no Brasil. In: THE LANCET - Saúde no Brasil. Disponível em: <<http://www.thelancet.com〉>. Acesso em: 03 MAI. 2011.

4. ALVIM, M. B. A relação do homem com o trabalho na contemporaneidade: uma visão crítica fundamentada na Gestalt-Terapia. Estudos e Pesquisas em Psicologia. Rio de Janeiro, v. 6, n. 2, p. 122-130, 2006.

5. ANDA, R. F.; FELITTI, V. J.; BREMNER, D.; WALKER, J. D.; WHITFIELD, C.; PERRY, B. D.; DUBE, S. R.; GILES, W. H. The enduring effectis of abuse and related adverse experiences in childhood. Eur Arch Psychiatry Clin Neurosci, Georgia, v. 256, n. 3, p. 174-186, 2006.

6. BAGNATO, M. H. S.; BASSIELlO, G. A. H.; LACAZ, C. P. C.; MISSIO, L. Ensino médio e educação profissionalizante em enfermagem: algumas reflexões. Rev. Esc. Enferm USP. São Paulo, v. 41, n. 2, p. 279-286, 2007.

7. BAPTISTA, S. S.; BARREIRA, I. A. Enfermagem de nível superior no Brasil e vida associativa. Rev. Bras. Enferm., Rio de Janeiro, v. 59, n. especial, p. 411-416, 2006.

8. BENEVIDES-PEREIRA, A. M. T. Burnout: quando o trabalho ameaça o bem-estar do trabalhador. 4. ed. São Paulo: Casa do Psicólogo, 2010.

9. BERNSTEIN, D. P.; STEIN, J. A.; NEWCOMB, M. D.; WALKER, E.; POGGE, D.; AHLUUVALIA, T.; STOKES, J.; HANDELSMAN, L.; MEDRANO, M.; DESMOND,

\footnotetext{
${ }^{1}$ De acordo com a Associação Brasileira de Normas Técnicas. NBR 6023.
} 
D.; ZULE, W. Development and validation of a brief screening version of the childhood trauma questionnaire. Child Abuse \& Neglect, v. 27, p. 169-190, 2003.

10. BERTOLIN, D. C. Modos de enfrentamento de pessoas com insuficiência renal crônica terminal em tratamento hemodialítico. 2007. 142f. Dissertação (Mestrado em Enfermagem) - Universidade de São Paulo, Escola de Enfermagem de Ribeirão Preto, Ribeirão Preto.

11. BORGES, L. O.; ARGOlO, J. C. T.; PEREIRA, A. L. de S.; MACHADO, E. A. P.; SILVA, W. S. da. A síndrome de Burnout e os valores organizacionais: um estudo comparativo em hospitais universitários. Psicologia: Reflexão e Crítica, Rio Grande do Sul, v. 15, n. 1, p. 189-200, 2002.

12. BRADY, K. T.; SONNE, S. C. The role of stress in alcohol use, alcoholism treatment, and relapse. Alcohol Research \& Health, v. 23, n. 4, p. 263-271, 1999.

13. BRASIL. Lei $\mathrm{n}^{\circ}$. 5.692, de 11 de agosto de 1971. Fixa diretrizes e bases para o ensino de $1^{\circ}$ e $2^{\circ}$ graus, e dá outras providências. Brasília, DF, 11 de ago 1971.

14. BRASIL. Lei n⿳o. 7.498, de 25 de junho de 1986. Dispõe sobre a regulamentação do exercício da enfermagem e dá outras providências. Brasília, DF, 25 de jun. 1986.

15. BRASIL. Constituição (1988). Constituição da República Federativa do Brasil. Brasília, DF: Senado, 1988.

16. BRASIL. Lei No. 8.080/90. Dispõe sobre as condições para a promoção, proteção e recuperação da saúde, a organização e o funcionamento dos serviços correspondentes e dá outras providências. Brasília: Congresso Nacional, 1990.

17. BRASIL. Resolução no. 196/96 de 10 de outubro de 1996. Aprova as diretrizes e normas regulamentadoras de pesquisas envolvendo seres humanos. Brasília: Congresso Nacional, 1996.

18. BRASIL. Decreto $n^{\circ}$. 2.208, de 17 de abril de 1997. Regulamenta o $\S 2^{\circ}$ do art. 36 a 42 da Lei 9.394, de 20 de dezembro de 1996, que estabelece as diretrizes e bases da educação nacional. Brasília, DF, 17 de abril 1997.

19. BRASIL. Decreto $\mathrm{n}^{\circ}$. 3.048, de 06 de maio de 1999. Aprova o Regulamento da Previdência Social, e dá outras providências. Brasília: Congresso Nacional, 06 de maio 1999. 
20. CARREIRO, G. S. P.; FERREIRA FILHA, M. de O.; LAZARTE, R.; SILVA, A. O.; DIAS, M. D. O processo de adoecimento mental do trabalhador da estratégia saúde da família. Rev. Eletr. Enf., Goiânia, v. 15, n. 1, p. 146-155, 2013.

21. CEBRIÀ-ANDREU, J. Comentario: el síndrome de desgaste profesional como problema de salud pública. Gac Sanit, Barcelona, v. 19, n. 6, p. 463-470, 2005.

22. COFEN. Resolução $\mathrm{n}^{0}$. 276/2003. Regula a concessão de inscrição provisória ao auxiliar de enfermagem. Rio de Janeiro, 16 de jun 2003.

23. CONASS. Conselho Nacional de Secretarias de Saúde. Assistência de Média e Alta Complexidade no SUS/Conselho Nacional de Secretários de Saúde. Brasília: CONASS, 2007.

24. CORREIA, A. de C. Um instante de reflexão sobre o homem e o trabalho. Cadernos de Pesquisas em Administração, São Paulo, v. 1, n. 11, p. 12-17, 2000.

25. CUMMINGS, S. R.; STWART, A.; RULLEY, S. B. Elaboração de questionários e instrumentos de colet a de dados. In: HULLEY, S. G. et al. Delineando a pesquisa clínica. Uma abordagem epidemiológica. Porto Alegre: Artmed, 2003.

26. CURANDI, C. B.; GREINER, B. A.; RAGLAND, D, R.; FISHER, J. M. Burnout and alcohol problems among urban transit operators in San Francisco. Addictive Behaviors, Nova York, v. 28, n. 1, p. 91-109, 2003.

27. DAL PAI, D. Violência no trabalho em pronto socorro: implicações para a saúde mental dos trabalhadores. 2011. 218f. Tese (Doutorado em Enfermagem) Universidade Federal do Rio Grande do Sul, Escola de Enfermagem, Porto Alegre, 2011 .

28. FARIA, J. B. de.; SEIDL, E. M. F. Religiosidade, enfrentamento e bem-estar subjetivo em pessoas vivendo com HIV/AIDS. Psicologia em Estudo, Maringá, v. 11, n. 1, p. 155-164, 2006.

29. FERREIRA, L. R. C.; DE MARTINO, M. M. F. Stress no cotidiano da equipe de enfermagem e sua correlação com o cronótipo. Estudos de Psicologia, Campinas, v. 26, n. 1, p. 65-72, 2009.

30. FOGAÇA, M. de C.; WERTHER, B. de C.; CÍTERO, V. de A.; NOGUEIRAMARTINS, L. A. Fatores que tornam estressante o trabalho de médicos e enfermeiros 
em terapia intensiva pediátrica e neonatal: estudo de revisão bibliográfica. Rev. Bras Ter Intensiva, São Paulo, v. 20, n. 3, p. 261-266, 2008.

31. GIL-MONTE, P. Influencia del gênero sobre el proceso de desarrollo del síndrome de quemarse por el trabajo (burnout) en profesionales de enfermería. Psicologia em Estudo, Maringá, v. 7, n. 1, p. 3-10, 2002.

32. GIL-MONTE, P. R.; CARLOTTO, M. S.; CÂMARA, S. G. Validação da versão brasileira do "Cuestionario para la evaluación del síndrome de quemarse por el trabajo". Rev Saúde Pública, São Paulo, v. 44, n.1, p. 140-147, 2010.

33. GRASSI-OLIVEIRA, R.; STEIN, L. M.; PEZZI, J. C. Tradução e validação de conteúdo da versão em português do Childhood Trauma Questionnaire. Rev Saúde Pública, São Paulo, v. 40, n. 2, p. 249-255, 2006.

34. HAHNMARY, K.; CARLOTTO, S. The burnout syndrome in monitors that act in a foundation of special protection. Revista Diversitas - Perspectivas em Psicologia, Bogotá, v. 4, n. 1, p. 53-62, 2008.

35. HEGADOREN, K. M.; LASIUK, G. C.; COUPLAND, J. Posttraumatic stress disorder part III: health effects of interpersonal violence among women. Perspectives in Psychiatric Care, v. 42, n. 3, p. 163-173, 2006.

36. HERNÁNDEZ ZAMORA, G. L.; CASTEJÓN, E. O; FERNÁNDEZ, I. I. Estar quemado (burnout) y su relación com el afrontamiento. International Journal of Clinical and Health Psychology, Espanha, v. 4, n. 2, p. 323-336, 2004.

37. IGNATTI, C. Sofrimento psíquico de enfermeiros - um olhar mitológico. Revista Científica Integrada, Guarujá, v. 1, n. 1, p. 1-12, 2012.

38. JODAS, D. A.; HADDAD, M. do C. L. Síndrome de burnout em trabalhadores de enfermagem de um pronto socorro de hospital universitário. Acta Paul Enferm, São Paulo, v. 22, n. 2, p. 192-197, 2009.

39. KEBIAN, L. V. A.; FURTADO, C. M. S. C.; PAULinO, E. de F. R. A síndrome de burnout nos estudos de enfermagem: uma revisão bibliográfica. Revista Corpus et Scientia, Rio de Janeiro, v. 6, n. 2, p. 51-61, 2010.

40. KINRYS, G.; WYGANT, L. E. Anxiety disorders in women: does gender matter to treatment? Rev Bras Psiquiatr, São Paulo, v. 27, n. 2, p. 543-550, 2005. 
41. LAAL, M.; ALIRAMAIE, N. Nursing and Coping With Stress. International Journal of Collaborative Research on Internal Medicine \& Public Health, v. 2, n. 5, p. 168181, maio 2010.

42. LAUTERT, L. O desgaste professional do enfermeiro. 1995. 275f. Tese (Doutorado em Psicologia) - Universidade Pontifícia de Salamanca, Faculdade de Psicologia, Salamanca, 1995.

43. LIMA, F. D.; BUUNK, A. P.; ARAÚJO, M. B. J.; CHAVES, J. G. M.; MUNIZ, D. L. O.; QUEIROZ, L. B. de. Síndrome de burnout em residentes da Universidade Federal de Uberlândia - 2004. Revista Brasileira de Educação Médica, Rio de Janeiro, v. 31, n. 2, p. 137-146, 2007.

44. LIPP, M. E. N.; TANGARELLI, M. S. Stress e qualidade de vida em magistrados da Justiça do Trabalho: diferenças entre homens e mulheres. Psicologia: Reflexão e Crítica, Rio Grande do Sul, v. 15, n. 3, p. 537-548, 2002.

45. LORENZ, V. R.; BENATTI, M. C. C.; SABINO, M. O. Burnout and stress among nurses in a University Tertiary Hospital. Rev. Latino-Am. Enfermagem, Ribeirão Preto, v. 18, n. 6, p. 1084-1091, 2010.

46. MAGNABOSCO, G.; GOULART, C. B.; HADDAD, M. do C. L.; VANNUCHI, M. T. O.; DALMAS, J. C. Síndrome de Burnout em trabalhadores de um hospital público de média complexidade. REME, Belo Horizonte, v. 13, n. 4, p. 506-514, 2009.

47. MARINHO, R. de C. Estresse ocupacional, estratégias de enfrentamento e síndrome de burnout: um estudo em hospital privado. 2005. 120f. Dissertação (Mestrado em Gestão e Desenvolvimento Regional) - Departamento de Economia, Contabilidade e Administração, Universidade de Taubaté, Taubaté, 2005.

48. MARTÍNEZ, O. F.; CABRERA, C. H.; TAPIA, A. M.; SUÁREZ, S. M.; GARCÍA, B. G. del R. Burnout among resident physicians Who work duty shifts in the emergency department. Emergencias, Rio Grande do Sul, v. 19, p. 116-121, 2007.

49. MARTINS, C. M. S.; TOFOLI, S. M. de C.; BAES, C. V. W.; JURUENA, M. Analysis of the occurrence of early life stress in adult psychiatric patients: a systematic review. Psychology \& Neuroscience, Brasília, v. 4, n. 2, p. 219-227, 2011.

50. MASLACH, C.; JACKSON, S. E. The measurement of experienced burnout. Journal of Occupational Behaviour, v. 2, n. 1, p. 99-113, 1981. 
51. MASLACH, C., \& JACKSON, S. E. The role of sex and family variables in burnout. Sex Roles, v. 12, n. 7, p. 837-851, 1985.

52. MASLACH, C.; SCHAUfEli, W. B.; LEITER, M. P. Job Burnout. Annu. Rev. Psychol., Califórnia, v. 52, p. 397-422, 2001.

53. MASLACH, C. Job burnout: new directions in research and intervention. Sage Publications, Nova York, v. 12, n. 5, p. 189-92, 2003.

54. MAZON, V.; CARLOTTO, M. S.; CÂMARA, S. Síndrome de Burnout e estratégias de enfrentamento em professores. Arquivos Brasileiros de Psicologia, Rio de Janeiro, v. 60, n. 1, p. 55-66, 2008.

55. MEARNS, J.; CAIN, J. E. Relationships between teacher's occupational stress and their burnout and distress: roles of coping and negative mood regulation expectancies. Anxiety, Stress e Coping, v. 16, n. 1, p. 71-82, 2003.

56. MENDES, A. M. B. Valores e vivências de prazer-sofrimento no contexto organizacional. 1999. 306f. Tese (Doutorado em Psicologia) - Universidade de Brasília, Instituto de Psicologia, Brasília, 1999.

57. MENEGÁZ, F. D. L. Características da incidência de Burnout em pediatras de uma organização hospitalar pública. 2004. 94f. Dissertação (Mestre em Psicologia) Universidade Federal de Santa Catarina, Centro de Filosofia e Ciências Humanas, Florianópolis, 2004.

58. MENEGHINI, F.; PAZ, A. A.; LAUTERT, L. Fatores ocupacionais associados aos componentes da síndrome de burnout em trabalhadores de enfermagem. Texto Contexto Enferm, Florianópolis, v. 20, n. 2, p. 255-233, 2011.

59. MIQUELIN, J. D. L.; CARVALHO, C. B. O.; GIR, E.; PELÁ, N. T. R. Estresse nos profissionais de enfermagem que atuam em uma unidade de pacientes portadores de HIV-AIDS. J. brás. Doenças Sex. Transm, Rio de Janeiro, v. 16, n. 3, p. 24-31, 2004.

60. MOREIRA, D. de S.; MAGNAGO, R. F.; SAKAE, T. M.; MAGAJEWSKI, F. R. L. Prevalência da syndrome de burnout em trabalhadores de enfermagem de um hospital de grande porte da Região Sul do Brasil. Cad. Saúde Pública, Rio de Janeiro, v. 25, n. 7, p. 1559-1568, jul, 2009. 
61. MUÑOZ, C. F. M.; GUTIÉRREZ, D. C. P. Relación entre lãs estratégias de afrontamento y el síndrome de burnout em docentes de básica primaria y secundaria pertenecientes a uma institución educativa privada del município de Cartago (Colombia). Psicogente, Barranquilla, v. 14, n. 26, p. 398-402, 2011.

62. MUROFUSE, N. T.; ABRANCHES, S. S.; NAPOLEÃO, A. A. Reflections on stress and burnout and their relationship with nursing. Rev. Latino-am Enfermagem, Ribeirão Preto, v. 13, n. 2, p.255-261, mar./abr. 2005.

63. NIGHTINGALE, F. Notes on nursing: that it is, and that it is not. London: Churchill Livingstone, 1980.

64. PAFARO, R. C.; MARTINO, M. M. F. de. Estudo do estresse do enfermeiro com dupla jornada de trabalho em um hospital de oncologia pediátrica de Campinas. Rev Esc Enferm USP, São Paulo, v. 38, n. 2, p. 152-60, 2004.

65. PEREIRA, V. M.; SILVA, C. E. S. Relação entre o estresse profissional e o ciclo motivacional na qualidade de vida no trabalho: estudo de caso. In: XI SIMPEP, 11, 2004, Bauru. XI SIMPEP. Bauru, 2004.

66. PEREIRA, Z.; SAVIR, J. H.; CALAFANGE, P.; COSTA, M. T. P.; RIBEIRO, A. M. Síndrome de burnout em profissionais da equipe de enfermagem do hospital infantil Varela Santiago/RN. Neurobiologia, Recife, v. 72, n. 4, p. 47-55, 2009.

67. POLIT, D. F.; BECK, C. T.; HUNGLER, B. P. Coleta dos dados de pesquisa Avaliação da mensuração e da qualidade dos dados. In: Ana Thorell. Fundamentos de pesquisa em enfermagem: métodos, avaliação e utilização. 5. ed. Porto Alegre: Artmed, 2004.

68. PRETO, V. A.; PEDRÃO, L. J. O estresse entre enfermeiros que atuam em unidade de terapia intensiva. Rev. Esc. Enferm. USP, São Paulo, v. 43, n. 4, p. 841-848, 2009.

69. RAMIREZ A. J.; GRAHAM, J.; RICHARDS, M. A.; CULL, A.; GREGORY, W. M.; LEANING, M. S.; SNASHALL, D. C.; TIMOTHY. A.R. Burnout and psychiatric disorder among cancer clinicians. British Journal of Cancer, Londres, v. 71, n. 6, p. 1263-1269, 1995.

70. RENNÓ JR, J.; DEMARQUE, R.; RIBEIRO LOBO, H.; CAVALSAN, J. P.; SILVA, A. G. da. Saúde mental da mulher: transtornos psiquiátricos relacionados ao ciclo reprodutivo. Revista debates em Psiquiatria, Rio de Janeiro, v. 2, n. 6, p. 6-13, Nov/dez, 2012. 
71. RICHARDSON, R. J. Pesquisa social: métodos e técnicas. São Paulo: Atlas, 2012.

72. RITTER, R. S.; STUMM, E. M. F.; KIRCHER, R. M. Análise de burnout em profissionais de uma unidade de emergência de um hospital geral. Revista Eletrônica de Enfermagem, Goiânia, v. 11, n. 2, p. 236-48, 2009.

73. RODRIGUES, A. B. Burn out e estilos de coping em enfermeiros que assistem pacientes oncológicos. 2006. 169f. Tese (Doutorado em Enfermagem) - Universidade de São Paulo, Escola de Enfermagem, São Paulo, 2006.

74. SAlOMÉ, G. M.; MARTINS, M. F. M. S.; ESPÓSITO, V. H. C. Sentimentos vivenciados pelos profissionais de enfermagem que atuam em unidade de emergência. Rev. Bras. Enferm. Brasília, v. 62, n. 6, p. 856-862, nov./dez. 2009.

75. SANTANA, J. J. R. A. de; ZANIN, C. R.; MANIGLIA, J. V. Pacientes com câncer: enfrentamento, rede social e apoio social. Paidéia, Ribeirão Preto, v. 18, n. 40, p. 371 384, 2008.

76. SANTOS, A. F.; ALVES JUNIOR, A. Estresse e estratégias de enfrentamento em mestrandos de ciências da saúde. Psicologia: Reflexão e Crítica, Rio Grande do Sul, v. 20, n. 1, p. 104-113, 2007.

77. SANTOS, E. M. dos; ARAÚJO, T. M. de. Processo de trabalho e saúde dos trabalhadores no Hospital Universitário Professor Edgard Santos. Rev. Baiana Saúde Pública, Salvador, v. 27, n. 2, p. 155-168, 2003.

78. SANTOS, F. E. dos; ALVES, J. A.; RODRIGUES, A. B. Síndrome de burnout em enfermeiros atuantes em uma unidade de terapia intensiva. Einstein, São Paulo, v. 7, n. 1, p. 59-63, 2009.

79. SCHER, C. D.; STEIN, M. B.; ASMUNDSON, G. J. G.; MCCREARY, D. R.; FORDE, D. R. The childhood trauma questionnaire in a community sample: psychometric properties and normative data. Journal of Traumatic Stress, v. 14, n. 4, p. 843-57, 2001.

80. SCHWARTZMANN, L. Estrés laboral, síndrome de desgaste (quemado), depresión: estamos hablando de ló mismo? Ciência e Trabajo. Montevideo, v. 6, n. 14, p. 174184, out./dez., 2004. 
81. SEIDL, E. M. F.; TRÓCCOLI, B. T.; ZANNON, C. M. L. C. Análise fatorial de uma medida de estratégias de enfrentamento. Psicologia Teoria e Pesquisa. Brasília, v. 17, n. 3, p. 225-234, set./dez. 2001.

82. SELYE, H. Stress and the general adaptation syndrome. British Medical Journal, London, v. 1, n. 1, p. 1383-1392, 1950.

83. SILVA, D. M. P. P. da.; MARZIALE, M. H. P. Absenteísmo de trabalhadores de enfermagem em um hospital universitário. Rev. Latino-am enfermagem, Ribeirão Preto, v. 8, n. 5, p. 44-51, 2000.

84. SILVA, G. Processo de enfrentamento no período pós-tratamento do câncer de mama. 2005. 151f. Dissertação (Mestrado em Psicologia) - Universidade de São Paulo, Faculdade de Filosofia, Ciência e Letras, Ribeirão Preto, 2005.

85. SILVA, J. L. L. da. Estresse e transtornos mentais comuns em trabalhadores de enfermagem. 2007. 184f. Dissertação (Mestrado em Enfermagem) - Universidade Federal Estado do Rio de Janeiro, Centro de Ciências Biológicas e da Saúde, Rio de Janeiro, 2007.

86. SILVA, J. L. L.; MELO, E. C. P. Estresse e implicações para o trabalhador de enfermagem. Informe-se em promoção da saúde. Rio de Janeiro, v.2, n. 2, p. 16-18. 2006.

87. SILVA, N. N. Amostragem probabilística. São Paulo: EDUSP, 2001.

88. TAMAYO, R. M. Burnout: implicações das fontes organizacionais de desajuste indivíduo-trabalho em profissionais de enfermagem. Reflexão e Crítica, Rio Grande do Sul, v. 22, n. 3, p. 474-482, 2008.

89. TELLES, K. K. P.; HASHIMOTO, F. A saúde mental do enfermeiro: um olhar psicanalítico sobre o cuidador. In: SEMINÁRIO DO TRABALHO, 6, 2008, Marília.

90. TELleS, S. H. Sindrome de Burnout em Agentes Comunitários de Saúde e estratégias de enfrentamento. 2008. 147f. Dissertação (Mestrado em Enfermagem) Universidade de São Paulo, Escola de Enfermagem, Ribeirão Preto, 2008.

91. TOWNSEND, M. C. Enfermagem Psiquiátrica: conceitos de cuidados. 3. ed. Rio de Janeiro: Guanabara, 2002. 
92. TRIGO, T. R.; TENG, C. T.; HALlAK, J. E. C. Síndrome de burnout ou estafa profissional e os transtornos psiquiátricos. Rev. Psiq. Clín, São Paulo, v. 34, n. 5, p. 223-233, 2007.

93. TRINDADE, L. de L. O estresse laboral da equipe saúde da família: implicações para saúde do trabalhador. 2007. 105f. Dissertação (Mestrado em Enfermagem) Universidade Federal do Rio Grande do Sul, Escola de Enfermagem, Rio Grande do Sul, 2007.

94. TRINDADE, L. de L.; LAUTERT, L.; BECK, C. L. C. Coping mechanisms used by non-burned out and burned out workers in the family health strategy. Rev. Latino-am Enfermagem, Ribeirão Preto, v. 17, n. 5, p. 607-612, 2009.

95. VIEIRA, I.; RAMOS, A.; MARTINS, D.; BUCASIO, E.; BENEVIDES-PEREIRA, A. M.; FIGUIERA, I.; JARDIM, S. Síndrome de Burnout na clínica psiquiátrica: relato de um caso. Rev. Psiquiatr, Rio Grande do Sul, v. 28, n. 3, p. 352-356, set./dez. 2006.

96. VILLANO, C. L.; CLELAND, C.; ROSENBLUM, A.; FONG, C.; NUTTBROCK, L.; MARTHOL, M.; WALLACE, J. Psychometric utility of the childhood trauma questionnaire with female street-based sex workers. J Trauma Dissociation, v. 5, n. 3, p. 33-41, 2004.

97. WALTZ, C. F.; STRICKLAND, O. L.; LENZ, E. R. Measurement in nursing research. 2. ed. Philadelphia: Davis Company, 2005. 
A-Parecer do Comitê de Ética em Pesquisa da EERP

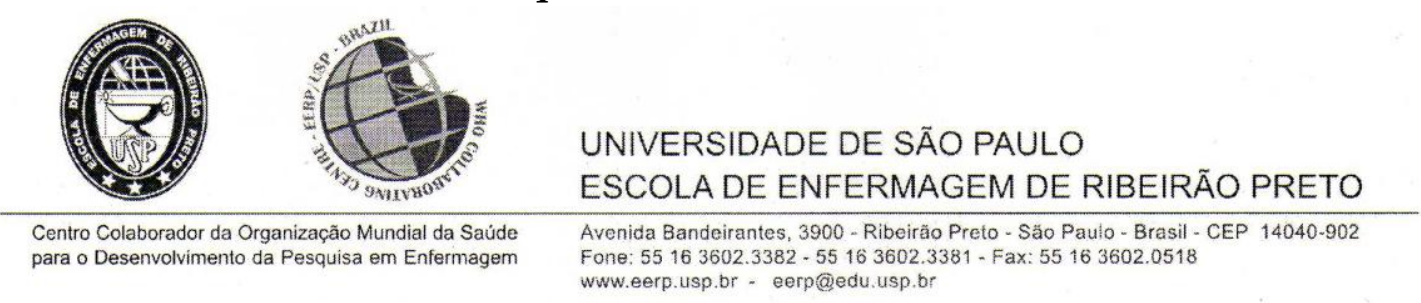

COMITÊ DE ÉTICA EM PESQUISA DA EERPIUSP

Of.CEP-EERP/USP - 086/2012

Ribeirão Preto, 17 de maio de 2012

Prezada Senhora,

Comunicamos que o projeto de pesquisa, abaixo especificado, foi analisado e considerado APROVADO AD REFERENDUM pelo Comitê de Ética em Pesquisa da Escola de Enfermagem de Ribeirão Preto da Universidade de São Paulo, em 17 de maio de 2012.

Protocolo CAAE: 01658912.1 .0000 .5393

Projeto: Estresse, esgotamento profissional e estratégias de enfrentamento entre profissionais de saúde.

Pesquisadores: Lucilene Cardoso

Em atendimento à Resolução 196/96, deverá ser encaminhado ao CEP o relatório final da pesquisa e a publicação de seus resultados, para acompanhamento, bem como comunicada qualquer intercorrência ou a sua interrupção.

\section{Atenciosamente,

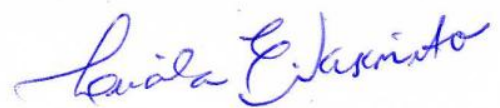 \\ Profa. Dra. Lucila Castanheira Nascimento Coordenadora do CEP-EERP/USP}

IIma. Sra.

Profa. Dra. Lucilene Cardoso

Departamento de Enfermagem Psiquiátrica e Ciências Humanas

Escola de Enfermagem de Ribeirão Preto - USP 


\section{B - Parecer do Comitê de Ética em Pesquisa do HCFMRP}

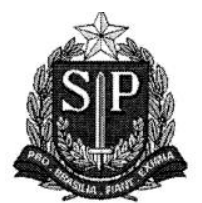

HOSPITAL DAS CLÍNICAS DA FACULDADE DE MEDICINA DE RIBEIRÃO PRETO DA UNIVERSIDADE DE SÃO PAULO

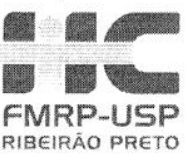

Ribeirão Preto, 31 de maio de 2012

Projeto de pesquisa: "Estresse, esgotamento profissional e estratégias de enfrentamento entre profissionais de saúde"

Pesquisadores responsáveis: Profa. Dra. Lucilene Cardoso

Instituição Proponente: Escola de Enfermagem de Ribeirão Preto-USP.

"O CEP do HC e da FMRP-USP concorda com o parecer ético emitido pelo CEP da Instituição Proponente, que cumpre as Resoluções Éticas Brasileiras, em especial a Resolução CNS 196/96. Diante disso, o HCFMRP-USP, como instituição co-participante do referido projeto de pesquisa, está ciente de suas co-responsabilidades e de seu compromisso no resguardo da segurança e bemestar dos sujeitos desta pesquisa, dispondo de infra-estrutura necessária para a garantia de tal segurança e bem-estar".

Ciente e de acordo:
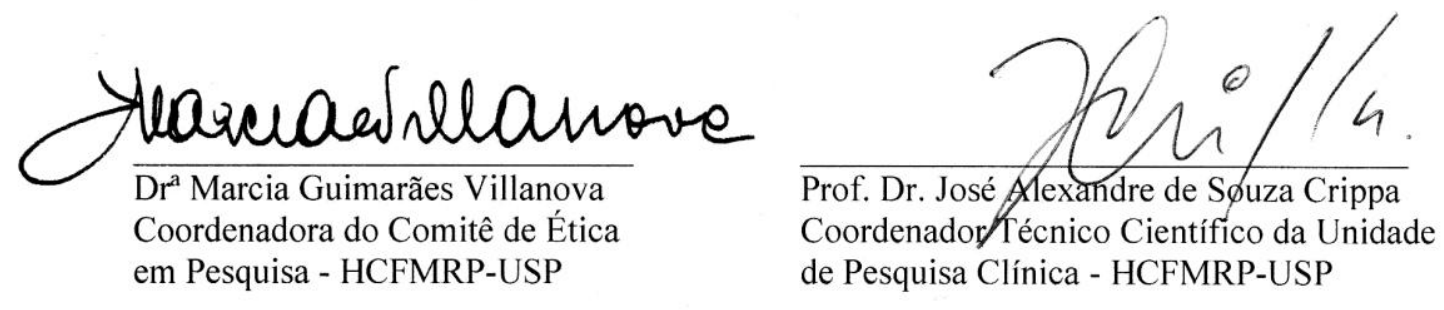

Campus Universitário - Monte Alegre 14048-900 Ribeirão Preto SP

Comitê de Ética em Pesquisa do HCRP e FMRP-USP FWA-00002733; IRB-00002186 e Registro SISNEP/CONEP n 4 (016) 3602-2228 www.hcrp.usp.br 
C-Escala de Modos de Enfrentamento dos Problemas - EMEP

\begin{tabular}{|c|c|c|c|c|c|}
\hline \multirow[b]{2}{*}{ AFIRMAÇÕES } & \multicolumn{5}{|c|}{ FATORES } \\
\hline & $\begin{array}{l}1-\mathrm{Eu} \\
\text { nunca } \\
\text { faço } \\
\text { isso }\end{array}$ & $\begin{array}{c}2-\mathrm{Eu} \\
\text { faço } \\
\text { isso } \\
\text { um } \\
\text { pouco }\end{array}$ & $\begin{array}{l}3 \text { - Eu } \\
\text { faço } \\
\text { isso às } \\
\text { vezes }\end{array}$ & $\begin{array}{l}4-\mathrm{Eu} \\
\text { faço } \\
\text { isso } \\
\text { muito }\end{array}$ & $\begin{array}{l}5 \text { - Eu } \\
\text { faço } \\
\text { isso } \\
\text { sempre }\end{array}$ \\
\hline 1. Eu levo em conta o lado positivo das coisas. & & & & & \\
\hline 2. Eu me culpo. & & & & & \\
\hline $\begin{array}{l}\text { 3. Eu me concentro em alguma coisa boa que pode vir desta } \\
\text { situação. }\end{array}$ & & & & & \\
\hline 4. Eu tento guardar meus sentimentos para mim mesmo. & & & & & \\
\hline 5. Procuro um culpado para a situação. & & & & & \\
\hline 6. Espero que um milagre aconteça. & & & & & \\
\hline 7. Peço conselho a um parente ou a um amigo que eu respeite. & & & & & \\
\hline 8. Eu rezo/oro. & & & & & \\
\hline 9. Converso com alguém sobre como estou me sentindo. & & & & & \\
\hline 10. Eu insisto e luto pelo que eu quero. & & & & & \\
\hline 11. Eu me recuso a acreditar que isto esteja acontecendo. & & & & & \\
\hline $\begin{array}{l}\text { 12. Eu brigo comigo mesmo; eu fico falando comigo mesmo } \\
\text { o que devo fazer. }\end{array}$ & & & & & \\
\hline 13. Desconto em outras pessoas. & & & & & \\
\hline 14. Encontro diferentes soluções para o meu problema. & & & & & \\
\hline 15. Tento ser uma pessoa mais forte e otimista. & & & & & \\
\hline $\begin{array}{l}\text { 16. Eu tento evitar que os meus sentimentos atrapalhem em } \\
\text { outras coisas na minha vida. }\end{array}$ & & & & & \\
\hline 17. Eu me concentro nas coisas boas da minha vida. & & & & & \\
\hline 18. Eu desejaria mudar o modo como eu me sinto. & & & & & \\
\hline 19. Aceito a simpatia e a compreensão de alguém. & & & & & \\
\hline $\begin{array}{l}\text { 20. Demonstro raiva para as pessoas que causaram o } \\
\text { problema. }\end{array}$ & & & & & \\
\hline 21. Pratico mais a religião desde que tenho este problema. & & & & & \\
\hline 22. Eu percebo que eu mesmo trouxe o problema para mim. & & & & & \\
\hline 23. Eu me sinto mal por não ter podido evitar o problema. & & & & & \\
\hline $\begin{array}{l}\text { 24. Eu sei o que deve ser feito e estou aumentando meus } \\
\text { esforços para se bem sucedido. }\end{array}$ & & & & & \\
\hline 25. Eu acho que as pessoas foram injustas comigo. & & & & & \\
\hline $\begin{array}{l}\text { 26. Eu sonho ou imagino um tempo melhor do que aquele em } \\
\text { que estou. }\end{array}$ & & & & & \\
\hline
\end{tabular}




\begin{tabular}{|c|c|c|c|c|c|}
\hline \multirow[b]{2}{*}{ AFIRMAÇÕES } & \multicolumn{5}{|c|}{ FATORES } \\
\hline & $\begin{array}{l}\text { - Eu } \\
\text { nunca } \\
\text { faço } \\
\text { isso }\end{array}$ & $\begin{array}{l}2 \text { - Eu } \\
\text { faço } \\
\text { isso } \\
\text { um } \\
\text { pouco }\end{array}$ & $\begin{array}{l}3 \text { - Eu } \\
\text { faço } \\
\text { isso às } \\
\text { vezes }\end{array}$ & $\begin{array}{l}4 \text { - Eu } \\
\text { faço } \\
\text { isso } \\
\text { muito }\end{array}$ & $\begin{array}{l}5-\mathrm{Eu} \\
\text { faço } \\
\text { isso } \\
\text { sempre }\end{array}$ \\
\hline 27. Tento esquecer o problema todo. & & & & & \\
\hline $\begin{array}{l}\text { 28. Estou mudando e me tornando uma pessoa mais } \\
\text { experiente. }\end{array}$ & & & & & \\
\hline 29. Eu culpo os outros. & & & & & \\
\hline 30. Eu fico me lembrando que as coisas poderiam ser piores. & & & & & \\
\hline $\begin{array}{l}\text { 31. Converso com alguém que possa fazer alguma coisa para } \\
\text { resolver o meu problema. }\end{array}$ & & & & & \\
\hline $\begin{array}{l}\text { 32. Eu tento não agir tão precipitadamente ou seguir minha } \\
\text { primeira ideia. }\end{array}$ & & & & & \\
\hline $\begin{array}{l}\text { 33. Mudo alguma coisa para que as coisas acabem dando } \\
\text { certo. }\end{array}$ & & & & & \\
\hline 34. Procuro me afastar das pessoas em geral. & & & & & \\
\hline $\begin{array}{l}\text { 35. Eu imagino ou tenho desejos sobre como as coisas } \\
\text { poderiam acontecer. }\end{array}$ & & & & & \\
\hline $\begin{array}{l}\text { 36. Encaro a situação por etapa, fazendo uma coisa de cada } \\
\text { vez. }\end{array}$ & & & & & \\
\hline 37. Descubro quem mais é ou foi responsável. & & & & & \\
\hline $\begin{array}{l}\text { 38. Penso em coisas fantásticas ou irreais (como uma } \\
\text { vingança perfeita ou achar muito dinheiro) que me fazem } \\
\text { sentir melhor. }\end{array}$ & & & & & \\
\hline 39. Eu sairei dessa experiência melhor do que entrei nela. & & & & & \\
\hline 40. Eu digo a mim mesmo o quanto já consegui. & & & & & \\
\hline 41. Eu desejaria poder mudar o que aconteceu comigo. & & & & & \\
\hline $\begin{array}{l}\text { 42. Eu fiz um plano de ação para resolver o meu problema e o } \\
\text { estou cumprindo. }\end{array}$ & & & & & \\
\hline $\begin{array}{l}\text { 43. Converso com alguém para obter informações sobre a } \\
\text { situação. }\end{array}$ & & & & & \\
\hline 44. Eu me apego a minha fé para superar esta situação. & & & & & \\
\hline $\begin{array}{l}\text { 45. Eu tento não fechar portas atrás de mim. Tento deixar em } \\
\text { aberto várias saídas para o problema. }\end{array}$ & & & & & \\
\hline
\end{tabular}


D-Maslach Burnout Inventory - MBI

\begin{tabular}{|c|c|c|c|c|c|}
\hline AFIRMAÇÕES & 1 & 2 & 3 & 4 & 5 \\
\hline Com que frequência sente isto? & Nunca & Raramente & $\begin{array}{l}\text { Algumas } \\
\text { vezes }\end{array}$ & Frequentemente & Sempre \\
\hline $\begin{array}{l}\text { 1. Eu me sinto emocionalmente exausto pelo } \\
\text { meu trabalho. }\end{array}$ & & & & & \\
\hline $\begin{array}{l}\text { 2. Eu me sinto esgotado ao final de um dia de } \\
\text { trabalho. }\end{array}$ & & & & & \\
\hline $\begin{array}{l}\text { 3. Eu me sinto cansado quando me levanto de } \\
\text { manhã e tenho que encarar outro dia de } \\
\text { trabalho. }\end{array}$ & & & & & \\
\hline $\begin{array}{l}\text { 4. Eu posso entender facilmente o que sentem } \\
\text { os meus pacientes acerca das coisas que } \\
\text { acontecem no dia a dia. }\end{array}$ & & & & & \\
\hline $\begin{array}{l}\text { 5. Eu sinto que eu trato alguns dos meus } \\
\text { pacientes como se eles fossem objetos. }\end{array}$ & & & & & \\
\hline $\begin{array}{l}\text { 6. Trabalhar o dia inteiro é realmente um } \\
\text { grande esforço para mim. }\end{array}$ & & & & & \\
\hline $\begin{array}{l}\text { 7. Eu trato de forma adequada os problemas dos } \\
\text { meus pacientes. }\end{array}$ & & & & & \\
\hline 8. Eu me sinto esgotado com meu trabalho. & & & & & \\
\hline $\begin{array}{l}\text { 9. Eu sinto que estou influenciando } \\
\text { positivamente a vida de outras pessoas através } \\
\text { do meu trabalho. }\end{array}$ & & & & & \\
\hline $\begin{array}{l}\text { 10. Eu sinto que me tornei mais insensível com } \\
\text { as pessoas desde que comecei este trabalho. }\end{array}$ & & & & & \\
\hline $\begin{array}{l}\text { 11. Eu sinto que este trabalho está me } \\
\text { endurecendo emocionalmente. }\end{array}$ & & & & & \\
\hline 12. Eu me sinto muito cheio de energia. & & & & & \\
\hline 13. Eu me sinto frustrado com o meu trabalho. & & & & & \\
\hline $\begin{array}{l}\text { 14. Eu sinto que estou trabalhando demais no } \\
\text { meu emprego. }\end{array}$ & & & & & \\
\hline $\begin{array}{l}\text { 15. Eu não me importo realmente com o que } \\
\text { acontece com alguns dos meus pacientes. }\end{array}$ & & & & & \\
\hline $\begin{array}{l}\text { 16. Trabalhar diretamente com pessoas me } \\
\text { deixa muito estressado. }\end{array}$ & & & & & \\
\hline $\begin{array}{l}\text { 17. Eu posso criar facilmente um ambiente } \\
\text { tranquilo com os meus pacientes. }\end{array}$ & & & & & \\
\hline $\begin{array}{l}\text { 18. Eu me sinto estimulado depois de trabalhar } \\
\text { lado a lado com os meus pacientes. }\end{array}$ & & & & & \\
\hline $\begin{array}{l}\text { 19. Eu tenho realizado muitas coisas } \\
\text { importantes neste trabalho. }\end{array}$ & & & & & \\
\hline $\begin{array}{l}\text { 20. No meu trabalho, eu me sinto como se } \\
\text { estivesse no final do meu limite. }\end{array}$ & & & & & \\
\hline $\begin{array}{l}\text { 21. No meu trabalho, eu lido com os problemas } \\
\text { emocionais com calma. }\end{array}$ & & & & & \\
\hline $\begin{array}{l}\text { 22. Eu sinto que os pacientes me culpam por } \\
\text { alguns dos seus problemas. }\end{array}$ & & & & & \\
\hline
\end{tabular}




\section{E - Childhood Trauma Questionnaire - CTQ}

\begin{tabular}{|c|c|c|c|c|c|}
\hline Enquanto eu crescia... & Nunca & $\begin{array}{c}\text { Poucas } \\
\text { Vezes }\end{array}$ & $\begin{array}{c}\text { Às } \\
\text { vezes }\end{array}$ & $\begin{array}{c}\text { Muitas } \\
\text { vezes }\end{array}$ & Sempre \\
\hline \multicolumn{6}{|l|}{ 1. Eu não tive o suficiente para comer. } \\
\hline \multicolumn{6}{|l|}{ 2. Eu soube que havia alguém para me cuidar e proteger. } \\
\hline \multicolumn{6}{|l|}{$\begin{array}{l}\text { 3. As pessoas da minha família me chamaram de coisas do } \\
\text { tipo "estúpido (a)", "preguiçoso (a)" ou "feio (a)". }\end{array}$} \\
\hline \multicolumn{6}{|l|}{$\begin{array}{l}\text { 4. Meus pais estiveram muito bêbados ou drogados para } \\
\text { poder cuidar da família. }\end{array}$} \\
\hline \multicolumn{6}{|l|}{$\begin{array}{l}\text { 5. Houve alguém na minha família que ajudou a me sentir } \\
\text { especial ou importante. }\end{array}$} \\
\hline \multicolumn{6}{|l|}{ 6. Eu tive que usar roupas sujas. } \\
\hline \multicolumn{6}{|l|}{ 7. Eu me senti amado (a). } \\
\hline \multicolumn{6}{|l|}{$\begin{array}{l}\text { 8. Eu achei que meus pais preferiam que eu nunca tivesse } \\
\text { nascido. }\end{array}$} \\
\hline \multicolumn{6}{|l|}{$\begin{array}{l}\text { 9. Eu apanhei tanto de alguém da minha família que tive de } \\
\text { ir ao hospital ou consultar um médico. }\end{array}$} \\
\hline \multicolumn{6}{|l|}{$\begin{array}{l}\text { 10. Não houve nada que eu quisesse mudar na minha } \\
\text { família. }\end{array}$} \\
\hline \multicolumn{6}{|l|}{$\begin{array}{l}\text { 11. Alguém da minha família me bateu tanto que me deixou } \\
\text { com machucados roxos. }\end{array}$} \\
\hline \multicolumn{6}{|l|}{$\begin{array}{l}\text { 12. Eu apanhei com cinto, vara, corda ou outras coisas que } \\
\text { machucaram. }\end{array}$} \\
\hline \multicolumn{6}{|l|}{ 13. As pessoas da minha família cuidavam umas das outras. } \\
\hline \multicolumn{6}{|l|}{$\begin{array}{l}\text { 14. Pessoas da minha família disseram coisas que me } \\
\text { machucaram ou me ofenderam. }\end{array}$} \\
\hline \multicolumn{6}{|l|}{ 15. Eu acredito que fui maltratado (a) fisicamente. } \\
\hline \multicolumn{6}{|l|}{ 16. Eu tive uma ótima infância. } \\
\hline \multicolumn{6}{|l|}{$\begin{array}{l}\text { 17. Eu apanhei tanto que um professor, vizinho ou médico } \\
\text { chegou a notar. }\end{array}$} \\
\hline \multicolumn{6}{|l|}{ 18. Eu senti que alguém da minha família me odiava. } \\
\hline \multicolumn{6}{|l|}{ 19. As pessoas da minha família se sentiam unidas. } \\
\hline \multicolumn{6}{|l|}{$\begin{array}{l}\text { 20. Tentaram me tocar ou me fizeram tocar de uma maneira } \\
\text { sexual. }\end{array}$} \\
\hline \multicolumn{6}{|l|}{$\begin{array}{l}\text { 21. Ameaçaram me machucar ou contar mentiras sobre mim } \\
\text { se eu não fizesse algo sexual. }\end{array}$} \\
\hline \multicolumn{6}{|l|}{ 22. Eu tive a melhor família do mundo. } \\
\hline \multicolumn{6}{|l|}{$\begin{array}{l}\text { 23. Tentaram me forçar a fazer algo sexual ou assistir coisas } \\
\text { sobre sexo. }\end{array}$} \\
\hline \multicolumn{6}{|l|}{ 24. Alguém me molestou. } \\
\hline \multicolumn{6}{|l|}{ 25. Eu acredito que fui maltratado (a) emocionalmente. } \\
\hline \multicolumn{6}{|l|}{$\begin{array}{l}\text { 26. Houve alguém para me levar ao médico quando eu } \\
\text { precisei. }\end{array}$} \\
\hline \multicolumn{6}{|l|}{ 27. Eu acredito que fui abusado (a) sexualmente. } \\
\hline 28. Minha família foi uma fonte de força e apoio. & & & & & \\
\hline
\end{tabular}




\section{F-Autorização para uso da EMEP}

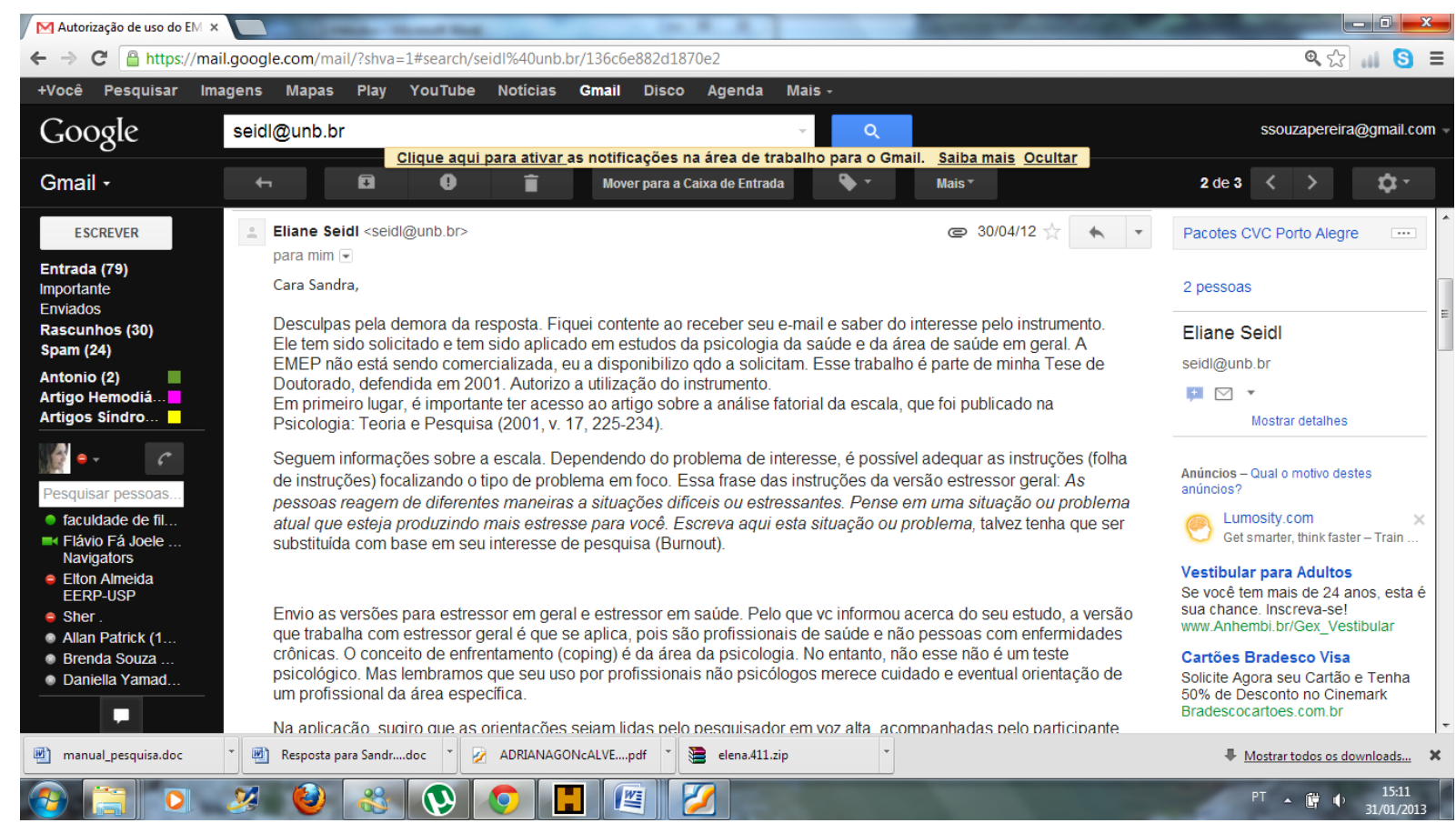




\section{G-Autorização para uso da MBI}

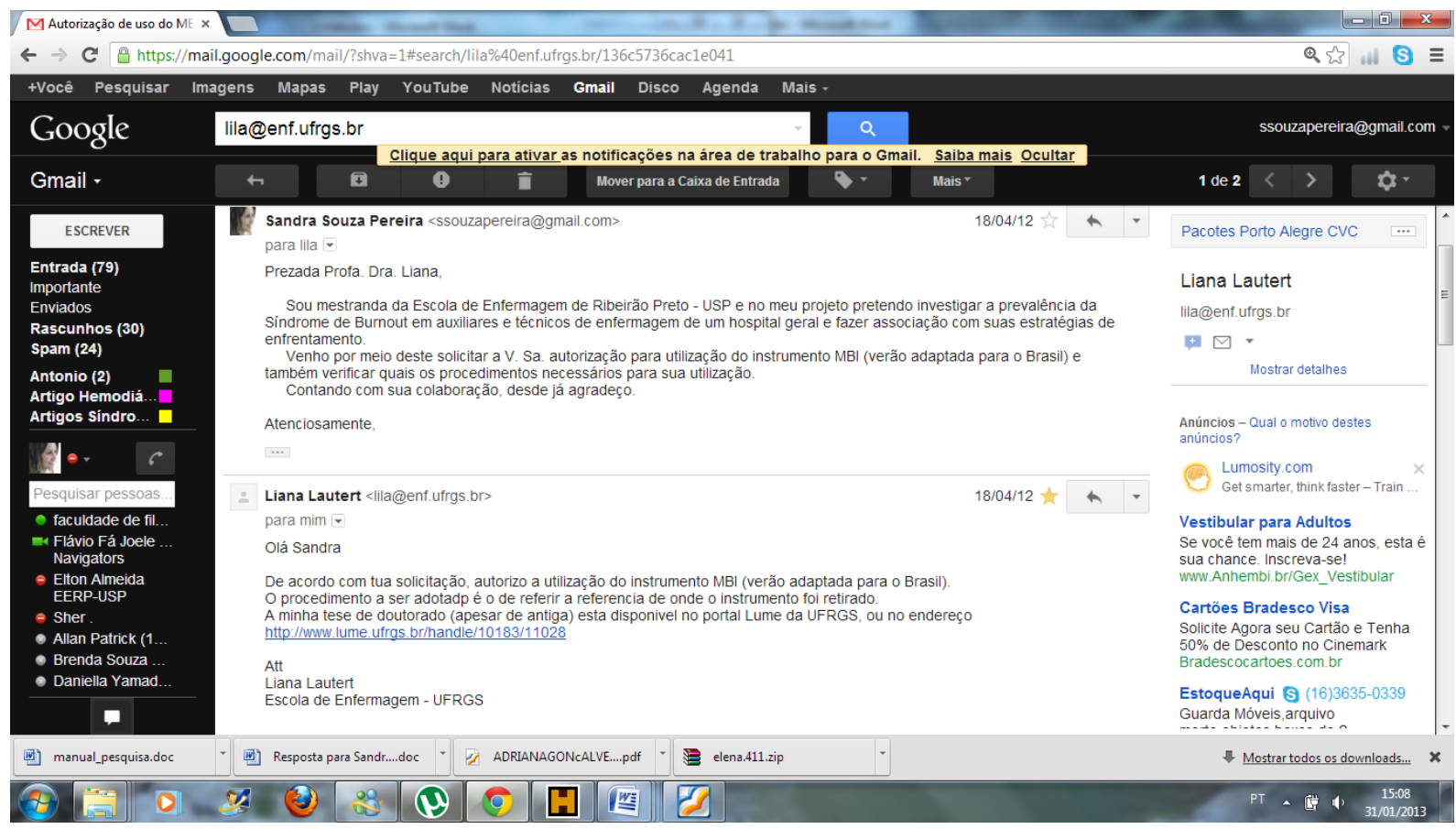


APÊNDICES 


\section{A - Termo de Consentimento Livre e Esclarecido}

Título: "Estresse, Esgotamento Emocional e Estratégias de Enfrentamento entre Profissionais de Saúde". Pesquisadoras: Lucilene Cardoso, Edilaine Cristina da Silva Gherardi Donato, Sandra de Souza Pereira e Carla Araújo Bastos Teixeira.

Caro participante:

Gostaria de convidá-lo a participar como voluntário da pesquisa intitulada "Estresse, Esgotamento Profissional e Estratégias de Enfrentamento entre Profissionais de Saúde", vinculada ao Programa de PósGraduação em Enfermagem Psiquiátrica da Escola de Enfermagem de Ribeirão Preto da Universidade de São Paulo- EERP/USP.

O objetivo desse trabalho é analisar a prevalência de estresse e esgotamento profissional e identificar estratégias de enfrentamento entre técnicos e auxiliares de enfermagem e a ocorrência de estresse precoce. Caso aceite participar você não terá riscos nem benefícios diretos, não haverá ônus, assim como não haverá remuneração financeira pela sua participação nesse estudo. Sua participação contribuirá para reflexões e avanços no conhecimento científico sobre esta temática.

Caso aceite participar, todos os procedimentos da pesquisa irão realizar-se de forma a garantir sua privacidade. Você irá responder algumas perguntas sobre: dados sociodemográficos, modos de enfrentamento dos problemas, estresse e esgotamento profissional. O tempo de preenchimento destes instrumentos será de aproximadamente 50 minutos. O preenchimento dos instrumentos será em local reservado no serviço em que você trabalha, após os esclarecimentos realizados pelas pesquisadoras do projeto de pesquisa.

Os dados coletados, pelos instrumentos, serão utilizados anonimamente para o relatório final da pesquisa e publicação dos resultados em periódicos científicos, seu nome não será divulgado em qualquer fase da pesquisa.

Sua participação será voluntária e você poderá recusar-se a participar ou retirar seu consentimento, ou ainda descontinuar sua participação, em qualquer momento da pesquisa, se assim o preferir, sem penalização ou prejuízo algum. Você também terá direito a ser esclarecido sobre o que desejar em qualquer momento da pesquisa.

Caso sinta-se sensibilizado de alguma maneira com as perguntas que serão feitas, ou caso seja identificada pelos pesquisadores alguma situação preocupante em relação a sua saúde, sua demanda será prontamente acolhida pelos pesquisadores e será realizada uma reflexão conjunta acerca de quais procedimentos precisarão ser tomados em consideração a seus sentimentos e necessidades.

Este termo será preenchido e assinado pelos pesquisadores e por você em duas vias. Uma delas ficará com você.

Caso necessite de esclarecimentos ou tenha alguma duvida você poderá entrar em contato com qualquer uma das pesquisadoras que assinam abaixo:

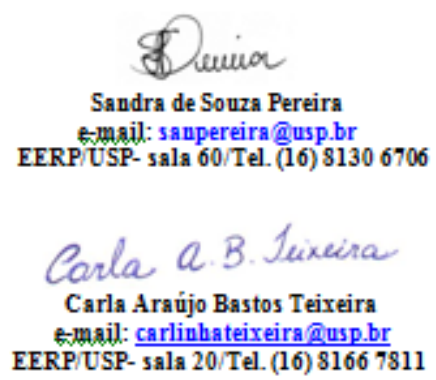

Consentimento pós-esclarecido

$\mathrm{Eu}$, $\mathrm{RG}$

confirmo que as minha participação também foram esclarecidas. Eu li e compreendi este termo de consentimento. Portanto, eu concordo em dar meu consentimento para participar como voluntário dessa pesquisa.

Ribeirão Preto, 1

Assinatura do participante 


\section{B - Questionário sóciodemográfico}

\section{Data da coleta}

1. Número do sujeito no banco:

2. Unidade $\mathrm{HC}$ :

3. Sexo: 1. Masculino / 2. Feminino

4. Data de Nascimento?

5. Escolaridade? 1. Fundamental completo / 2. Médio incompleto / 3. Médio completo / 4. Superior incompleto 5. Superior completo

6. Estado Civil? 1. Casado ou com companheiro / 2. Solteiro / 3. Divorciado / 4. Viúvo

7. Religião? 1. Católico / 2. Evangélico / 3. Protestante / 4. Espírita / 5. Agnóstico

8. Qual a sua profissão?

1. Auxiliar de enfermagem / 2. Técnico de enfermagem / 3. Enfermeiro (a)

\section{Cargo que exerce nesse serviço:}

1. Auxiliar de enfermagem / 2. Técnico de enfermagem / 3. Outro Qual:

10. Tempo de serviço no HC:

11. Tempo de serviço na profissão:

12. Possui mais de um vínculo empregatício?

1. Não / 2. Sim - Quantos?

\section{Carga horária de trabalho semanal?}

1. Diurno - Carga horária: 2. Noturno - Carga horária:

14. Você mora com: 1. Família (mãe, pai ou filhos) / 2. Parentes (tios, primos, avós) / 3. República / 4. Sozinho / 5. Outros:

15. Número de pessoas que residem com você:

16. Número de filhos:

Quantos dependentes da sua renda?

17. No último ano você esteve em consulta com o médico? 1. Não (passe para a questão 21) /2. Sim

18. Qual o motivo principal pelo qual você procurou esse atendimento? 1. Acidente ou lesão / 2. Doença /

3. Atestado de saúde / 4. Para fazer consulta de rotina /

5. Outros atendimentos preventivos / 6. NSA ou IGN

19. Esse serviço de saúde onde o (a) Sr (a). foi atendido era: 1. Público (SUS) ( ) emergência ou ( ) UBS / 2. Particular ( ) emergência ou ( ) consulta agendada / 3. Por convênio ( ) emergência ou ( ) consulta agendada / 4. NSA ou IGN

20. Toma algum medicamento (analgésicos, calmantes, relaxantes musculares, etc)?

1. Não / 2. Sim - Qual:

21. Teve algum afastamento do trabalho no último ano? 1 . Não / 2. Sim - Motivo: 


\section{Fuma atualmente?}

1. Não

2. Sim Quantos cigarros ao dia?

Há quanto tempo?

\section{Consome bebida alcoólica?}

1. Não / 2. Sim Quantas vezes na semana?

\begin{tabular}{|c|c|c|}
\hline $\begin{array}{l}\text { 24. Algum médico ou profissional de } \\
\text { saúde já disse que você tem: }\end{array}$ & $\begin{array}{l}\text { 25. Prescreveu } \\
\text { alguma Medicação? }\end{array}$ & $\begin{array}{l}\text { 26. Você fez o } \\
\text { tratamento } \\
\text { prescrito? }\end{array}$ \\
\hline $\begin{array}{l}\text { a. Doença de coluna ou costas? } \\
\text { 1. Não / 2. Sim }\end{array}$ & a. 1. Não / 2. Sim & a. 1. Não / 2. Sim \\
\hline $\begin{array}{l}\text { b. Diabetes? } \\
\text { 1. Não / 2. Sim }\end{array}$ & b. 1. Não / 2. Sim & b. 1. Não / 2. Sim \\
\hline $\begin{array}{l}\text { c. Hipertenção? } \\
\text { 1. Não / 2. Sim }\end{array}$ & c. 1. Não / 2. Sim & c. 1. Não / 2. Sim \\
\hline $\begin{array}{l}\text { d. Doença do coração ou cardiovascular? } \\
\text { 1. Não / } 2 . \text { Sim }\end{array}$ & d. 1. Não / 2. Sim & d. 1. Não / 2. Sim \\
\hline $\begin{array}{l}\text { e. Depressão? } \\
\text { 1. Não / 2. Sim }\end{array}$ & e. 1. Não / 2. Sim & e. 1. Não / 2. Sim \\
\hline $\begin{array}{l}\text { f. Tendinite ou tendossinovite? } \\
\text { 1. Não / 2. Sim }\end{array}$ & f. 1. Não / 2. Sim & f. 1. Não / 2. Sim \\
\hline $\begin{array}{l}\text { g. Gastrite? } \\
\text { 1. Não / 2. Sim }\end{array}$ & g. 1. Não / 2. Sim & g. 1. Não / 2. Sim \\
\hline $\begin{array}{l}\text { h. Úlcera no estômago ou duodeno? } \\
\text { 1. Não / 2. Sim }\end{array}$ & h. 1. Não / 2. Sim & h. 1. Não / 2. Sim \\
\hline $\begin{array}{l}\text { i. Doença de pele? } \\
\text { 1. Não / 2. Sim }\end{array}$ & i. 1. Não / 2. Sim & i. 1. Não / 2. Sim \\
\hline $\begin{array}{l}\text { j. Ansiedade? } \\
\text { 1. Não / 2. Sim }\end{array}$ & j. 1. Não / 2. Sim & j. 1. Não / 2. Sim \\
\hline $\begin{array}{l}\text { k. Distúrbios do sono? } \\
\text { 1. Não / 2. Sim }\end{array}$ & k. 1. Não / 2. Sim & k. 1. Não / 2. Sim \\
\hline $\begin{array}{l}\text { 1. Distúrbios sexuais? } \\
\text { 1. Não / 2. Sim }\end{array}$ & 1. 1. Não / 2. Sim & 1. 1. Não / 2. Sim \\
\hline
\end{tabular}


C - Forma de coleta das variáveis do questionário sociodemográfico, de condições de trabalho e saúde

\begin{tabular}{|c|c|c|c|}
\hline Variáveis & Instrumento & $\begin{array}{l}\text { Natureza } \\
\text { da variável }\end{array}$ & Definição \\
\hline \multicolumn{4}{|c|}{ Sociodemográficas } \\
\hline Sexo & Questionário & Nominal & $\begin{array}{l}\text { Masculino } \\
\text { Feminino }\end{array}$ \\
\hline Idade & Questionário & Nominal & Data de nascimento \\
\hline Escolaridade & Questionário & Ordinal & $\begin{array}{l}\text { Fundamental completo } \\
\text { Médio incompleto } \\
\text { Médio completo } \\
\text { Superior incompleto } \\
\text { Superior completo }\end{array}$ \\
\hline Estado civil & Questionário & Nominal & $\begin{array}{l}\text { Casado ou com companheiro } \\
\text { Solteiro } \\
\text { Divorciado } \\
\text { Viúvo }\end{array}$ \\
\hline Religião & Questionário & Nominal & $\begin{array}{l}\text { Católico } \\
\text { Evangélico } \\
\text { Protestante } \\
\text { Espírita } \\
\text { Agnóstico } \\
\end{array}$ \\
\hline Morar com quem & Questionário & Nominal & $\begin{array}{l}\text { Família } \\
\text { Parentes } \\
\text { República } \\
\text { Sozinho } \\
\end{array}$ \\
\hline $\begin{array}{l}\text { Número de pessoas que } \\
\text { residem na moradia }\end{array}$ & Questionário & Discreta & Número absoluto \\
\hline Número de filhos & Questionário & Discreta & Número absoluto \\
\hline $\begin{array}{lcc}\text { Quantos filhos são } \\
\text { dependentes da renda }\end{array}$ & Questionário & Discreta & Número absoluto \\
\hline \multicolumn{4}{|c|}{ Condições de trabalho } \\
\hline Profissão & Questionário & Nominal & $\begin{array}{l}\text { Auxiliar de enfermagem } \\
\text { Técnico de enfermagem } \\
\text { Enfermeiro }\end{array}$ \\
\hline Cargo exercido & Questionário & Nominal & $\begin{array}{l}\text { Auxiliar de enfermagem } \\
\text { Técnico de enfermagem } \\
\text { Outro }\end{array}$ \\
\hline Tempo de serviço & Questionário & Discreta & $\begin{array}{l}\text { Anos completos no momento da } \\
\text { pesquisa }\end{array}$ \\
\hline Tempo de profissão & Questionário & Discreta & $\begin{array}{l}\text { Anos completos no momento da } \\
\text { pesquisa }\end{array}$ \\
\hline $\begin{array}{l}\text { Possuir mais de um } \\
\text { vínculo }\end{array}$ & Questionário & Nominal & $\begin{array}{l}\text { Não } \\
\text { Sim }\end{array}$ \\
\hline $\begin{array}{l}\text { Carga horária semanal de } \\
\text { trabalho }\end{array}$ & Questionário & Discreta & Horas completas \\
\hline \multicolumn{4}{|c|}{ Condições de saúde } \\
\hline Referir ter passado por & Questionário & Nominal & Não \\
\hline
\end{tabular}




\begin{tabular}{|c|c|c|c|}
\hline $\begin{array}{l}\text { consulta médica no último } \\
\text { ano }\end{array}$ & & & Sim \\
\hline Qual o principal motivo & Questionário & Nominal & $\begin{array}{l}\text { Acidente ou lesão } \\
\text { Doença } \\
\text { Atestado de saúde } \\
\text { Consulta de rotina } \\
\text { Atendimentos preventivos }\end{array}$ \\
\hline Tipo de serviço utilizado & Questionário & Nominal & $\begin{array}{l}\text { Público } \\
\text { Particular } \\
\text { Convênio } \\
\text { Ignorado }\end{array}$ \\
\hline $\begin{array}{ll}\text { Fazer uso } & \text { de } \\
\text { medicamentos } & \end{array}$ & Questionário & Nominal & $\begin{array}{l}\text { Não } \\
\text { Sim e quais }\end{array}$ \\
\hline $\begin{array}{l}\text { Houve afastamento do } \\
\text { trabalho no último ano }\end{array}$ & Questionário & Nominal & $\begin{array}{l}\text { Não } \\
\text { Sim e motivo }\end{array}$ \\
\hline Uso de tabaco & Questionário & Nominal & $\begin{array}{l}\text { Não } \\
\text { Sim }\end{array}$ \\
\hline Quantos cigarros por dia & Questionário & Discreta & Em número absoluto \\
\hline Há quanto tempo & Questionário & Discreta & $\begin{array}{l}\text { Em anos completos no momento } \\
\text { da pesquisa }\end{array}$ \\
\hline Consome bebida alcoólica & Questionário & Nominal & $\begin{array}{l}\text { Não } \\
\text { Sim }\end{array}$ \\
\hline Quantas vezes por semana & Questionário & Discreta & Em número absoluto \\
\hline Doenças crônicas & Questionário & Nominal & $\begin{array}{l}\text { Não } \\
\text { Sim }\end{array}$ \\
\hline $\begin{array}{l}\text { Foi prescrito tratamento } \\
\text { medicamentoso }\end{array}$ & Questionário & Nominal & $\begin{array}{l}\text { Não } \\
\text { Sim }\end{array}$ \\
\hline Segue o tratamento & Questionário & Nominal & $\begin{array}{l}\text { Não } \\
\text { Sim }\end{array}$ \\
\hline
\end{tabular}


D - Forma de coleta das variáveis da Escala de Modos de Enfrentamento dos Problemas (EMEP)

\begin{tabular}{|c|c|c|c|}
\hline Variáveis & Instrumento & $\begin{array}{l}\text { Natureza } \\
\text { da variável }\end{array}$ & Definição \\
\hline \multicolumn{4}{|c|}{ Estratégias de enfrentamento dos problemas } \\
\hline $\begin{array}{l}\text { 1. Eu levo em conta o lado positivo } \\
\text { das coisas. }\end{array}$ & Escala & Ordinal & $\begin{array}{l}\text { 1. Nunca faço isso } \\
\text { 2. Faço isso um pouco } \\
\text { 3. Faço isso às vezes } \\
\text { 4. Faço isso muito } \\
\text { 5. Faço isso sempre }\end{array}$ \\
\hline 2. Eu me culpo. & Escala & Ordinal & $\begin{array}{l}\text { 1. Nunca faço isso } \\
\text { 2. Faço isso um pouco } \\
\text { 3. Faço isso às vezes } \\
\text { 4. Faço isso muito } \\
\text { 5. Faço isso sempre }\end{array}$ \\
\hline $\begin{array}{l}\text { 3. Eu me concentro em alguma coisa } \\
\text { boa que pode vir desta situação. }\end{array}$ & Escala & Ordinal & $\begin{array}{l}\text { 1. Nunca faço isso } \\
\text { 2. Faço isso um pouco } \\
\text { 3. Faço isso às vezes } \\
\text { 4. Faço isso muito } \\
\text { 5. Faço isso sempre }\end{array}$ \\
\hline $\begin{array}{l}\text { 4. Eu tento guardar meus } \\
\text { sentimentos para mim mesmo. }\end{array}$ & Escala & Ordinal & $\begin{array}{l}\text { 1. Nunca faço isso } \\
\text { 2. Faço isso um pouco } \\
\text { 3. Faço isso às vezes } \\
\text { 4. Faço isso muito } \\
\text { 5. Faço isso sempre }\end{array}$ \\
\hline $\begin{array}{l}\text { 5. Procuro um culpado para a } \\
\text { situação. }\end{array}$ & Escala & Ordinal & $\begin{array}{l}\text { 1. Nunca faço isso } \\
\text { 2. Faço isso um pouco } \\
\text { 3. Faço isso às vezes } \\
\text { 4. Faço isso muito } \\
\text { 5. Faço isso sempre }\end{array}$ \\
\hline 6. Espero que um milagre aconteça. & Escala & Ordinal & $\begin{array}{l}\text { 1. Nunca faço isso } \\
\text { 2. Faço isso um pouco } \\
\text { 3. Faço isso às vezes } \\
\text { 4. Faço isso muito } \\
\text { 5. Faço isso sempre }\end{array}$ \\
\hline $\begin{array}{l}\text { 7. Peço conselho a um parente ou a } \\
\text { um amigo que eu respeite. }\end{array}$ & Escala & Ordinal & $\begin{array}{l}\text { 1. Nunca faço isso } \\
\text { 2. Faço isso um pouco } \\
\text { 3. Faço isso às vezes } \\
\text { 4. Faço isso muito } \\
\text { 5. Faço isso sempre }\end{array}$ \\
\hline 8. Eu rezo/oro. & Escala & Ordinal & $\begin{array}{l}\text { 1. Nunca faço isso } \\
\text { 2. Faço isso um pouco } \\
\text { 3. Faço isso às vezes } \\
\text { 4. Faço isso muito } \\
\text { 5. Faço isso sempre }\end{array}$ \\
\hline $\begin{array}{l}\text { 9. Converso com alguém sobre } \\
\text { como estou me sentindo. }\end{array}$ & Escala & Ordinal & $\begin{array}{l}\text { 1. Nunca faço isso } \\
\text { 2. Faço isso um pouco } \\
\text { 3. Faço isso às vezes }\end{array}$ \\
\hline
\end{tabular}




\begin{tabular}{|c|c|c|c|}
\hline & & & $\begin{array}{l}\text { 4. Faço isso muito } \\
\text { 5. Faço isso sempre }\end{array}$ \\
\hline $\begin{array}{l}\text { 10. Eu insisto e luto pelo que eu } \\
\text { quero. }\end{array}$ & Escala & Ordinal & $\begin{array}{l}\text { 1. Nunca faço isso } \\
\text { 2. Faço isso um pouco } \\
\text { 3. Faço isso às vezes } \\
\text { 4. Faço isso muito } \\
\text { 5. Faço isso sempre }\end{array}$ \\
\hline $\begin{array}{l}\text { 11. Eu me recuso a acreditar que isto } \\
\text { esteja acontecendo. }\end{array}$ & Escala & Ordinal & $\begin{array}{l}\text { 1. Nunca faço isso } \\
\text { 2. Faço isso um pouco } \\
\text { 3. Faço isso às vezes } \\
\text { 4. Faço isso muito } \\
\text { 5. Faço isso sempre }\end{array}$ \\
\hline $\begin{array}{l}\text { 12. Eu brigo comigo mesmo; eu fico } \\
\text { falando comigo mesmo o que devo } \\
\text { fazer. }\end{array}$ & Escala & Ordinal & $\begin{array}{l}\text { 1. Nunca faço isso } \\
\text { 2. Faço isso um pouco } \\
\text { 3. Faço isso às vezes } \\
\text { 4. Faço isso muito } \\
\text { 5. Faço isso sempre }\end{array}$ \\
\hline 13. Desconto em outras pessoas. & Escala & Ordinal & $\begin{array}{l}\text { 1. Nunca faço isso } \\
\text { 2. Faço isso um pouco } \\
\text { 3. Faço isso às vezes } \\
\text { 4. Faço isso muito } \\
\text { 5. Faço isso sempre }\end{array}$ \\
\hline $\begin{array}{l}\text { 14. Encontro diferentes soluções } \\
\text { para o meu problema. }\end{array}$ & Escala & Ordinal & $\begin{array}{l}\text { 1. Nunca faço isso } \\
\text { 2. Faço isso um pouco } \\
\text { 3. Faço isso às vezes } \\
\text { 4. Faço isso muito } \\
\text { 5. Faço isso sempre }\end{array}$ \\
\hline $\begin{array}{l}\text { 15. Tento ser uma pessoa mais forte } \\
\text { e otimista. }\end{array}$ & Escala & Ordinal & $\begin{array}{l}\text { 1. Nunca faço isso } \\
\text { 2. Faço isso um pouco } \\
\text { 3. Faço isso às vezes } \\
\text { 4. Faço isso muito } \\
\text { 5. Faço isso sempre }\end{array}$ \\
\hline $\begin{array}{l}\text { 16. Eu tento evitar que os meus } \\
\text { sentimentos atrapalhem em outras } \\
\text { coisas na minha vida. }\end{array}$ & Escala & Ordinal & $\begin{array}{l}\text { 1. Nunca faço isso } \\
\text { 2. Faço isso um pouco } \\
\text { 3. Faço isso às vezes } \\
\text { 4. Faço isso muito } \\
\text { 5. Faço isso sempre }\end{array}$ \\
\hline $\begin{array}{l}\text { 17. Eu me concentro nas coisas boas } \\
\text { da minha vida. }\end{array}$ & Escala & Ordinal & $\begin{array}{l}\text { 1. Nunca faço isso } \\
\text { 2. Faço isso um pouco } \\
\text { 3. Faço isso às vezes } \\
\text { 4. Faço isso muito } \\
\text { 5. Faço isso sempre }\end{array}$ \\
\hline $\begin{array}{l}\text { 18. Eu desejaria mudar o modo } \\
\text { como eu me sinto. }\end{array}$ & Escala & Ordinal & $\begin{array}{l}\text { 1. Nunca faço isso } \\
\text { 2. Faço isso um pouco } \\
\text { 3. Faço isso às vezes } \\
\text { 4. Faço isso muito } \\
\text { 5. Faço isso sempre }\end{array}$ \\
\hline 19. Aceito a simpatia e a & Escala & Ordinal & $\begin{array}{l}\text { 1. Nunca faço isso } \\
\text { 2. Faço isso um pouco }\end{array}$ \\
\hline
\end{tabular}




\begin{tabular}{|c|c|c|c|}
\hline compreensão de alguém. & & & $\begin{array}{l}\text { 3. Faço isso às vezes } \\
\text { 4. Faço isso muito } \\
\text { 5. Faço isso sempre }\end{array}$ \\
\hline $\begin{array}{l}\text { 20. Demonstro raiva para as pessoas } \\
\text { que causaram o problema. }\end{array}$ & Escala & Ordinal & $\begin{array}{l}\text { 1. Nunca faço isso } \\
\text { 2. Faço isso um pouco } \\
\text { 3. Faço isso às vezes } \\
\text { 4. Faço isso muito } \\
\text { 5. Faço isso sempre }\end{array}$ \\
\hline $\begin{array}{l}\text { 21. Pratico mais a religião desde que } \\
\text { tenho este problema. }\end{array}$ & Escala & Ordinal & $\begin{array}{l}\text { 1. Nunca faço isso } \\
\text { 2. Faço isso um pouco } \\
\text { 3. Faço isso às vezes } \\
\text { 4. Faço isso muito } \\
\text { 5. Faço isso sempre }\end{array}$ \\
\hline $\begin{array}{l}\text { 22. Eu percebo que eu mesmo } \\
\text { trouxe o problema para mim. }\end{array}$ & Escala & Ordinal & $\begin{array}{l}\text { 1. Nunca faço isso } \\
\text { 2. Faço isso um pouco } \\
\text { 3. Faço isso às vezes } \\
\text { 4. Faço isso muito } \\
\text { 5. Faço isso sempre }\end{array}$ \\
\hline $\begin{array}{l}\text { 23. Eu me sinto mal por não ter } \\
\text { podido evitar o problema. }\end{array}$ & Escala & Ordinal & $\begin{array}{l}\text { 1. Nunca faço isso } \\
\text { 2. Faço isso um pouco } \\
\text { 3. Faço isso às vezes } \\
\text { 4. Faço isso muito } \\
\text { 5. Faço isso sempre }\end{array}$ \\
\hline $\begin{array}{l}\text { 24. Eu sei o que deve ser feito e } \\
\text { estou aumentando meus esforços } \\
\text { para se bem sucedido. }\end{array}$ & Escala & Ordinal & $\begin{array}{l}\text { 1. Nunca faço isso } \\
\text { 2. Faço isso um pouco } \\
\text { 3. Faço isso às vezes } \\
\text { 4. Faço isso muito } \\
\text { 5. Faço isso sempre }\end{array}$ \\
\hline $\begin{array}{l}\text { 25. Eu acho que as pessoas foram } \\
\text { injustas comigo. }\end{array}$ & Escala & Ordinal & $\begin{array}{l}\text { 1. Nunca faço isso } \\
\text { 2. Faço isso um pouco } \\
\text { 3. Faço isso às vezes } \\
\text { 4. Faço isso muito } \\
\text { 5. Faço isso sempre }\end{array}$ \\
\hline $\begin{array}{l}\text { 26. Eu sonho ou imagino um tempo } \\
\text { melhor do que aquele em que estou. }\end{array}$ & Escala & Ordinal & $\begin{array}{l}\text { 1. Nunca faço isso } \\
\text { 2. Faço isso um pouco } \\
\text { 3. Faço isso às vezes } \\
\text { 4. Faço isso muito } \\
\text { 5. Faço isso sempre }\end{array}$ \\
\hline 27. Tento esquecer o problema todo. & Escala & Ordinal & $\begin{array}{l}\text { 1. Nunca faço isso } \\
\text { 2. Faço isso um pouco } \\
\text { 3. Faço isso às vezes } \\
\text { 4. Faço isso muito } \\
\text { 5. Faço isso sempre }\end{array}$ \\
\hline $\begin{array}{l}\text { 28. Estou mudando e me tornando } \\
\text { uma pessoa mais experiente. }\end{array}$ & Escala & Ordinal & $\begin{array}{l}\text { 1. Nunca faço isso } \\
\text { 2. Faço isso um pouco } \\
\text { 3. Faço isso às vezes } \\
\text { 4. Faço isso muito } \\
\text { 5. Faço isso sempre }\end{array}$ \\
\hline
\end{tabular}




\begin{tabular}{|c|c|c|c|}
\hline 29. Eu culpo os outros. & Escala & Ordinal & $\begin{array}{l}\text { 1. Nunca faço isso } \\
\text { 2. Faço isso um pouco } \\
\text { 3. Faço isso às vezes } \\
\text { 4. Faço isso muito } \\
\text { 5. Faço isso sempre }\end{array}$ \\
\hline $\begin{array}{l}\text { 30. Eu fico me lembrando que as } \\
\text { coisas poderiam ser piores. }\end{array}$ & Escala & Ordinal & $\begin{array}{l}\text { 1. Nunca faço isso } \\
\text { 2. Faço isso um pouco } \\
\text { 3. Faço isso às vezes } \\
\text { 4. Faço isso muito } \\
\text { 5. Faço isso sempre }\end{array}$ \\
\hline $\begin{array}{l}\text { 31. Converso com alguém que possa } \\
\text { fazer alguma coisa para resolver o } \\
\text { meu problema. }\end{array}$ & Escala & Ordinal & $\begin{array}{l}\text { 1. Nunca faço isso } \\
\text { 2. Faço isso um pouco } \\
\text { 3. Faço isso às vezes } \\
\text { 4. Faço isso muito } \\
\text { 5. Faço isso sempre }\end{array}$ \\
\hline $\begin{array}{l}\text { 32. Eu tento não agir tão } \\
\text { precipitadamente ou seguir minha } \\
\text { primeira ideia. }\end{array}$ & Escala & Ordinal & $\begin{array}{l}\text { 1. Nunca faço isso } \\
\text { 2. Faço isso um pouco } \\
\text { 3. Faço isso às vezes } \\
\text { 4. Faço isso muito } \\
\text { 5. Faço isso sempre }\end{array}$ \\
\hline $\begin{array}{l}\text { 33. Mudo alguma coisa para que as } \\
\text { coisas acabem dando certo. }\end{array}$ & Escala & Ordinal & $\begin{array}{l}\text { 1. Nunca faço isso } \\
\text { 2. Faço isso um pouco } \\
\text { 3. Faço isso às vezes } \\
\text { 4. Faço isso muito } \\
\text { 5. Faço isso sempre }\end{array}$ \\
\hline $\begin{array}{l}\text { 34. Procuro me afastar das pessoas } \\
\text { em geral. }\end{array}$ & Escala & Ordinal & $\begin{array}{l}\text { 1. Nunca faço isso } \\
\text { 2. Faço isso um pouco } \\
\text { 3. Faço isso às vezes } \\
\text { 4. Faço isso muito } \\
\text { 5. Faço isso sempre }\end{array}$ \\
\hline $\begin{array}{l}\text { 35. Eu imagino ou tenho desejos } \\
\text { sobre como as coisas poderiam } \\
\text { acontecer. }\end{array}$ & Escala & Ordinal & $\begin{array}{l}\text { 1. Nunca faço isso } \\
\text { 2. Faço isso um pouco } \\
\text { 3. Faço isso às vezes } \\
\text { 4. Faço isso muito } \\
\text { 5. Faço isso sempre }\end{array}$ \\
\hline $\begin{array}{l}\text { 36. Encaro a situação por etapa, } \\
\text { fazendo uma coisa de cada vez. }\end{array}$ & Escala & Ordinal & $\begin{array}{l}\text { 1. Nunca faço isso } \\
\text { 2. Faço isso um pouco } \\
\text { 3. Faço isso às vezes } \\
\text { 4. Faço isso muito } \\
\text { 5. Faço isso sempre }\end{array}$ \\
\hline $\begin{array}{l}\text { 37. Descubro quem mais é ou foi } \\
\text { responsável. }\end{array}$ & Escala & Ordinal & $\begin{array}{l}\text { 1. Nunca faço isso } \\
\text { 2. Faço isso um pouco } \\
\text { 3. Faço isso às vezes } \\
\text { 4. Faço isso muito } \\
\text { 5. Faço isso sempre }\end{array}$ \\
\hline $\begin{array}{l}\text { 38. Penso em coisas fantásticas ou } \\
\text { irreais (como uma vingança perfeita } \\
\text { ou achar muito dinheiro) que me } \\
\text { fazem sentir melhor. }\end{array}$ & Escala & Ordinal & $\begin{array}{l}\text { 1. Nunca faço isso } \\
\text { 2. Faço isso um pouco } \\
\text { 3. Faço isso às vezes } \\
\text { 4. Faço isso muito }\end{array}$ \\
\hline
\end{tabular}




\begin{tabular}{|c|c|c|c|}
\hline & & & 5. Faço isso sempre \\
\hline $\begin{array}{l}\text { 39. Eu sairei dessa experiência } \\
\text { melhor do que entrei nela. }\end{array}$ & Escala & Ordinal & $\begin{array}{l}\text { 1. Nunca faço isso } \\
\text { 2. Faço isso um pouco } \\
\text { 3. Faço isso às vezes } \\
\text { 4. Faço isso muito } \\
\text { 5. Faço isso sempre }\end{array}$ \\
\hline $\begin{array}{l}\text { 40. Eu digo a mim mesmo o quanto } \\
\text { já consegui. }\end{array}$ & Escala & Ordinal & $\begin{array}{l}\text { 1. Nunca faço isso } \\
\text { 2. Faço isso um pouco } \\
\text { 3. Faço isso às vezes } \\
\text { 4. Faço isso muito } \\
\text { 5. Faço isso sempre }\end{array}$ \\
\hline $\begin{array}{l}\text { 41. Eu desejaria poder mudar o que } \\
\text { aconteceu comigo. }\end{array}$ & Escala & Ordinal & $\begin{array}{l}\text { 1. Nunca faço isso } \\
\text { 2. Faço isso um pouco } \\
\text { 3. Faço isso às vezes } \\
\text { 4. Faço isso muito } \\
\text { 5. Faço isso sempre }\end{array}$ \\
\hline $\begin{array}{l}\text { 42. Eu fiz um plano de ação para } \\
\text { resolver o meu problema e o estou } \\
\text { cumprindo. }\end{array}$ & Escala & Ordinal & $\begin{array}{l}\text { 1. Nunca faço isso } \\
\text { 2. Faço isso um pouco } \\
\text { 3. Faço isso às vezes } \\
\text { 4. Faço isso muito } \\
\text { 5. Faço isso sempre }\end{array}$ \\
\hline $\begin{array}{l}\text { 43. Converso com alguém para obter } \\
\text { informações sobre a situação. }\end{array}$ & Escala & Ordinal & $\begin{array}{l}\text { 1. Nunca faço isso } \\
\text { 2. Faço isso um pouco } \\
\text { 3. Faço isso às vezes } \\
\text { 4. Faço isso muito } \\
\text { 5. Faço isso sempre }\end{array}$ \\
\hline $\begin{array}{l}\text { 44. Eu me apego a minha fé para } \\
\text { superar esta situação. }\end{array}$ & Escala & Ordinal & $\begin{array}{l}\text { 1. Nunca faço isso } \\
\text { 2. Faço isso um pouco } \\
\text { 3. Faço isso às vezes } \\
\text { 4. Faço isso muito } \\
\text { 5. Faço isso sempre }\end{array}$ \\
\hline $\begin{array}{l}\text { 45. Eu tento não fechar portas atrás } \\
\text { de mim. Tento deixar em aberto } \\
\text { várias saídas para o problema. }\end{array}$ & Escala & Ordinal & $\begin{array}{l}\text { 1. Nunca faço isso } \\
\text { 2. Faço isso um pouco } \\
\text { 3. Faço isso às vezes } \\
\text { 4. Faço isso muito } \\
\text { 5. Faco isso sempre }\end{array}$ \\
\hline
\end{tabular}


E - Forma de coleta das variáveis da Maslach Burnout Inventory (MBI)

\begin{tabular}{|c|c|c|c|}
\hline Variáveis & Instrumento & $\begin{array}{l}\text { Natureza da } \\
\text { variável }\end{array}$ & Definição \\
\hline \multicolumn{4}{|c|}{ Síndrome de Burnout } \\
\hline $\begin{array}{l}\text { 1. Eu me sinto emocionalmente exausto } \\
\text { pelo meu trabalho. }\end{array}$ & Escala & Ordinal & $\begin{array}{l}\text { 1. Nunca } \\
\text { 2. Raramente } \\
\text { 3. Algumas vezes } \\
\text { 4. Frequentemente } \\
\text { 5. Sempre }\end{array}$ \\
\hline $\begin{array}{l}\text { 2. Eu me sinto esgotado ao final de um } \\
\text { dia de trabalho. }\end{array}$ & Escala & Ordinal & $\begin{array}{l}\text { 1. Nunca } \\
\text { 2. Raramente } \\
\text { 3. Algumas vezes } \\
\text { 4. Frequentemente } \\
\text { 5. Sempre }\end{array}$ \\
\hline $\begin{array}{l}\text { 3. Eu me sinto cansado quando me } \\
\text { levanto de manhã e tenho que encarar } \\
\text { outro dia de trabalho. }\end{array}$ & Escala & Ordinal & $\begin{array}{l}\text { 1. Nunca } \\
\text { 2. Raramente } \\
\text { 3. Algumas vezes } \\
\text { 4. Frequentemente } \\
\text { 5. Sempre }\end{array}$ \\
\hline $\begin{array}{l}\text { 4. Eu posso entender facilmente o que } \\
\text { sentem os meus pacientes acerca das } \\
\text { coisas que acontecem no dia a dia. }\end{array}$ & Escala & Ordinal & $\begin{array}{l}\text { 1. Nunca } \\
\text { 2. Raramente } \\
\text { 3. Algumas vezes } \\
\text { 4. Frequentemente } \\
\text { 5. Sempre }\end{array}$ \\
\hline $\begin{array}{l}\text { 5. Eu sinto que eu trato alguns dos } \\
\text { meus pacientes como se eles fossem } \\
\text { objetos. }\end{array}$ & Escala & Ordinal & $\begin{array}{l}\text { 1. Nunca } \\
\text { 2. Raramente } \\
\text { 3. Algumas vezes } \\
\text { 4. Frequentemente } \\
\text { 5. Sempre }\end{array}$ \\
\hline $\begin{array}{l}\text { 6. Trabalhar o dia inteiro é realmente } \\
\text { um grande esforço para mim. }\end{array}$ & Escala & Ordinal & $\begin{array}{l}\text { 1. Nunca } \\
\text { 2. Raramente } \\
\text { 3. Algumas vezes } \\
\text { 4. Frequentemente } \\
\text { 5. Sempre }\end{array}$ \\
\hline $\begin{array}{l}\text { 7. Eu trato de forma adequada os } \\
\text { problemas dos meus pacientes. }\end{array}$ & Escala & Ordinal & $\begin{array}{l}\text { 1. Nunca } \\
\text { 2. Raramente } \\
\text { 3. Algumas vezes } \\
\text { 4. Frequentemente } \\
\text { 5. Sempre }\end{array}$ \\
\hline $\begin{array}{l}\text { 8. Eu me sinto esgotado com meu } \\
\text { trabalho. }\end{array}$ & Escala & Ordinal & $\begin{array}{l}\text { 1. Nunca } \\
\text { 2. Raramente } \\
\text { 3. Algumas vezes } \\
\text { 4. Frequentemente } \\
\text { 5. Sempre }\end{array}$ \\
\hline $\begin{array}{l}\text { 9. Eu sinto que estou influenciando } \\
\text { positivamente a vida de outras pessoas } \\
\text { através do meu trabalho. }\end{array}$ & Escala & Ordinal & $\begin{array}{l}\text { 1. Nunca } \\
\text { 2. Raramente } \\
\text { 3. Algumas vezes } \\
\text { 4. Frequentemente }\end{array}$ \\
\hline
\end{tabular}




\begin{tabular}{|c|c|c|c|}
\hline & & & 5. Sempre \\
\hline $\begin{array}{l}\text { 10. Eu sinto que me tornei mais } \\
\text { insensível com as pessoas desde que } \\
\text { comecei este trabalho. }\end{array}$ & Escala & Ordinal & $\begin{array}{l}\text { 1. Nunca } \\
\text { 2. Raramente } \\
\text { 3. Algumas vezes } \\
\text { 4. Frequentemente } \\
\text { 5. Sempre }\end{array}$ \\
\hline $\begin{array}{l}\text { 11. Eu sinto que este trabalho está me } \\
\text { endurecendo emocionalmente. }\end{array}$ & Escala & Ordinal & $\begin{array}{l}\text { 1. Nunca } \\
\text { 2. Raramente } \\
\text { 3. Algumas vezes } \\
\text { 4. Frequentemente } \\
\text { 5. Sempre }\end{array}$ \\
\hline 12. Eu me sinto muito cheio de energia. & Escala & Ordinal & $\begin{array}{l}\text { 1. Nunca } \\
\text { 2. Raramente } \\
\text { 3. Algumas vezes } \\
\text { 4. Frequentemente } \\
\text { 5. Sempre }\end{array}$ \\
\hline $\begin{array}{l}\text { 13. Eu me sinto frustrado com o meu } \\
\text { trabalho. }\end{array}$ & Escala & Ordinal & $\begin{array}{l}\text { 1. Nunca } \\
\text { 2. Raramente } \\
\text { 3. Algumas vezes } \\
\text { 4. Frequentemente } \\
\text { 5. Sempre }\end{array}$ \\
\hline $\begin{array}{l}\text { 14. Eu sinto que estou trabalhando } \\
\text { demais no meu emprego. }\end{array}$ & Escala & Ordinal & $\begin{array}{l}\text { 1. Nunca } \\
\text { 2. Raramente } \\
\text { 3. Algumas vezes } \\
\text { 4. Frequentemente } \\
\text { 5. Sempre }\end{array}$ \\
\hline $\begin{array}{l}\text { 15. Eu não me importo realmente com } \\
\text { o que acontece com alguns dos meus } \\
\text { pacientes. }\end{array}$ & Escala & Ordinal & $\begin{array}{l}\text { 1. Nunca } \\
\text { 2. Raramente } \\
\text { 3. Algumas vezes } \\
\text { 4. Frequentemente } \\
\text { 5. Sempre }\end{array}$ \\
\hline $\begin{array}{l}\text { 16. Trabalhar diretamente com pessoas } \\
\text { me deixa muito estressado. }\end{array}$ & Escala & Ordinal & $\begin{array}{l}\text { 1. Nunca } \\
\text { 2. Raramente } \\
\text { 3. Algumas vezes } \\
\text { 4. Frequentemente } \\
\text { 5. Sempre }\end{array}$ \\
\hline $\begin{array}{l}\text { 17. Eu posso criar facilmente um } \\
\text { ambiente tranquilo com os meus } \\
\text { pacientes. }\end{array}$ & Escala & Ordinal & $\begin{array}{l}\text { 1. Nunca } \\
\text { 2. Raramente } \\
\text { 3. Algumas vezes } \\
\text { 4. Frequentemente } \\
\text { 5. Sempre }\end{array}$ \\
\hline $\begin{array}{l}\text { 18. Eu me sinto estimulado depois de } \\
\text { trabalhar lado a lado com os meus } \\
\text { pacientes. }\end{array}$ & Escala & Ordinal & $\begin{array}{l}\text { 1. Nunca } \\
\text { 2. Raramente } \\
\text { 3. Algumas vezes } \\
\text { 4. Frequentemente } \\
\text { 5. Sempre }\end{array}$ \\
\hline $\begin{array}{l}\text { 19. Eu tenho realizado muitas coisas } \\
\text { importantes neste trabalho. }\end{array}$ & Escala & Ordinal & $\begin{array}{l}\text { 1. Nunca } \\
\text { 2. Raramente } \\
\text { 3. Algumas vezes }\end{array}$ \\
\hline
\end{tabular}




\begin{tabular}{|c|c|c|c|}
\hline & & & $\begin{array}{l}\text { 4. Frequentemente } \\
\text { 5. Sempre }\end{array}$ \\
\hline $\begin{array}{l}\text { 20. No meu trabalho, eu me sinto como } \\
\text { se estivesse no final do meu limite. }\end{array}$ & Escala & Ordinal & $\begin{array}{l}\text { 1. Nunca } \\
\text { 2. Raramente } \\
\text { 3. Algumas vezes } \\
\text { 4. Frequentemente } \\
\text { 5. Sempre }\end{array}$ \\
\hline $\begin{array}{l}\text { 21. No meu trabalho, eu lido com os } \\
\text { problemas emocionais com calma. }\end{array}$ & Escala & Ordinal & $\begin{array}{l}\text { 1. Nunca } \\
\text { 2. Raramente } \\
\text { 3. Algumas vezes } \\
\text { 4. Frequentemente } \\
\text { 5. Sempre }\end{array}$ \\
\hline $\begin{array}{l}\text { 22. Eu sinto que os pacientes me } \\
\text { culpam por alguns dos seus problemas. }\end{array}$ & Escala & Ordinal & $\begin{array}{l}\text { 1. Nunca } \\
\text { 2. Raramente } \\
\text { 3. Algumas vezes } \\
\text { 4. Frequentemente } \\
\text { 5. Sempre }\end{array}$ \\
\hline
\end{tabular}


F - Forma de coleta das variáveis da Childhood Trauma Questionnaire (CTQ)

\begin{tabular}{|c|c|c|c|}
\hline Variáveis & Instrumento & $\begin{array}{l}\text { Natureza da } \\
\text { variável }\end{array}$ & Definição \\
\hline \multicolumn{4}{|c|}{ Estresse precoce } \\
\hline 1. Eu não tive o suficiente para comer. & Escala & Ordinal & \begin{tabular}{|l} 
Nunca \\
Poucas vezes \\
Âs vezes \\
Muitas vezes \\
Sempre
\end{tabular} \\
\hline $\begin{array}{l}\text { 2. Eu soube que havia alguém para me } \\
\text { cuidar e proteger. }\end{array}$ & Escala & Ordinal & \begin{tabular}{|l} 
Nunca \\
Poucas vezes \\
Âs vezes \\
Muitas vezes \\
Sempre \\
\end{tabular} \\
\hline $\begin{array}{l}\text { 3. As pessoas da minha família me } \\
\text { chamaram de coisas do tipo "estúpido } \\
\text { (a)", "preguiçoso (a)" ou "feio (a)". }\end{array}$ & Escala & Ordinal & \begin{tabular}{|l} 
Nunca \\
Poucas vezes \\
Âs vezes \\
Muitas vezes \\
Sempre
\end{tabular} \\
\hline $\begin{array}{l}\text { 4. Meus pais estiveram muito bêbados } \\
\text { ou drogados para poder cuidar da } \\
\text { família. }\end{array}$ & Escala & Ordinal & \begin{tabular}{|l} 
Nunca \\
Poucas vezes \\
Âs vezes \\
Muitas vezes \\
Sempre \\
\end{tabular} \\
\hline $\begin{array}{l}\text { 5. Houve alguém na minha família que } \\
\text { ajudou a me sentir especial ou } \\
\text { importante. }\end{array}$ & Escala & Ordinal & $\begin{array}{l}\text { Nunca } \\
\text { Poucas vezes } \\
\text { Âs vezes } \\
\text { Muitas vezes } \\
\text { Sempre } \\
\end{array}$ \\
\hline 6. Eu tive que usar roupas sujas. & Escala & Ordinal & $\begin{array}{l}\text { Nunca } \\
\text { Poucas vezes } \\
\text { Às vezes } \\
\text { Muitas vezes } \\
\text { Sempre } \\
\end{array}$ \\
\hline 7. Eu me senti amado (a). & Escala & Ordinal & $\begin{array}{l}\text { Nunca } \\
\text { Poucas vezes } \\
\text { Às vezes } \\
\text { Muitas vezes } \\
\text { Sempre }\end{array}$ \\
\hline $\begin{array}{l}\text { 8. Eu achei que meus pais preferiam } \\
\text { que eu nunca tivesse nascido. }\end{array}$ & Escala & Ordinal & \begin{tabular}{|l} 
Nunca \\
Poucas vezes \\
Âs vezes \\
Muitas vezes \\
Sempre \\
\end{tabular} \\
\hline $\begin{array}{l}\text { 9. Eu apanhei tanto de alguém da minha } \\
\text { família que tive de ir ao hospital ou } \\
\text { consultar um médico. }\end{array}$ & Escala & Ordinal & \begin{tabular}{|l|} 
Nunca \\
Poucas vezes \\
Âs vezes \\
Muitas vezes \\
\end{tabular} \\
\hline
\end{tabular}




\begin{tabular}{|c|c|c|c|}
\hline & & & Sempre \\
\hline $\begin{array}{l}\text { 10. Não houve nada que eu quisesse } \\
\text { mudar na minha família. }\end{array}$ & Escala & Ordinal & $\begin{array}{l}\text { Nunca } \\
\text { Poucas vezes } \\
\text { Às vezes } \\
\text { Muitas vezes } \\
\text { Sempre }\end{array}$ \\
\hline $\begin{array}{l}\text { 11. Alguém da minha família me bateu } \\
\text { tanto que me deixou com machucados } \\
\text { roxos. }\end{array}$ & Escala & Ordinal & $\begin{array}{l}\text { Nunca } \\
\text { Poucas vezes } \\
\text { Às vezes } \\
\text { Muitas vezes } \\
\text { Sempre }\end{array}$ \\
\hline $\begin{array}{l}\text { 12. Eu apanhei com cinto, vara, corda } \\
\text { ou outras coisas que machucaram. }\end{array}$ & Escala & Ordinal & $\begin{array}{l}\text { Nunca } \\
\text { Poucas vezes } \\
\text { Às vezes } \\
\text { Muitas vezes } \\
\text { Sempre }\end{array}$ \\
\hline $\begin{array}{l}\text { 13. As pessoas da minha família } \\
\text { cuidavam umas das outras. }\end{array}$ & Escala & Ordinal & $\begin{array}{l}\text { Nunca } \\
\text { Poucas vezes } \\
\text { Às vezes } \\
\text { Muitas vezes } \\
\text { Sempre }\end{array}$ \\
\hline $\begin{array}{l}\text { 14. Pessoas da minha família disseram } \\
\text { coisas que me machucaram ou me } \\
\text { ofenderam. }\end{array}$ & Escala & Ordinal & $\begin{array}{l}\text { Nunca } \\
\text { Poucas vezes } \\
\text { Às vezes } \\
\text { Muitas vezes } \\
\text { Sempre }\end{array}$ \\
\hline $\begin{array}{l}\text { 15. Eu acredito que fui maltratado (a) } \\
\text { fisicamente. }\end{array}$ & Escala & Ordinal & $\begin{array}{l}\text { Nunca } \\
\text { Poucas vezes } \\
\text { Às vezes } \\
\text { Muitas vezes } \\
\text { Sempre }\end{array}$ \\
\hline 16. Eu tive uma ótima infância. & Escala & Ordinal & $\begin{array}{l}\text { Nunca } \\
\text { Poucas vezes } \\
\text { Às vezes } \\
\text { Muitas vezes } \\
\text { Sempre }\end{array}$ \\
\hline $\begin{array}{l}\text { 17. Eu apanhei tanto que um professor, } \\
\text { vizinho ou médico chegou a notar. }\end{array}$ & Escala & Ordinal & $\begin{array}{l}\text { Nunca } \\
\text { Poucas vezes } \\
\text { Âs vezes } \\
\text { Muitas vezes } \\
\text { Sempre }\end{array}$ \\
\hline $\begin{array}{l}\text { 18. Eu senti que alguém da minha } \\
\text { família me odiava. }\end{array}$ & Escala & Ordinal & $\begin{array}{l}\text { Nunca } \\
\text { Poucas vezes } \\
\text { Às vezes } \\
\text { Muitas vezes } \\
\text { Sempre }\end{array}$ \\
\hline $\begin{array}{l}\text { 19. As pessoas da minha família se } \\
\text { sentiam unidas. }\end{array}$ & Escala & Ordinal & $\begin{array}{l}\text { Nunca } \\
\text { Poucas vezes } \\
\text { Às vezes }\end{array}$ \\
\hline
\end{tabular}




\begin{tabular}{|c|c|c|c|}
\hline & & & $\begin{array}{l}\text { Muitas vezes } \\
\text { Sempre }\end{array}$ \\
\hline $\begin{array}{l}\text { 20. Tentaram me tocar ou me fizeram } \\
\text { tocar de uma maneira sexual. }\end{array}$ & Escala & Ordinal & $\begin{array}{l}\text { Nunca } \\
\text { Poucas vezes } \\
\text { Às vezes } \\
\text { Muitas vezes } \\
\text { Sempre }\end{array}$ \\
\hline $\begin{array}{l}\text { 21. Ameaçaram me machucar ou contar } \\
\text { mentiras sobre mim se eu não fizesse } \\
\text { algo sexual. }\end{array}$ & Escala & Ordinal & $\begin{array}{l}\text { Nunca } \\
\text { Poucas vezes } \\
\text { Às vezes } \\
\text { Muitas vezes } \\
\text { Sempre }\end{array}$ \\
\hline 22. Eu tive a melhor família do mundo. & Escala & Ordinal & $\begin{array}{l}\text { Nunca } \\
\text { Poucas vezes } \\
\text { Às vezes } \\
\text { Muitas vezes } \\
\text { Sempre }\end{array}$ \\
\hline $\begin{array}{l}\text { 23. Tentaram me forçar a fazer algo } \\
\text { sexual ou assistir coisas sobre sexo. }\end{array}$ & Escala & Ordinal & $\begin{array}{l}\text { Nunca } \\
\text { Poucas vezes } \\
\text { Às vezes } \\
\text { Muitas vezes } \\
\text { Sempre }\end{array}$ \\
\hline 24. Alguém me molestou. & Escala & Ordinal & $\begin{array}{l}\text { Nunca } \\
\text { Poucas vezes } \\
\text { Às vezes } \\
\text { Muitas vezes } \\
\text { Sempre }\end{array}$ \\
\hline $\begin{array}{l}\text { 25. Eu acredito que fui maltratado (a) } \\
\text { emocionalmente. }\end{array}$ & Escala & Ordinal & $\begin{array}{l}\text { Nunca } \\
\text { Poucas vezes } \\
\text { Às vezes } \\
\text { Muitas vezes } \\
\text { Sempre }\end{array}$ \\
\hline $\begin{array}{l}\text { 26. Houve alguém para me levar ao } \\
\text { médico quando eu precisei. }\end{array}$ & Escala & Ordinal & $\begin{array}{l}\text { Nunca } \\
\text { Poucas vezes } \\
\text { Às vezes } \\
\text { Muitas vezes } \\
\text { Sempre } \\
\end{array}$ \\
\hline $\begin{array}{l}\text { 27. Eu acredito que fui abusado (a) } \\
\text { sexualmente. }\end{array}$ & Escala & Ordinal & $\begin{array}{l}\text { Nunca } \\
\text { Poucas vezes } \\
\text { Às vezes } \\
\text { Muitas vezes } \\
\text { Sempre }\end{array}$ \\
\hline $\begin{array}{l}\text { 28. Minha família foi uma fonte de } \\
\text { força e apoio. }\end{array}$ & Escala & Ordinal & $\begin{array}{l}\text { Nunca } \\
\text { Poucas vezes } \\
\text { Às vezes } \\
\text { Muitas vezes } \\
\text { Sempre }\end{array}$ \\
\hline
\end{tabular}

